\title{
Antihypertensive drugs and the microcirculation
}

Citation for published version (APA):

Messing, M. W. J. (1992). Antihypertensive drugs and the microcirculation. [Doctoral Thesis, Maastricht University]. Datawyse / Universitaire Pers Maastricht. https://doi.org/10.26481/dis.19920911mm

Document status and date:

Published: 01/01/1992

DOI:

10.26481/dis. $19920911 \mathrm{~mm}$

Document Version:

Publisher's PDF, also known as Version of record

\section{Please check the document version of this publication:}

- A submitted manuscript is the version of the article upon submission and before peer-review. There can be important differences between the submitted version and the official published version of record.

People interested in the research are advised to contact the author for the final version of the publication, or visit the DOI to the publisher's website.

- The final author version and the galley proof are versions of the publication after peer review.

- The final published version features the final layout of the paper including the volume, issue and page numbers.

Link to publication

\footnotetext{
General rights rights.

- You may freely distribute the URL identifying the publication in the public portal. please follow below link for the End User Agreement:

www.umlib.nl/taverne-license

Take down policy

If you believe that this document breaches copyright please contact us at:

repository@maastrichtuniversity.nl

providing details and we will investigate your claim.
}

Copyright and moral rights for the publications made accessible in the public portal are retained by the authors and/or other copyright owners and it is a condition of accessing publications that users recognise and abide by the legal requirements associated with these

- Users may download and print one copy of any publication from the public portal for the purpose of private study or research.

- You may not further distribute the material or use it for any profit-making activity or commercial gain

If the publication is distributed under the terms of Article $25 \mathrm{fa}$ of the Dutch Copyright Act, indicated by the "Taverne" license above, 
Antihypertensive drugs and the microcirculation 


\section{Antihypertensive drugs and the microcirculation}

\section{Proefschrift}

ter verkrijging van de graad van doctor

aan de Rijksuniversiteit Limburg te Maastricht, op gezag van de Rector Magnificus, Prof. mr. M.J. Cohen, volgens het besluit van het College van Dekanen, in het openbaar te verdedigen op vrijdag, 11 september 1992 om 14.00 uur

door

Marcellinus Wilhelmus Johannes Messing

geboren te Steenderen in 1958

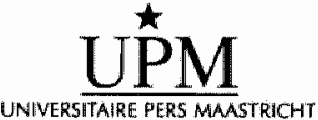


Promotor:

Co-promotor:

Beoordelingscommissie: Prof. dr. R.S. Reneman, voorzitter

Winston-Salem, NC, VS

Prof. dr. P. R. Saxena, Erasmus Universiteit Rotterdam

Dr. M.J. Jacobs

Dr. K.L. Leunissen

\section{CIP-GEGEVENS KONINKLIJKE BIBLIOTHEEK, DEN HAAG}

Messing, Marcellinus Wilhelmus Johannes

Antihypertensive drugs and the microcirculation /

Marcellinus Wilhelmus Johannes Messing. - [S.I. : s.n.].

- III.

Proefschrift Maastricht. - Met lit. opg. - Met

samenvatting in het Nederlands.

ISBN 90-9005095-7

NUGI 746/731

Trefw: bloeddruk / antihypertensiva / microcirculatie

Zoötechnische assistentie: Helma van Essen

Secretariële ondersteuning: Els Geurts en Mia Hogenboom

Met dank aan iedereen die heeft bijgedragen aan het tot stand komen van dit proefschrift 
Будущему 


\section{Contents}

1 General introduction 9

1.1 Hypertension and the microcirculation

1.1.1 Introduction 9

1.1.2 The microcirculation 9

1.1.3 Vascular resistance 10

1.1.4 Regulation of vascular resistance 11

The blood 11

The vasculature: structural factors 12

The vasculature: functional factors 13

1.2 Vascular smooth muscle cells and antihypertensive drugs

1.2.1 Vascular smooth muscle contraction 15

Regulation of intracellular calcium 15

Calcium channels 16

1.2.2 Drugs influencing VSMC contraction 17

Calcium antagonists 18

Porassium channel openers 19

Drugs acting on $\alpha$-adrenoceptors 19

Drugs inhibiting the renin-angiotensin system 20

1.3 Models to study the microcirculation

1.3.1 Anaesthetised models 22

1.3.2 Conscious models 23

Superficial vascular beds 23

Transparent chambers 24

1.3.3 Choice of our model 25

1.4 This thesis

2 Materials and methods

2.1 Animals

2.2 Surgery

2.2.1

The dorsal microcirculatory chamber 28

Design of the DMC 28

2.2.2 Catheters 33

Implantation of the DMC 30

Construction of catheters 33

Implantation of catheters 33

2.3 Microvascular studies

Use of catheters 34

2.3.1 Experimental setup 34

2.3.2 General experimental protocol 35

2.3.3 Analysis of videotapes 36 
2.4 Data analysis $\quad 36$

$\begin{array}{lll}2.5 & \text { Drugs used in this thesis } & 37\end{array}$

3 A comparison between microvascular network characteristics in striated muscle of conscious adult normotensive and spontaneously hypertensive rats

3.1 Introduction

3.2 Materials and methods

3.2.1 Experimental protocol 40

3.2.2 Photography and slide analysis 41

3.2.3 Statistics 42

3.3 Results

3.4 Discussion

3.4.1 Evaluation of the experimental data 46

3.4.2 Comparison with reports in the literature 49

4 Microvascular actions of calcium antagonists

4.1 Introduction

52

4.2 Materials and methods

4.3 Results

53

4.4 Discussion

5 Preferential small arteriolar vasodilatation by the potassium channel opener lemakalim in conscious spontaneously hypertensive rats

5.1 Introduction

5.2 Materials and methods 61

5.3 Results

5.4 Discussion

6 Alpha-adrenergic reactivity of striated muscle microvessels in conscious spontaneously hypertensive rats

6.1 Introduction

6.2 Materials and methods
6.2 .1
Determination of $\alpha$-adrenergic reactivity 65
6.2 .2
Haemorrhage experiment 65
6.2 .3
Statistics 65

6.3 Results

6.4 Discussion 
7 On the role of angiotensin II in striated muscle microvascular tone in conscious spontaneously hypertensive rats

7.1 Introduction

7.2 Materials and methods

7.2.1 ACE-inhibitors 74

7.2.2 Exogenous AII and losartan 74

7.2.3 Endogenous AII and losartan 74

7.2.4 Statistics 75

7.3 Results

7.3.1 ACE-inhibitors 76

7.3.2 Exogenous $A I I$ and losartan 77

7.3.3 Endogenous AII and losartan 77

7.4 Discussion

8 General discussion

$9 \quad$ References

10 Summary

11 Samenvatting

11.1 Antihypertensiva en de microcirculatie

11.1.1 Inleiding 103

11.1.2 De microcirculatie: een deel van het bloedvatenstelsel 103

11.1.3 De bloeddruk 104

11.1.4 De microcirculatie en bloeddrukregulatie 105

11.2 De uitvoering van de experimenten

11.3 De onderzochte antihypertensiva

11.4 Resultaten en conclusies

Curriculum vitae 


\section{CHAPTER 1}

\section{General introduction}

\subsection{Hypertension and the microcirculation}

\subsubsection{Introduction}

Blood pressure is regulated by an extremely complex but integrated interplay of cardiovascular, renal, neural, endocrine and metabolic control mechanisms in which numerous endogenous biologically active compounds are involved. Alterations in the regulation of these control systems play an important role in the pathogenesis and maintenance of hypertension. Such alterations may be induced by genetic (Ganten et al., 1991) or environmental factors, which possibly comprise important factors like dietary salt intake (Blaustein and Hamlyn, 1991) and excessive psychological, but not physical stress (Pickering, 1990). Although various factors are suspected to be involved in the development of hypertension, in most cases, about $90 \%$, of human chronic hypertension the cause is unknown and the disorder is referred to as essential or primary hypertension. It is likely that primary hypertension consists of different forms, each with a multifactorial etiology. Secondary hypertension refers to those cases in which blood pressure is elevated as a result of an earlier disease or abnormality like primary aldosteronism, pheochromocytoma, chronic glomerulonephritis, and renovascular hypertension.

\subsubsection{The microcirculation}

The input for the microcirulation of an organ are the small arteries. These vessels branch into tiny ramifications, the arterioles, which feed the capillary network. Venules collect the blood from the capillaries. Arterioles are not defined by their diameter size because this very much depends on their contractile state. Rather, arterioles are defined as precapillary vessels with no more than two layers of vascular smooth muscle cells (Rhodin, 1980). As a rough indication, arterioles have a lumen size of up to $200-300 \mu \mathrm{m}$. Venules are up to $500-1000 \mu \mathrm{m}$ in diameter and their walls do not possess a confluent layer of smooth muscle cells. Small, immediatelly postcapillary venules do not possess real smooth muscle cells (Rhodin, 1980). 


\subsubsection{Vascular resistance}

Systemic blood pressure (BP) equals the product of overall blood flow in the circulation, i.e. cardiac output (CO), and total peripheral resistance (TPR):

$$
\mathrm{BP}=\mathrm{CO} * \mathrm{TPR}
$$

In the initial phase of experimental (Evenwel et al., 1983) as well as clinical (Blaustein and Hamlyn, 1991) primary hypertension, cardiac output has been shown to be elevated. Gradually, cardiac output normalises while total peripheral resistance rises. Thus, in the established phase of hypertension, blood pressure is elevated because of an increased total peripheral resistance. In individual vascular beds total peripheral resistance is the resultant of parallel and in series resistances. For one straight blood vessel, resistance $R$ can be described by the Hagen-Poisseuille law:

$$
R=\frac{8 L \eta}{\pi r^{4}}
$$

Here, $L$ is vessel length, $\eta$ is blood viscosity and $r$ is the diameter. Total resistance $\left(R_{\text {total }}\right)$ for a number of $n$ in series coupled vessels is equal to the sum of the individual resistances:

$$
R_{\text {total }}=\sum_{i=1}^{n} R_{i}
$$

For a number of $\mathrm{m}$ parallel coupled vessels, total resistance can be calculated from:

$$
\frac{1}{R_{\text {tosal }}}=\sum_{i=1}^{m} \frac{1}{R_{i}}
$$

If in a vascular network the resistance in any vessel increases, this will lead to an increase in total resistance. This may be caused by an increased length or a decreased diameter. If the number of parallel vessels is decreased, again the result is an increased resistance. The arteriolar microcirculation is the main site of total peripheral resistance regulation since in this part of the circulation the largest pressure drop occurs (Folkow, 1991; Zweifach, 1991; see fig. 1.1).

In hypertension, the main part of the increase in TPR is located in the microcirculation (Schmid-Schönbein and Chien, 1986; Bohlen, 1989; Mulvany, 1990). Data on the pressure drop over the systemic arteries proximal to the microcirculation 


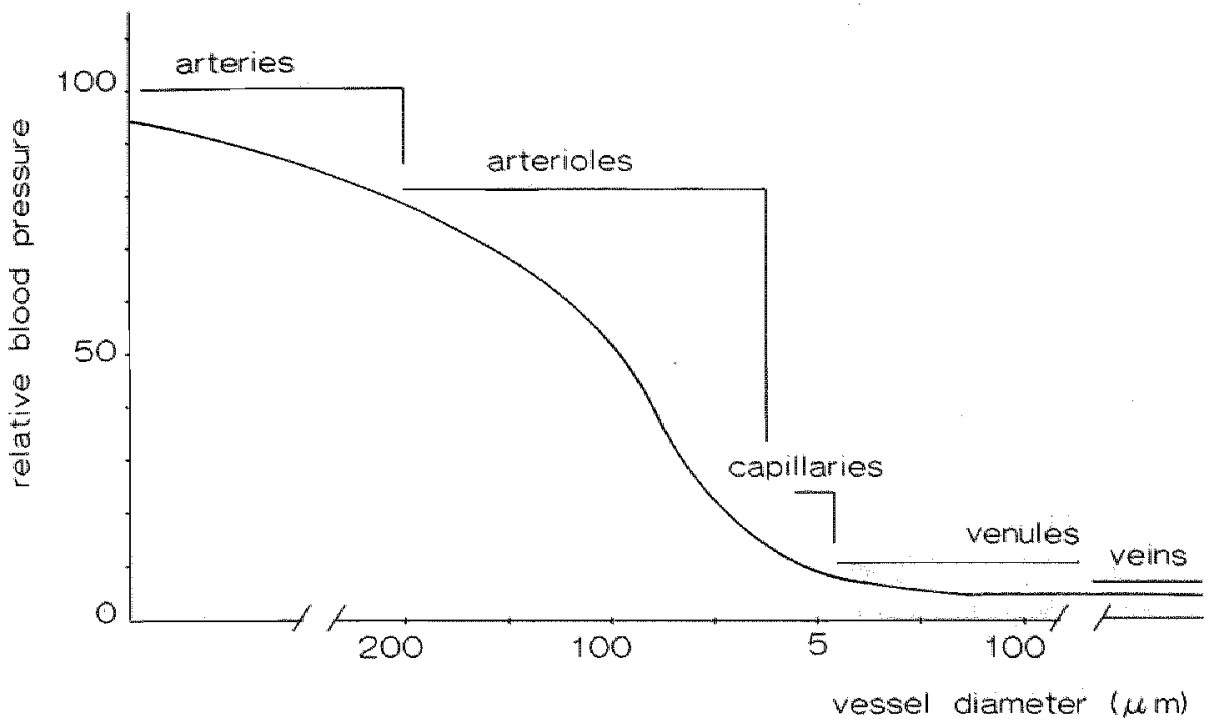

Figure 1.1 A typical pressure profile, generalised from the literature cited in section 1.1.3. The major pressure decrease occurs in the arteriolar part of the vasculature.

have not been consistent. However, recent studies carried out by de DeLano and colleagues (DeLano et al., 1991) have shown that blood pressure in feedings vessels at the entrance of various intact striated muscles can be as high as $90 \%$ of systemic blood pressure, both in normotensive and hypertensive rats. These data strongly confirm the importance of the microcirculation in the regulation of resistance control. Furthermore, normalised pressure profiles were similar, proving that in hypertension the largest absolute resistance increase occurs in the microcirculation.

\subsubsection{Regulation of vascular resistance}

Table 1.1 summarises factors that determine vascular resistance. In hypertension, a change in each of these factors might contribute to an elevated total peripheral resistance. However, such changes have not been observed for all factors, at least not to a relevant degree, as discussed below.

\section{The blood}

Vascular resistance depends on blood viscosity. Haematocrit is the main determinant of viscosity. In hypertension haematocrit can be elevated, but reports on this matter are not consistent (Bohr and Webb, 1986). Viscosity may also be elevated by a decreased cell deformability or an increased tendency for cell aggregation. However, there is no information on these parameters in hypertension. Recently, leucocytes have also been shown to contribute significantly to blood 
Table 1.I Factors deteriming wascular resistance. For each factor the effect of an increase on vascular resistance is indlicated.

\author{
Bllood viscosity \\ - haematocrit \\ - leucocyte count \\ - cell deformabillity \\ - cell aggregation \\ Structural characteristics \\ - vessel diameter \\ - vessel length $\uparrow$ \\ - number of parallel vessels \\ Functional characteristics ( = vascular smooth muscle cell activity) \\ - local control: - myogenic activity

$\begin{array}{ll}\text { - physical factors } & \uparrow \\ - \text { - tissue metabolites } & \uparrow \downarrow \\ \text { - locally released factors } & \uparrow \\ \text { - nerve activity } & \uparrow \\ \text { - hormones } & \uparrow \downarrow\end{array}$

viscosity. Leucocytes provide approximately $20 \%$ of resistance to blood flow in rat gracilis muscle (Sutton and Schmid-Schönbein, 1990). Therefore, an increase in leucocyte count of $100 \%$, as has been found in mature spontaneously hypertensive rats (SHR), might significantly contribute to an elevated blood pressure in these rats (Schmid-Schönbein et al., 1991).

The vasculature: structural factors

Diameter is the most powerful variable to change vascular resistance. This can be seen from the Hagen Poiseuille law, where diameter appears to the inverse fourth power. The primary structural factor determining diameter is distensibility of the vessel wall. Distensibility is influenced by wall thickness. A thickened vascular wall can encroach on the vessel lumen and also amplify the effect of vascular smooth muscle contraction (Folkow, 1982). A reduced distensibility, as determined by the composition of the vascular wall often leads to a reduced diameter. This can be especially important in the thin walled vessels of the microcirculation. A change in vessel length can also change resistance on a structural 
basis. This can be achieved by altering vessel length per unit of tissue volume, thus by changing tortuosity.

The last factor listed in table 1.1 that influences resistance on a structural basis is the number of parallel vessels. A decrease in number of parallel vessels will increase resistance. Disappearance of microvessels (structural rarefaction) has been reported for both primary (Prewitt et al., 1982) as well as secondary (Hashimoto et al., 1987) forms of experimental hypertension in rats. This may result from prolonged closure of microvessels (functional rarefaction) in the early phase of hypertension. Structural rarefaction may also result from impeded development of the microvascular network during growth of young subjects, which is likely to occur in genetic forms of hypertension (Hutchins and Darnell, 1974; Henrich et al., 1978; Haack et al., 1980).

\section{The vasculature: functional factors}

Functional diameter regulation is aimed at the maintenance of an appropriate whole-organ perfusion, relatively independent of systemic blood pressure and in accordance with metabolic need. This phenomenon is known as autoregulation. Some tissues can very effectively maintain a constant blood flow, like kidney and brain, while flow in others, like striated muscle, can vary widely. As a consequence, in striated muscle a high level of basal vascular tone is present to allow for sufficient dilating capacity. Functional vascular diameter is determined by vascular smooth cell activity which is regulated by a number of local and remote control systems, as depicted in fig. 1.2 (Bohr and Webb, 1986; Folkow, 1991). Under basal conditions, local mechanisms are the prevailing control system. Only under circumstances when large changes in systemic blood flow are required, central mechanisms overrule local ones. For instance, during physical exercise, blood flow to the skeletal muscle can be increased 10-15 fold. In the case of haemorrhage the opposite happens; blood flow to vital organs is guaranteed at the expense of flow to organs like skeletal muscle.

Basal microvascular tone is to a great extent of myogenic origin, i.e. an intrinsic constrictor property of the vascular smooth muscle cell (Osol, 1991). The relative importance of myogenic mechanisms increases towards the smaller arterioles. Locally, myogenic tone is modulated by physical and metabolic factors, and by locally released substances. Physical factors are stretch and stress imposed on the vascular smooth muscle cell by the flow of blood. Stretch of the vessel wall by an increased transmural pressure will induce a vasoconstrictor response, a phenomenon referred to as "myogenic response". It is especially prominent in arterioles and small arteries. The cellular mechanisms by which stretch induces vascular smooth muscle cell contraction are unknown, but it probably stimulates calcium influx into the cell (see section 1.2.1; Osol, 1991). Metabolic factors like $\mathrm{pCO}_{2}, \mathrm{pO}_{2}$, and $\mathrm{pH}$, the latter being dependent on the concentration of metabolites like lactic acid and adenosine, are also local modulators of vascular tone. Furthermore, ions like $\mathrm{Ca}^{++}, \mathrm{Na}^{+}$and $\mathrm{K}^{+}$play an important role. Finally, a number of locally released factors, mostly endothelium-derived, exert an effect on vascular tone. Examples are 


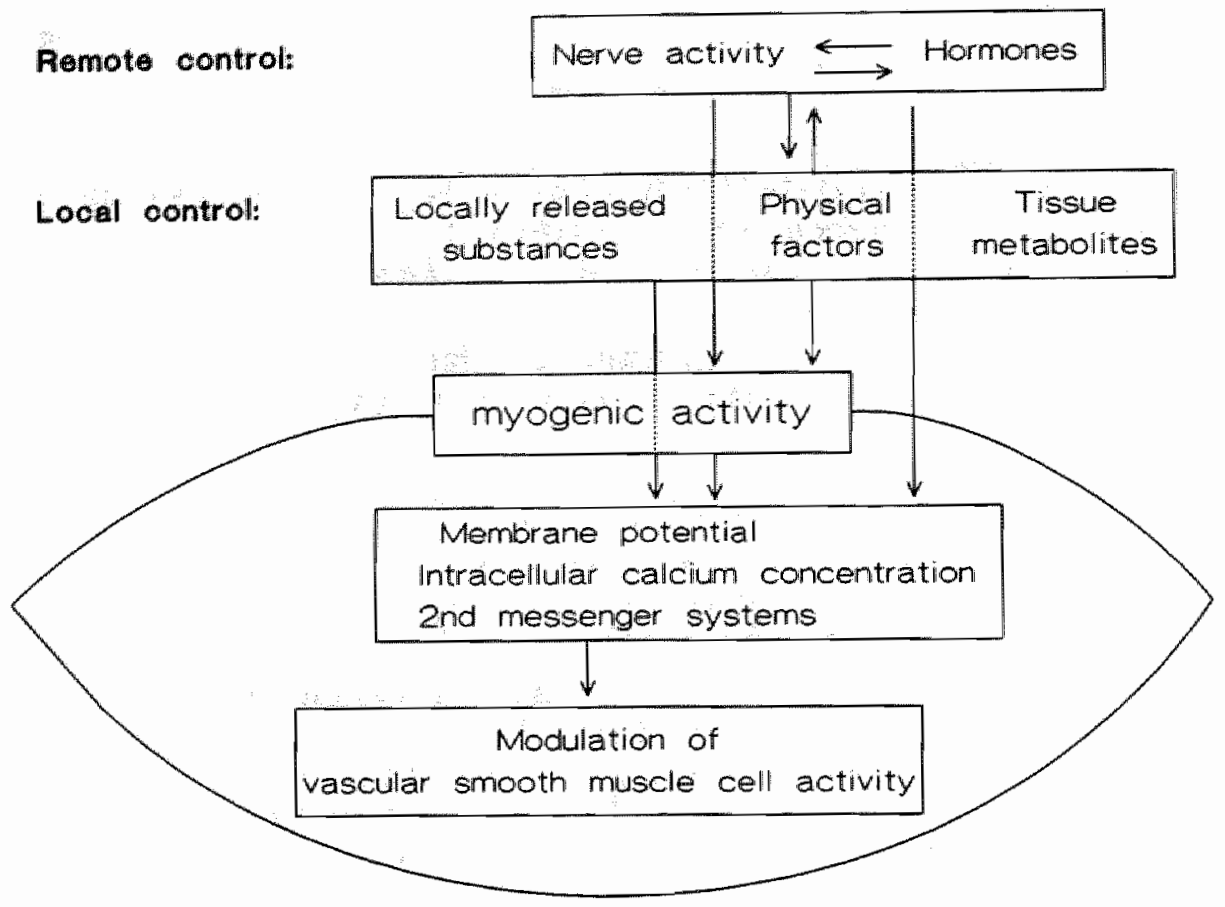

Figure 1.2 Scheme illustrating the regulation of vascular smooth muscle cell activity.

the vasodilators nitric oxide (the endothelium-derived relaxing factor EDRF) and prostacylin, and the vasoconstrictor substance endothelin.

The above described local control systems can all be modulated by remote control systems. Remote control systems are the autonomic nervous system and circulating hormones. The influence of the autonomic nervous system is quantitatively large and can be adjusted in a rapid and flexible manner. Nervous regulation of vascular resistance is mediated through the neurohormone noradrenaline, that is released from sympathetic nerve terminals. Noradrenaline exerts a vasoconstrictor effect because of the predominance of $\alpha$-adrenoceptors in the vascular system. The secretion of noradrenaline is regulated by its own release through a negative feedback mechanism and by central nervous control mechanisms. Also, the levels of circulating hormones regulate noradrenaline release. For instance, angiotensin II, a potent directly acting vasoconstrictor, potentiates noradrenaline release, enhancing its own vasoconstrictor effect. Opposite to this, acetylcholine inhibits noradrenaline release, thereby enhancing its own endothelium-dependent vasodilator effect. In the central nervous system, angiotensin II increases sympathetic activity and stimulates vasopressin release. This hormone, also known as the antidiuretic hormone, is a very potent vasoconstrictor. Furthermore, a number of other hormones that influence vascular resistance, have been described, such as serotonin, atrial 
natriuretic peptide (ANP), prostaglandins, and kinins. Beside their direct effect on vascular smooth muscle cell activity, they interact with other mechanisms of resistance control.

In hypertension, the functional regulation of (micro)vascular diameter is altered. This may be caused by an increased tonic contraction of blood vessels, due to an altered permeability of the sarcolemma to ions and an increased sensitivity to vasoactive substances (Bohr and Webb, 1986). Structural and functional microvascular alterations associated with hypertension contribute to a protection of the capillary bed and adapt the precapillary vasculature to the elevated intramural pressure. Normal capillary pressure ensures normal exchange of metabolites, which is essential for tissue homeostasis. It is not yet clear whether microvascular alterations cause or are secondary to hypertension (Mulvany, 1991a). However, treatment of hypertension should be aimed at the achievement of a decrease in total peripheral resistance.

Blood pressure is to a large degree determined by peripheral resistance, which on its turn depends on structural and functional properties of the vasculature. Structural properties include composition and thickness of the vascular wall, determining compliance and relaxed diameter of the blood vessel, and the architecture of the vascular tree. Since the present investigations comprise only functional studies, structural properties of the vasculature will not further be discussed here. For further information on this subject, the reader is referred to recent reviews (Struyker Boudier et al., 1990a; Mulvany, 1991a).

\subsubsection{Vascular smooth muscle contraction}

Functional vascular resistance is determined by the degree of vascular smooth muscle cell (VSMC) contraction. VSMC contraction can be initiated by several stimuli, that through an increase in cytosolic free calcium ions, $\left[\mathrm{Ca}^{++}\right]_{\mathrm{i}}$, can lead to an activation of the contractile apparatus. Calcium ions bind to the protein calmodulin and this complex activates the enzyme myosin light chain kinase (MLCK). Activated MLCK phosphorylates the contractile filament myosin, which through interaction with actin leads to VSMC contraction (Abdel-Latif, 1989; Murray, 1990). Research on the regulation and mechanisms of VSMC contraction has been extensive, but has not yet led to a general agreement on this subject (Nelson et al., 1990).

\section{Regulation of intracellular calcium}

As depicted in fig. 1.3, two mechanisms lead to an increase of $\left[\mathrm{Ca}^{++}\right]_{\mathrm{i}}$, and thereby to an activation of the contractile apparatus. Firstly, $\mathrm{Ca}{ }^{++}$ can be released from the sarcoplasmic reticulum, that serves as an intracellular 
calcium store (Minneman, 1988). Secondly, sarcolemmal calcium channels exist, through which extracellular calcium ions can flow into the sarcoplasm (Nichols et al., 1989; Zelis and Moore, 1989). Both processes can be initiated by activation of a number of receptor types that are coupled by G-proteins to the membrane-bound enzyme phospholipase C (PLC) or adenyl cyclase (AC). G-proteins are membranebound proteins that act as transducers of receptor signals onto second-messenger systems, thereby hydrolysing GTP (Birnbaumer, 1990, Jackson, 1991). A G-protein can either be inhibitory or stimulatory with respect to the second-messenger system. Activation of PLC leads to the hydrolysis of phosphatidyl inositol biphosphate $\left(\mathrm{PIP}_{2}\right)$ into diacylglycerol (DAG) and inositol triphosphate $\left(\mathrm{IP}_{3}\right)$. The latter compound triggers the rellease of $\mathrm{Ca}^{++}$from the sarcoplasmic reticulum, while DAG activates protein kinase $\mathrm{C}$ ( $\mathrm{PKC}$ ) which also has a positive effect on the contractile apparatus (Minneman, 1988). Receptors coupled to PLC can also increase $\left[\mathrm{Ca}^{++}\right]_{\mathrm{i}}$ directly via stimulation of influx of extracellular $\mathrm{Ca}^{++}$through specific calcium channels (Boonen and De Mey, 1990). Stimulation of receptors that are coupled by an inhibitory G-protein to $\mathrm{AC}$ also induces $\mathrm{Ca}^{++}$influx (Nichols et al., 1989; Zelis and Moore, 1989). It also induces a decrease in cytosolic cAMP concentration, which leads to a decreased activity of the enzyme protein kinase A (PKA) and thus to a diminished inhibitory influence on the contractile apparatus (Murray, 1990). Stimulation of receptors that are coupled to $A C$ via a stimulatory G-protein, on the other hand, leads to an activation of PKA and thus to VSMC relaxation (Murray, 1990).

\section{Calcium channels}

Influx of extracellular $\mathrm{Ca}^{++}$can be induced not only by receptor stimulation, but also by depolarisation of the cell membrane and subsequent activation of second-messenger systems. Furthermore, stretch can induce calcium influx and activation of second messengers (Laher and Bevan, 1989; Osol, 1991). Calcium channels that open after receptor stimulation have been designated as receptor-operated channels (ROC), while those opened by depolarisation as voltageor potential-operated channels (VOC, POC, respectively). VOC's have been subdivided in transient (T-type) and long-lasting (L-type) channels. The latter are ubiquitous in most excitable tissues, including vascular smooth muscle, and are also found in non-excitable cells. Other types are the neural (N-type) channel, found only in neural tissue, and the P-type channel that is especially prominent in the cerebellar Purkinje cells (Zelis and Moore, 1989; Struyker Boudier et al., 1990c; Tsien et al., 1991). All calcium channel types differ in electrophysiological and pharmacological properties which is related to differences in molecular structure. Thus, the L-, N-, and P-type open after strong depolarisation, while the T-type is opened by small depolarisations. Each channel type can be blocked pharmacologically by specific agents. $\mathrm{T}$-type channels by $\mathrm{Ni}^{+}+$, amiloride and octanol; the $\mathrm{L}$ type by $\mathrm{Cd}^{++}$and organic compounds like verapamil, diltiazem, and dihydropyridines; the $\mathrm{N}$-type also by $\mathrm{Cd}^{++}$and $\omega$-conotoxin, and the P-type by FTX, a spider venom (Zelis and Moore, 1989; Tsien et al., 1991). The L-type calcium channel, 


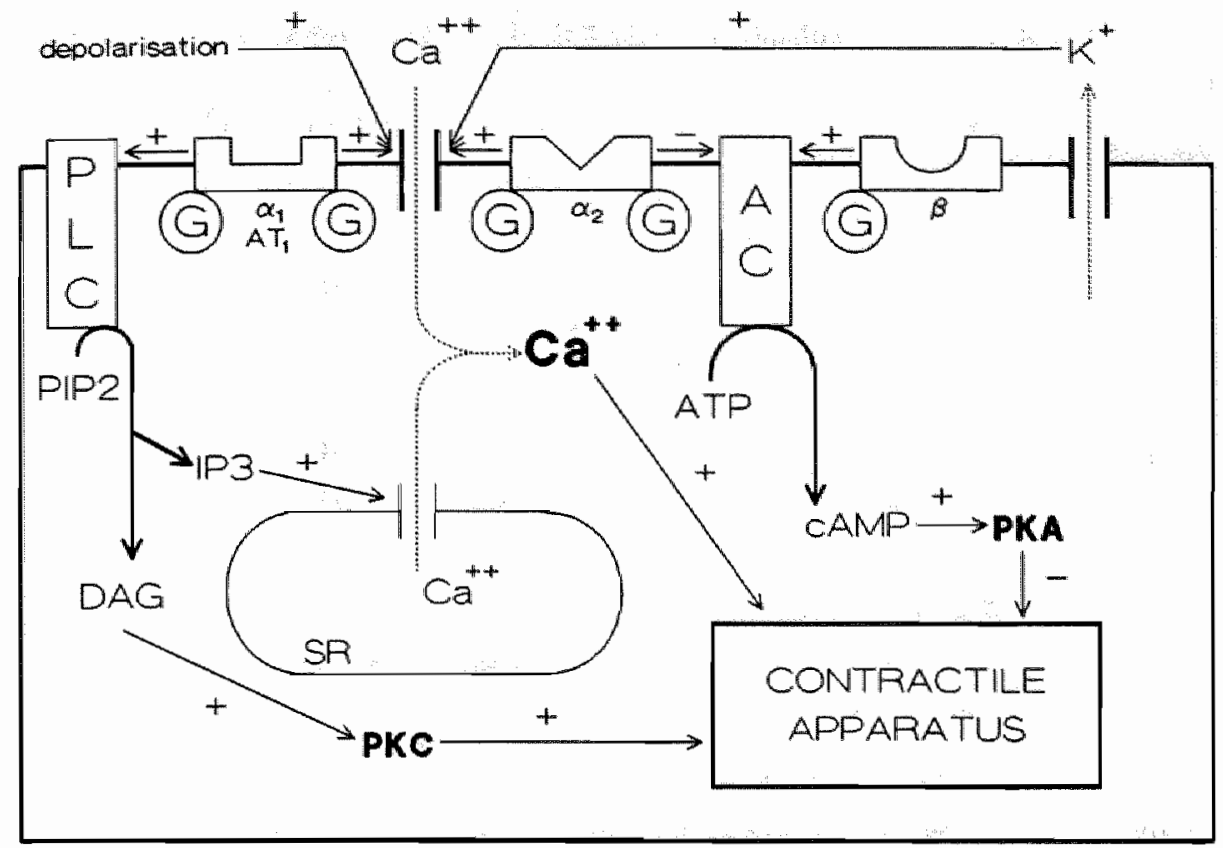

Fig. 1.3 Schematic representation of the vascular smooth muscle cell with signal transduction pathways linked to different types of receptors. The $\alpha_{1}$-adrenoceptor and the $A T_{I^{-r e c e p t o r}}$ are linked to the same signal transduction pathways. Other examples are the $\alpha_{2}$ and the $\beta$-adrenoceptors.

Thick solid arrows: biachemical pathways. Thin solid arrows: positive $(+)$ and negative $(-)$ influences. Stippled arrows: ion currents.

Abbreviations. AC, adenyl cyclase; $D A G_{n}$ diacyl glycerol; $G, G_{\text {-protein, }}{ }^{2}{ }_{3}$, inositol triphosphate; PIP, phosphoinositol biphosphate; PKA and PKC, protein kinases $A$ and $C_{;}$PLC, phospholipase $C_{;, "} S R$, sarcoplasmatic reticulum.

which is the most studied type, is wery prominent on VSMC. However, no conclusive data are yet available on the distinction that is made between $R O C$ 's and VOC's (Boonen and De Mey, 1990; Nelson et al., 1990); it may well be that the two types represent different states of the same channel. Therefore, in fig. 1.3 no distinction has been made between different calcium-channel types.

\section{2 .2}

Drugs influencing VSMC contraction

VSMC contraction can be influenced pharmacologically at practically every step of the process described above. Many of the compounds used for this 
purpose are only used as pharmacological tools in biomedical research and have no clinical application. Most substances we studied in the present investigations were representatives of different classes of antihypertensive drugs. The way in which each of these drug types can influence microvascular diameter and, hence, resistance will be discussed below.

\section{Calcium antagonists}

Calcium antagonists induce a decreased intracellular calcium ion concentration, because they inhibit the influx of extracellular calcium through (Ltype) calcium channels. These drugs do not inhibit the effects of calcium, but rather inhibit the passage of the ions through specific cell membrane channels. Therefore, other names, like calcium entry blockers and calcium channel blockers, have been proposed, and are often encountered. The recent WHO classification (Paoletti and Vanhoutte, 1987) uses the common designation calcium antagonists, which we will also use in this thesis.

Calcium antagonists can be classified on the basis of differences in (clinical) mode of action or physical properties, but usually they are subdivided on the basis of their chemical structure (Wood, 1989; van Zwieten, 1989b; Struyker Boudier et al, 1990c). Hence, four major classes arise: the phenylalkylamines, of which verapamil is the prototype, the benzothiazepines (prototype: diltiazem); the dihydropyridines (prototype: nifedipine), and the diphenylalkylamines or piperazines (prototype: flunarezine). Additionally, some miscellaneous agents exist, like caroverine, bepridil, and perhexiline. All of these compounds induce vasodilatation by inhibition of influx of extracellular $\mathrm{Ca}^{++}$into the VSMC (fig. 1.3), but not all vascular beds are equally sensitive. The skeletal muscle and coronary vasculatures are strongly dilated by most calcium antagonists, while the effects on renal, gastrointestinal and cerebral vascular beds are small, and almost absent in the skin vasculature (Struyker Boudier et al., 1989; van Zwieten, 1989b). Regional differences in the effects of calcium antagonists may be explained by differences in degree of myogenic tone.

In addition to their vasodilator effect the phenylalkylamines and benzothiazepines have a direct effect on the myocardium. They induce a negative inotropic effect by antagonising myocardial contractility and atrioventricular conduction. However, this direct negative inotropic effect is usually compensated by an indirect baroreflexmediated positive inotropic effect (Struyker Boudier et al., 1989; van Zwieten, $1989 \mathrm{~b}$ ). Since the dihydropyridines have little direct effect on the myocardium, they may induce a baroreflex mediated positive inotropic effect.

Because of their vasodilator action on the peripheral vasculature, dihydropyridines, and also verapamil, have found widespread use in antihypertensive therapy. For treatment of arrhythmic disorders the phenylalkylamines are particularly used. Angina pectoris is a well established indication for verapamil, the dihydropyridines and diltiazem. Furthermore, dihydropyridines are used for treatment of cardiovascular disorders like congestive heart failure and Raynaud's phenomenon (van Zwieten, 1989b). 
In chapter 4 , the microvascular effects of verapamil and the dihydropyridines nifedipine and fellodipine will be discussed in detail.

\section{Potassium channel openers}

Potassium channel openers, a relatively new drug class, comprise a heterogenous group of compounds that induce vasodilatation by an efflux of potassium ions from the cytoplasm of VSMC. This efflux means a loss of positive charge from the cytoplasm, which leads to hyperpolarisation of the cell membrane and thus to vasodilatation. Indirectly, hyperpolarisation influences calcium channels, contributing to vasodilatation through a decrease of influx of calcium (fig. 1.3). A variety of potassium channel subtypes has been described but the one that is affected by the available potassium channel openers is characterised by its sensitivity to intracellular ATP levels, and can be blocked by glibenclamide (Edwards and Weston, 1990; Kajioka et al., 1991). However, in various tissues and regions of tissues, different subtypes of ATP- and glibenclamide-sensitive potassium channels exist (Kajioka et al., 1991).

Potassium channels can be opened by substances that differ greatly in chemical and pharmacological characteristics. Edwards and Weston (1990) proposed a classification based on these characteristics. They distinguished seven groups: benzopyrans (prototype: cromakalim), guanidine derivatives (prototype: pinacidil), pyridine derivatives (prototype: nicorandil), pyrimidine derivatives (prototype: minoxidil) and benzothiazidines (prototype: diazoxide). The last two groups included novel developments, like the thioformamides (protoype: RP 52891) and some dihydropyridine-like substances, like the $(+)$-enantiomer of niguldipine, However, the drug class of potassium channel openers is still expanding, and not all newly synthesised substances fit in this classification (Kajioka et al., 1991). All of these substances lower blood pressure by inducing vasodilatation and are therefore likely to find application in the treatment of cardiovascular disorders. Current investigations on these drugs include the assessment of their effects on hypertension, angina pectoris, intermittent claudication, heart failure and the like (Duty and Weston, 1990; Richer et al., 1990).

Until recently, cromakalim was the standard potassium channel opener with which the activity of all others was compared. However, some adverse side-effects led to the cancellation of human studies with cromakalim (Edwards and Weston, 1990). A successor compound, the trans(-)enantiomer lemakalim is now intensively studied and we investigated the microvascular effects of this compound, as described in chapter 5 .

\section{Drugs acting on $\alpha$-adrenoceptors}

The endogenous catecholamines adrenaline and noradrenaline are important substances involved in blood pressure regulation. Besides by influencing vascular tone, they affect blood pressure through actions on the central nervous system, modulation of sodium homeostasis and the activity of the renin-angiotensin system (Raymond et al., 1990). These actions are all mediated through stimulation 
of adrenoceptors. On the basis of pharmacological properties, Ahlquist (1948) divided them into $\alpha$ - and $\beta$-adrenoceptors, and in the following decades a further subdivision of each of these two receptor subtypes was made. A recent overview of receptor nomenclature (Watson and Abbott, 1992) distinguishes two $\alpha$-adrenoceptor and three $\beta$ aadrenoceptor subtypes. The $\alpha_{1}$ and $\alpha_{2}$-receptor subtypes can each be further subclassified into an A-, B- and C-type. The individual receptor subtypes do not only differ in specificity to various ligands, but also in their coupling to secondmessenger systerns (see section 1.2.1; Minneman, 1988; Raymond et al., 1990; Watson and Abbott, 1992).

The $\alpha_{1}$-adrenoceptor is coupled to PLC, while the $\alpha_{2}$-adrenoceptor is coupled to $A C$ via an inhibitory $G$-protein (fig. 1.3). Beta-adrenoceptors are coupled to $A C$ via a stimulatory G-protein (Raymond et al., 1990). Alpha ${ }_{1}$-adrenoceptors are located post-synaptically throughout the cardiovascular system. Besides on this location, $\alpha_{2}$ adrenoceptors are also located presynaptically and in the central nervous system.

Therapeutic use of $\alpha$-adrenoceptor antagonists in treatment of hypertension or other cardiovascular diseases is not as common as that of other drugs. However, selective $\alpha_{1}$-adrenoceptor antagonists, which exert peripheral vasodilatation, are being used. Examples of such drugs are prazosin and its newer derivatives doxazin and terazosin. Especially the latter two compounds have the advantage not to induce reflex tachycardia (van Zwieten, 1989a). Application of drugs that act on $\alpha_{2}$ adrenoceptors is rather difficult, because of the various locations where this receptor is present. A depressor effect can be mediated through either stimulation of central and/or presynaptic $\alpha_{2}$-adrenoceptors or inhibition of postsynaptic $\alpha_{2}$ adrenoceptors (Brown, 1988). Most known $\alpha_{2}$-adrenoceptor agonists exert an antihypertensive effect via stimulation of central $\alpha_{2}$-adrenoceptors. These drugs include clonidine, guanfacine, $\alpha$-methyldopa (van Zwieten, 1989a), and rilmenidine (van $Z$ wieten, 1988). A number of drugs with $\alpha_{1}$-antagonistic action have additional pharmacodynamic properties, and these drugs have found broad application in cardiovascular therapy. These drugs include labetolol, which also has $\beta$-antagonistic properties and ketanserin and urapidil, which both are also antagonists for serotonergic receptors (van Zwieten, 1989a). Besides their application in clinical practice, $\alpha$-adrenergic antagonists and agonists are extensively used as pharmacological tools.

Vascular smooth muscle contraction partly depends on $\alpha$-adrenergic reactivity. A differential distribution of postsynaptic $\alpha$-adrenoceptor subtypes may be a phenomenon involved in the regulation of vascular tone in different segments of the microcirculation. To test this hypothesis, we used the specific adrenoceptor antagonists prazosin $\left(\alpha_{1}\right)$ and yohimbine $\left(\alpha_{2}\right)$ and the specific agonist phenylephrine $\left(\alpha_{1}\right)$ and azepexole $\left(\alpha_{2}\right)$ and examined microvascular diameter changes induced by these drugs (chapter 6).

\section{Drugs inhibiting the renin-angiotensin system}

An important regulator of cardiovascular homeostasis is the reninangiotensin system (RAS). Its active vasoconstrictor substance, angiotensin II (AII), is generated through a cascade of reactions (fig. 1.4). The components of the 


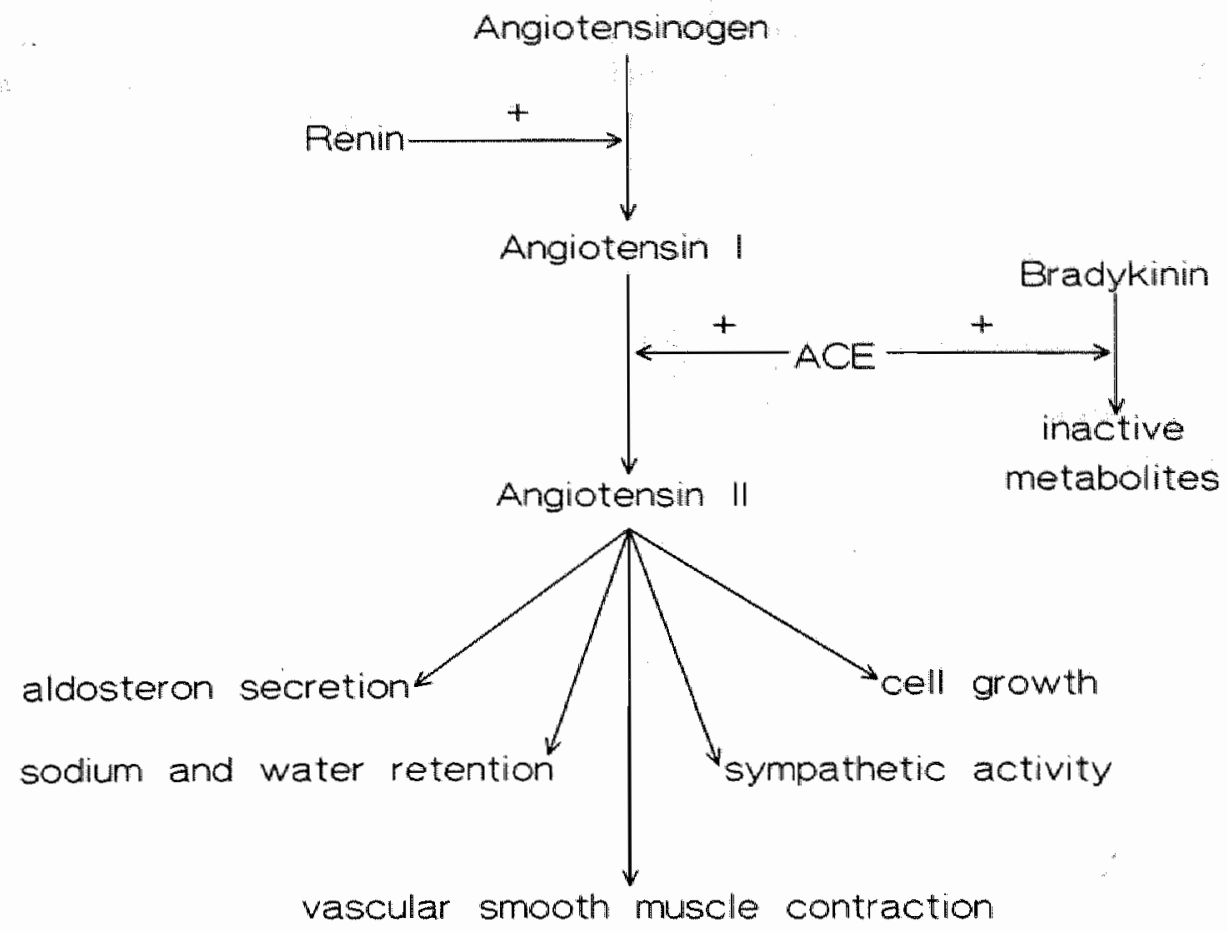

Figure 1.4 The reniw-angiotensin system and its major effects.

system are released into the blood by specific organs: the precursor hormone angiotensin by the liver, and the enzymes renin and angiotensin-converting enzyme (ACE) by the kidneys and the lungs, respectively, resulting in the production of circulating AII. Recently, it has been demonstrated that compounds of the RAS are also synthesised in many peripheral tissues, including the vascular wall (Mizuno et al., 1988; Eglème et al., 1990; Higashimori et al., 1991; Kvist et al., 1991). This indicates that AII can be produced locally, either directly or in part from circulating precursors.

AII increases blood pressure directly by vasoconstriction through stimulation of PLC receptors (Mulvany, 1991b) and indirectly through a number of other effects as depicted in fig. 1.4. The effects of All can be antagonised by inhibition of its synthesis, using renin- (Boger, 1987; Iizuka et al., 1990), or ACE-inhibitors (Ondetti, 1991), or by inhibiting its action, using monoclonal AII antibodies (Reilly et al., 1988; Wong et al., 1990d) or AII-receptor antagonists (Streeten and Anderson, 1984; Chiu et al., 1989; Whitebread et al., 1989; Timmermans et al., 1991). A limitation of inhibition of All-synthesis by renin- or ACE-inhibitors may be the generation of ACE by alternative pathways (Dzau, 1990). Moreover, ACE-inhibitors not only cause inhibition of All-formation, but also inhibit breakdown of bradykinin, a vasodilator polypeptide (fig. 1.4). However, especially ACE-inhibi- 
tors are widely used for research and therapeutic purposes.

The first AII-receptor antagonists were peptides with a chemical structure similar to All such as saralasin (Streeten and Anderson, 1984). These drugs therefore also have agonistic properties, which together with their peptide nature strongly limits their clinical application. Recently, two groups of non-peptide AII-receptor antagonists have been developed. In receptor-binding studies these compounds revealed the existence of two AII-receptor subtypes, the $\mathrm{AT}_{1}$ and $\mathrm{AT}_{2}$ receptors (Bumpus et al., 1991). The biphenylimidazoles have a specific affinity for the $\mathrm{AT}_{1}$ receptor, which is, via different G-proteins, coupled to both PLC and AC in a way that leads to VSMC contraction. On vascular tissue only the $\mathrm{AT}_{1}$-receptor has thus far been found (Whitebread et al., 1989). The non-peptide $\mathrm{AT}_{1}$-antagonist losartan, until recently referred to as DuP 753 , is now used as an orally active, selective, competitive $\mathrm{AT}_{1}$-receptor antagonist (Timmermans et al., 1991). The $\mathrm{AT}_{2}$-receptor has specific affinity for the tetrahydroimidazopyridine PD 123177 (Chiu et al., 1989) and the peptide CGP 42112A (Whitebread et al., 1989). The function of the $\mathrm{AT}_{2}-$ receptor is thus far unknown, but possibly plays a role in angiogenesis (le Noble et al., 1992) or prostaglandin synthesis (Jaiswal et al., 1991). We investigated the microvascular effects of the ACE-inhibitors captopril and enalaprilat and the nonpeptide $\mathrm{AT}_{1}$-receptor antagonist losartan (chapter 7).

\subsection{Models to study the microcirculation}

This section gives a survey of models that enable intravital microscopic observations of intact microvessels. The aims are to give some insight in the wide variety of models that are available for this purpose (Wiedeman et al., 1981; Baker and Nastuk, 1986) and to explain the choice of the model used for the present thesis.

\subsection{1}

Anaesthetised models

For most models, anaesthesia is required to allow intravital microscopic observations. Anaesthetics serve to immobilise the animal and, more importantly, to enable surgery to make the tissue of interest accessible to the intravital microscope. This, and the need for proper illumination often requires exteriorisation of the tissue into an appropriate organ bath, although a number of preparations permit in situ observations. In order to maintain physiological conditions after surgery, precautions have to be taken to avoid cooling and desiccation of the tissue; therefore, proper warming and superfusion with or immersion in a saline solution are required to maintain physiological $\mathrm{pO}_{2}$ and $\mathrm{pH}$. Nevertheless, after a couple of hours most of these preparations start to deteriorate, therefore allowing only acute experiments.

Since the beginning of this century, many microvascular preparations of various tissues have been described. A number of them are now widely used in different fields of biomedical research because they yield reproducible preparations of good quality with relatively simple techniques. The techniques are usually applicable to 
multiple species common in normal laboratory practice. Probably the most widely used preparations are those of the mesentery (Chambers and Zweifach, 1944) and the cremaster muscle (Majno et al., 1967; Baez, 1973; Vicaut and Stucker, 1990). The former is usually studied in rabbit or rat, the latter mainly in rat, but also in hamster and mouse. These tissues have to be exteriorised to allow transillumination, necessary for observation of the microvasculature. Striated muscles like the gracilis (Henrich and Hecke, 1978) and spinotrapezius muscles (Gray, 1973) of rat and the tenuissimus muscle of rabbit (Brånemark and Eriksson, 1972; Reneman et al., 1980) are also widely used. They can be studied in situ by inserting a small light source under the muscle. A special well known preparation is the hamster cheek pouch (Fulton et al., 1946; Duling, 1973). The pia mater, often studied in rat and rabbit, is a tissue that can be studied as an open acute preparation (Forbes, 1928) or used as a chronic preparation (Levasseur et al., 1975; Yuan et al., 1990) after closing the skull with a transparent window (see next section). Reports on preparations that are not commonly used, include lung (Wearn et al., 1934), spleen (Knisely, 1936), liver (Irwin and MacDonald, 1953), myocardium (Martini and Honig, 1969), stomach (Rosenberg and Guth, 1970), small intestine (Bohlen and Gore, 1976), omentum (Zweifach and Lipowsky, 1977) and kidney (Steinhausen et al., 1983). Their limited use can to some extent be explained by low reproducibility of the preparation, associated with complicated surgical procedures, or lack of interest in the tissue.

\subsubsection{Conscious models}

The use of conscious models requires the presence of a tissue with a microvasculature that is visible under microscopic view without acute surgery. The structure of some superficial tissues allows such observations; others require the use of a transparent chamber.

\section{Superficial vascular beds}

The most obvious candidate for intravital microvascular observations in conscious subjects is man. The capillaries in the nailfold can easily be made visible by intravital microscopy. Measurement on this capillary bed are routinely used for diagnosis of (stages of) diseases like hypertension, diabetes, intermittent claudication, Raynaud's phenomenon, and scleroderma (Bollinger and Fagrell, 1990). Recently, a first report on AIDS concerning this subject has appeared (Xiu et al., 1991). The bulbar conjunctiva can be used as well (Lee and Holze, 1950; Harper et al., 1978; Sullivan et al., 1983), but has so far not found general application. In short, intravital microscopic observations in man are often descriptive and are generally used for diagnostic purposes.

One of the first mammalian tissues used for intravital microscopy in conscious animals is the bat wing (Jones, 1852). It is an extremely thin tissue and its microvasculature can easily be studied through a microscope. This is further facilitated by the fact that bats are nocturnal animals so they will stay quiet during daytime and can simply be put in a tubular holder with one wing extruded and spread under the 
microscope. The witg possesses a skin microcirculation, while in some bat species the tensor plagiopatagii muscle extends between the fifth digit and the body, allowing study of striated muscle microcirculation (Wiederhielm and Slaaf, 1987). To obtain bats, they usually have to be caught at large, which implies a more severe genetic variation between individuals than in inbred laboratory species. Keeping rats in captivity is rather difficult, but possible. The bat wing is a valuable preparation for studying of angiogenesis and microvascular parameters like diameter, pressure and flow velocity. For pharmacological purposes, it has so far found little or no application.

A final tissue that should be mentioned here is the chorio-allantoic membrane of the chick embryo. This membrane serves as a lung for the growing chick embryo. It has already been used for decades as a model to study tumour growth factors, but since some years, it is also used to study the regulation of normal angiogenesis (Dusseau et al., 1986; DeFouw et al., 1989; Dusseau and Hutchins, 1989; le Noble et al., 1991).

\section{Transparent chambers}

The skin of some mammals is suitable for use in a transparent chamber. Such chambers can serve to study the vascularisation of regenerating normal or cancer tissue. In these cases, the chamber is implanted on a hole in a skinfold. The chamber design determines the thickness of the regenerating tissue, which should be very thin to yield enough optical clarity. More recently developed chambers allow intravital microscopic observations of intact preformed tissue fixed in the chamber. These include skinfold preparations (see below) and so-called pial windows (Levasseur et al., 1975; Yuan et al., 1990) which allow chronic study of the pial microcirculation through a transparent window inserted into the skull.

The first report on a transparent chamber was written by Sandison in 1924. It concerned a rabbit ear chamber, which was modified and improved several times (Sandison, 1928). In 1934, Williams adapted the chamber for use on the skin of the body of the rabbit. In 1943, Algire implanted the chamber into the dorsal skinfold of the mouse. Subsequently, transparent chambers were developed for the hamster cheek pouch (Sanders, 1963; Sanders and Shubik, 1964), the skinfold of the inner side of the human upper arm (Brannemark, 1971) and the dorsal skinfold of the hamster (Endrich et al., 1980) and the rat (Yamaura et al., 1971; Papenfuss et al., 1979; Smith et al., 1985).

Most chambers mentioned above contain regenerated tissue. Some relatively recent rabbit ear chambers (Brảnemark and Lindström, 1963; Arfors et al., 1970) and the rat dorsal skinfold chambers described by Yamaura and colleagues (1971) and Papenfuss and co-workers (1979) contain preformed connective tissue. The hamster dorsal skinfold chamber (Endrich et al., 1980) and the one in the rat developed by Smith and co-workers (1985) contain intact striated muscle, the cutaneous maximus muscle. 
We wanted to study microvascular effects of antihypertensive drugs in an intact, physiologically relevant tissue in conscious animals. In biomedical research, the rat is a common species that can easily be obtained and housed. The spontaneously hypertensive rat (SHR) is a well described model for essential hypertension (Okamota and Aoki, 1963). Therefore, the SHR was chosen as a research model. The genetic basis for hypertension in this model, like in other forms of essential hypertension, is not known, but recently (Hilbert et al., 1991; Jacob et al., 1991) strong evidence has been obtained that a gene that resides in a region that contains, amongst others, the angiotensin converting (ACE) enzyme gene contributes significantly to the elevated blood pressure in stroke prone SHR.

Striated muscle tissue comprises the largest body mass and therefore strongly determines peripheral resistance. Intravital observations of intact striated muscle in conscious animals demand the use of a transparent chamber. Sewell (1966) stated that a chamber preparation must possess "anatomical and physiological normality" and postulated four criteria for an ideal chamber preparation: (1) optimum optical resolution; (2) repeated observations of the same tissue over extended periods of time, preferably in the unanaesthetised, conscious animal; (3) direct accessibility to the interior portion of the chamber for experimental manipulation, and (4) a minimal amount of surgically induced trauma. Smith and co-workers (1985), in trying to meet these criteria when designing their chamber for the rat dorsal skinfold, added that (1) the chamber should be made of light weight, non-reactive, and thermoneutral material, and (2) should be of small size. Satisfaction of these criteria further guarantees anatomical and physiological normality since such a chamber does not interfere with normal activity of the animal or cause undue stress and does not conduct heat from the preparation or the body as a whole.

The above given criteria are met by the chamber designed by Smith and coworkers (1985). The only criterium that is not satisfied is access to the interior of the chamber although recent developments allow infusion of minute volumes (Hutchins et al., 1991). However, this allows only for chronic studies, and therefore the technique was not suitable for the acute studies described in this thesis.

\subsection{This thesis}

A wide variety of antihypertensive drugs is available for treatment of hypertension. The choice of the therapy depends on various considerations like, for instance, severity and etiology of the disease, responsiveness of the patient, and the occurrence of side effects. A highly important factor in this regard is the microcirculatory effect of the drug. As pointed out in the preceding sections, microvascular alterations play an important role in the pathogenesis and maintenance of hypertension. 
Sensitivity to:

calcium antagonists lemakalim

$\alpha_{1}$-adrenergic drugs $\alpha_{2}$-adrenergic drugs angiotens in $\| 1$ inhibition

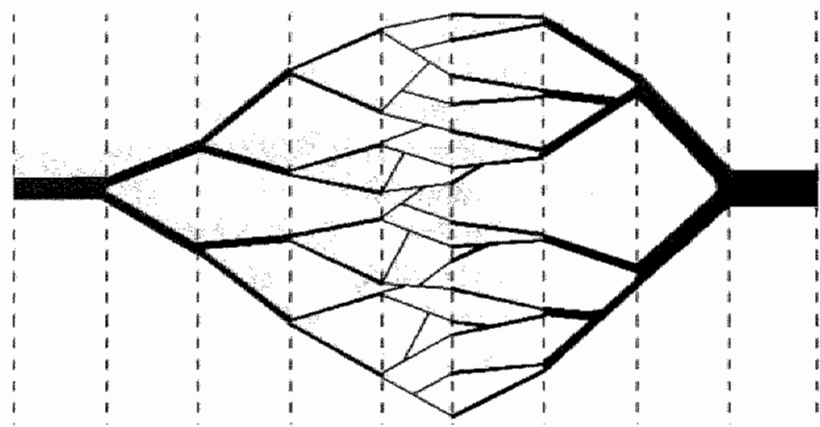

$\begin{array}{lllllllll}A_{1} & A 2 & A_{3} & A 4 & \text { cap } & \vee 4 & V_{3} & V_{2} & V_{1}\end{array}$
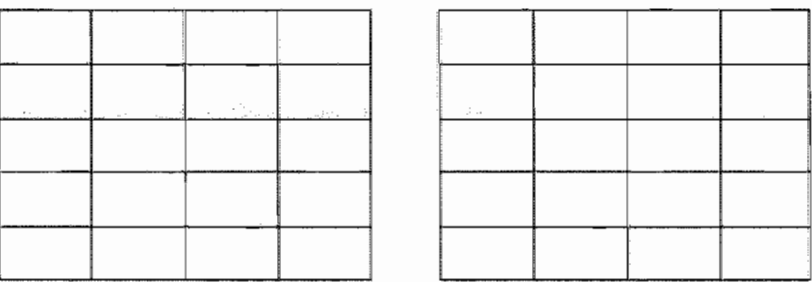

Figure I.5 Schematic representation of the micracirculation. The sensitivity of SHR cutaneous maximus muscle microvessels to various vasoactive drugs is yet unknown.

The macrocirculatory effects of most antihypertensive drugs are well established since they have been examined in whole animal studies and controlled human trials. The fact that macrocirculatory parameters like blood pressure, heart rate, compliance of large arteries and a large scale of derived variables can be determined in a non-invasive manner has greatly contributed to this knowledge. Furthermore, the introduction of Doppler flow probes and radioactively labelled microspheres has allowed the assessment of regional effects of antihypertensive drugs on blood flow in animal studies.

Little is known of microcirculatory effects of antihypertensive drugs. Moreover, reports on this subject published so far all comprise studies on acute effects on the microvasculature of exteriorised or in situ studied organs in anaesthetised animals, in some cases after a preceding long term antihypertensive treatment. The microvascular reactivity of such preparations is influenced by the anaesthetic(s) used and by the effects of acute surgery. This complicates the interpretation of the experimental results and makes it more difficult to extrapolate findings to the human situation.

We are the first to use an intact striated muscle preparation, the cutaneous maximus muscle in conscious, unstressed SHR for pharmacological studies. The aim was to investigate the acute microvascular effects of a number of established as well as recently developed antihypertensive drugs on the microvasculature of this preparation. The chosen model allowed us to avoid anaesthesia and acute surgery. 
The first experimental chapter of this thesis (chapter 3) describes a non-pharmacological, morphometric study, in which the microvascular topology of the cutaneous maximus muscle in SHR and their normotensive counterpart, the Wistar-Kyoto rat (WKY), are compared. The aim was to determine whether alterations in angioarchitecture in this muscle could contribute to an elevated blood pressure in SHR. The remaining experimental chapters describe experiments carried out with vasoactive drugs. In chapters 4 and 5 the effects of drugs that act on ion channels are presented, i.e. calcium antagonists and potassium channel openers, respectively. In chapter 6 , the effects of $\alpha$-adrenoceptor agonists and antagonists are described. On the basis of the results of these experiments, we propose a functional distribution of $\alpha$-adrenergic reactivity over the microvasculature of SHR cutaneous maximus muscle. Furthermore, in this chapter, the microvascular effects of graded haemorrhage are reported. Haemorrhage is a non-pharmacological way of inducing a depressor response, the microvascular effects of which we used to determine the drug specificity of the microvascular effects induced by the antihypertensive drugs used. In the last experimental chapter, chapter 7 , the microvascular effects of different ways of inhibiting the renin-angiotensin system are discussed.

We hypothesise that individual segments of the microcirculation differ in sensitivity to antihypertensive drugs. This hypothesis can be visualised schematically as represented in fig. 1.5. The box under the scheme is empty but will be filled on the basis of the results of the experiments described in this thesis. This will be done in chapter 8: the general discussion. 


\section{CHAPTER 2}

\section{Materials and methods}

\section{1}

\section{Animals}

In all experiments described in this thesis, male spontaneously hypertensive rats (SHR) were used. In the morphometric study described in chapter 3, we also used male Wistar-Kyoto rats (WKY). All rats were obtained from the Central Animal Facilities of the University of Limburg and entered our laboratory shortly after weaning $(80-100 \mathrm{~g})$. At this point of time a training protocol was started to get the animals used to sit unstressed in a rodent restrainer for at least 2 hours. The restrainer (figure 2.1) was built in our own workshop according to the descriptions of Smith and co-workers (1985). The device minimises motion without impeding normall respiration, while its design allowes adaptation to rats of various sizes. Prior to surgery, 3-4 rats were housed in a cage; after surgery each rat had an individual cage. Rats were kept at a 12 hour day/night rhythm. Unless stated otherwise, regular rat food (Hope Farms, Woerden, the Netherlands) and regular tap water were available ad libitum.

\section{Surgery}

\subsubsection{The dorsal microcirculatory chamber}

All rats used in the present studies were implanted with a dorsal microcirculatory chamber (DMC). This technique was first published in 1985 by Smith and co-workers. In the DMC, the cutaneous maximus muscle is exposed for intravital microcirculatory observations in conscious rats. An adapted version, as described by Hutchins and colleagues (1988) was used in our laboratory. The most important modification in this version was the removal from the dorsal skinfold of the right layer of the cutaneous maximus muscle as will be described below. Thus, the thickness of the preparation was reduced and optical clarity greatly enhanced.

\section{Design of the $D M C$}

The DMC consists of 2 halves made of polycarbonate by injection moulding (Carolina Medical Electronics, King, NC, USA). Polycarbonate is an extremely light weight material with very low heat conductivity, which makes it 


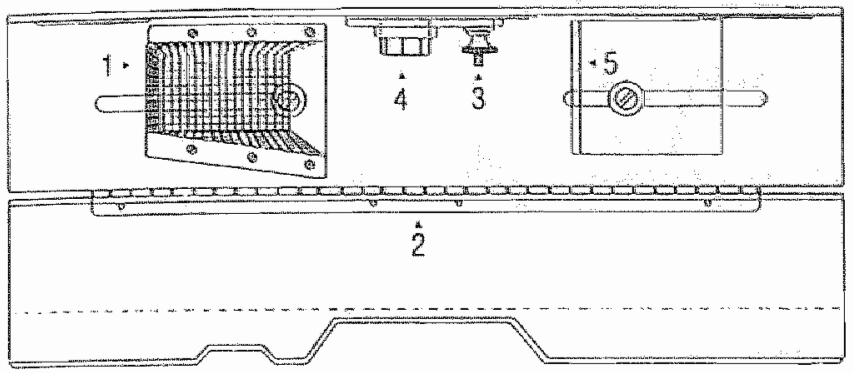

top view (opened)

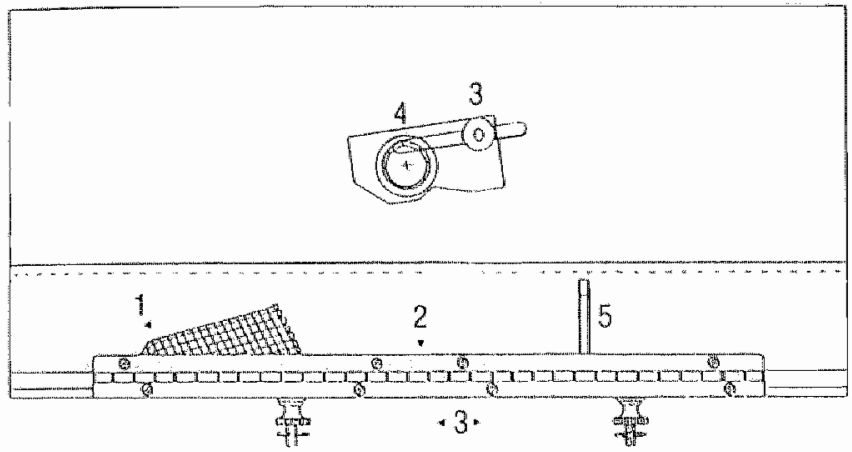

frontal view

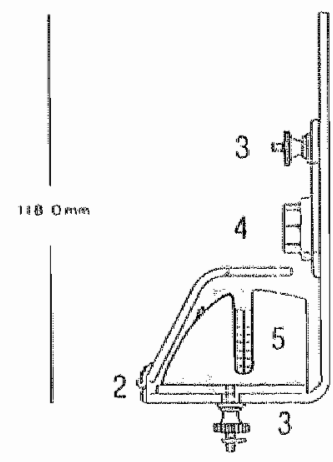

sidle view

Fig. 2.1 Rodent restrainer for in vivo microscopy. Materials are perspex slabs with stainless steel nose piece (1), hinge (2), and fasteners (3). The perspex opvical rod (4), rearstop (5) and nose piece (1) are adjustable, allowing adequate restraint of rats of various sizes. Not shown are three adherence straps, used to keep the restrainer closed ${ }_{n}$ and clips to fix the chamber the optical rod. A modified version of the restrainer, with a lower back side, was used for training purposes. (adapted from Smith et al., 1985)

highly suitable for the present purpose (see section 1.3). The dimensions of one chamber half are represented in figure 2.2. This half contains a cover slip (Thermanox tissue culture cover slips, $13 \mathrm{~mm}$ round (no 11/2); Nunc Inc, Naperville, IL, USA) and 4 stainless steel pins (diameter $0.61 \mathrm{~mm}$, SWX 024 stainless steel wire, straightened and coiled; Small Parts Inc., Miami, FL, USA) that match sockets in the second half, maintaining an interdistance of 500-600 $\mu \mathrm{m}$ between the cover slips. This allows sufficient space for one layer of cutaneous maximus muscle (200$300 \mu \mathrm{m})$. The chamber is reusable, except for the cover slips, that face the muscle tissue. Prior to each implantation, a set of new cover slips is attached to the 


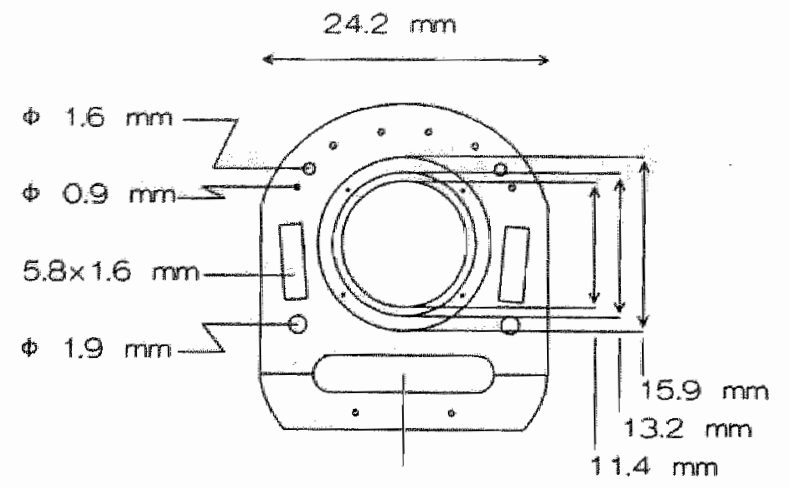

$12.7 \times 3.4 \mathrm{~mm}$

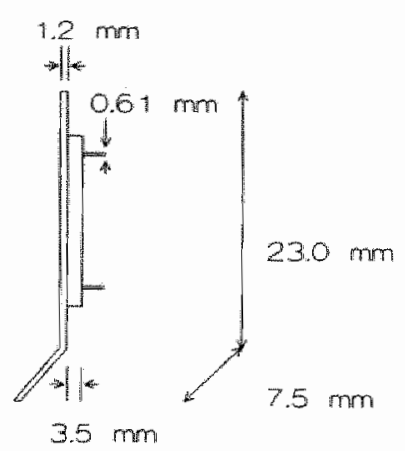

Figure 2.2 The dorsal microcirculatory chamber, mode of polycarbonate by injection moulding. Srainless steel pins keep the no chamber halves separated at a distance of 500-600 um. Four nylon screws are insented through the 1.6 and 1.9 mn holes (two of each). The remaining holes serve for weight reduction and to promote drying of the underlying skin. The inner ridge (11.4 to $13.2 \mathrm{~mm}$ ) at the inside of the chamber is countersunk and accomodates the cover slips.

chamber (see fig. 2.2) using a commercially available epoxy glue. Once implanted, the chamber is kept in place by a set of nylon screws and corresponding stainless steell nuts (pan head machine screws; Small Parts Inc, Miami, FL, USA; top: 2 each $\# 0-80 x^{1 / 2 "}$; bottom: 2 each $\# 1-72 x^{1 / 2 "} "$; nuts (lef $\# 303 \mathrm{~s} / \mathrm{s}$, burnfree 3 ); J.J. Morris Co., Southbridge, MA, USA).

\section{Implantation of the DMC}

One day before the implantation, 5-6 weeks old rats received a prophylactic antibiotic injection of $20 \mathrm{mg} / \mathrm{kg}$ trimethoprim and $100 \mathrm{mg} / \mathrm{kg}$ sulfamethoxazole s.c. (Bactrimel, Hoffmann-La Roche, Basel, Switzerland). On the day of surgery, rats were anaesthetised with a mixture of ketamine/xylazine $(5 \mathrm{mg} / \mathrm{kg} ; 1$ $\mathrm{mg} / \mathrm{kg} \mathrm{i.m.).} \mathrm{Just} \mathrm{before} \mathrm{the} \mathrm{actual} \mathrm{surgery} \mathrm{was} \mathrm{started,} \mathrm{an} \mathrm{additional} \mathrm{dose} \mathrm{of}$ pentobarbital was given ( $30 \mathrm{mg} / \mathrm{kg}$ i.p.) to achieve an anaesthetic effect of about three hours. To further prepare the animal for surgery the entire back was shaven, using an animal clipper and depilated with a commercially available chemical depilatory agent. After mechanical removal of the depilatory agent, the skin was carefully washed with warm water and betadine-shampoo and sterilised with povidone iodine (Betadine, Dagra, Diemen, the Netherlands). The eyes of the rat were covered with an antimicrobial eye ointment (chloramphenicol, AUV, Cuyk, the Netherlands) to prevent cornea damage.

Implantation of the DMC was carried out with autoclaved surgical tools, the chamber was gas sterilised. The actual procedure started with the removal of the iodine from those areas on the back that were to be subject of surgical handling, using sterile saline and a cotton wool stick. Next, four $15-20 \mathrm{~cm}$ long 3-0 silk 


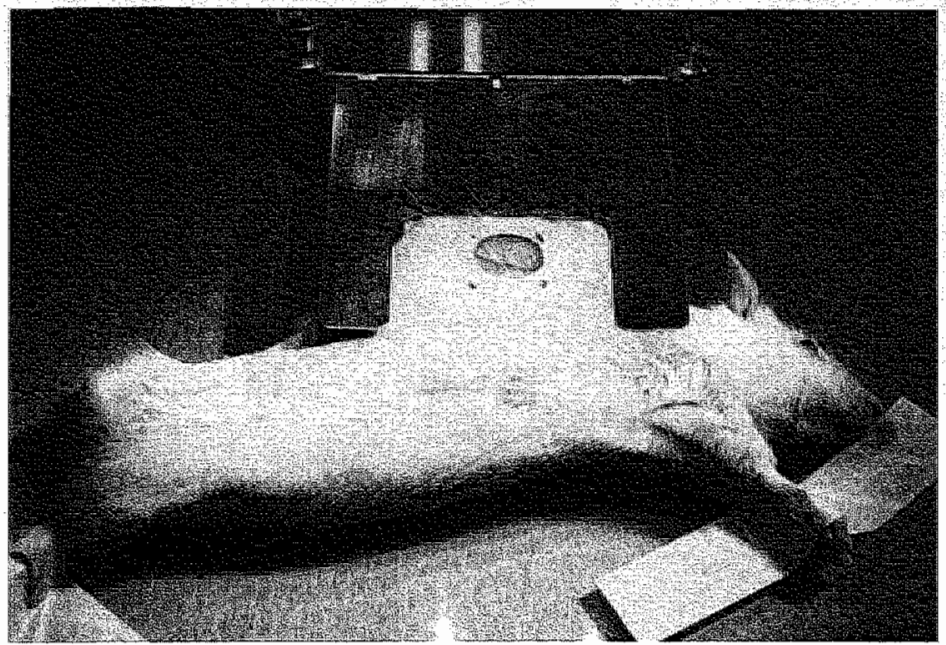

Fig. $2.3 \mathrm{~A}$ rat during the implantation of a dorsal microcirculatory chamber. The animal is tied to a D-shaped frame to form the skinfold. Through the hole in the right side of the skinfold, the inner side of the cutaneous maximus muscle on the left side of the skinfold is wisible. The entry holes for the screws that keep the two chamber hatwes tagether are also visible.

sutures were inserted through the skin along the vertebral column. The first suture was placed approximately $1 \mathrm{~cm}$ below the cranial angles of the scapulace, the remaining were placed in the caudal direction at regular interdistances over a length of approximately $4 \mathrm{~cm}$. By pulling the sutures up, a dorsal skinfold of about $3 \mathrm{~cm}$ high was formed. A circular spot was outlined on the right side of the skinfold with a dermal punch (diameter $11 \mathrm{~mm}$ ). The fold was then released and the entire skin within the outline was cut away, using small scissors. The rat was placed on its left side on a $40 \times 40 \mathrm{~cm}$ perspex surgery board and the sutures were lied to a $\mathrm{D}$ shaped metal frame that was mounted on the middle of the board to form the skinfold (fig 2.3). The skinfold was stabilised by extending the rat over the board, securing the front- and hindlimbs with tape and supporting the fold by a pile of sterile gauzes. The rat was covered with a sterile drape (Dextex, Dexter Nonwovens, Chirnside, Scotland, UK) to avoid contamination of the operation field. Sterile saline was applied to the hole in the fold, and the operation area was kept moist throughout the rest of the implantation procedure. Connective tissue, covering the cutaneous maximus muscle at the inside of the skinfold was removed. Microbleedings were stopped with thrombin (Trombistat, Parke-Davis, Morris Plains, NJ, USA). The right chamber half was positioned and holes indicating the entry sites for the securing screws were made with a 20 gauge needle and made wider by stretching them with fine-tipped scissors. After microbleedings had stopped completely, the operation field was filled with fresh saline and the right chamber half (containing the stainless steel pins) was put in place together with securing 


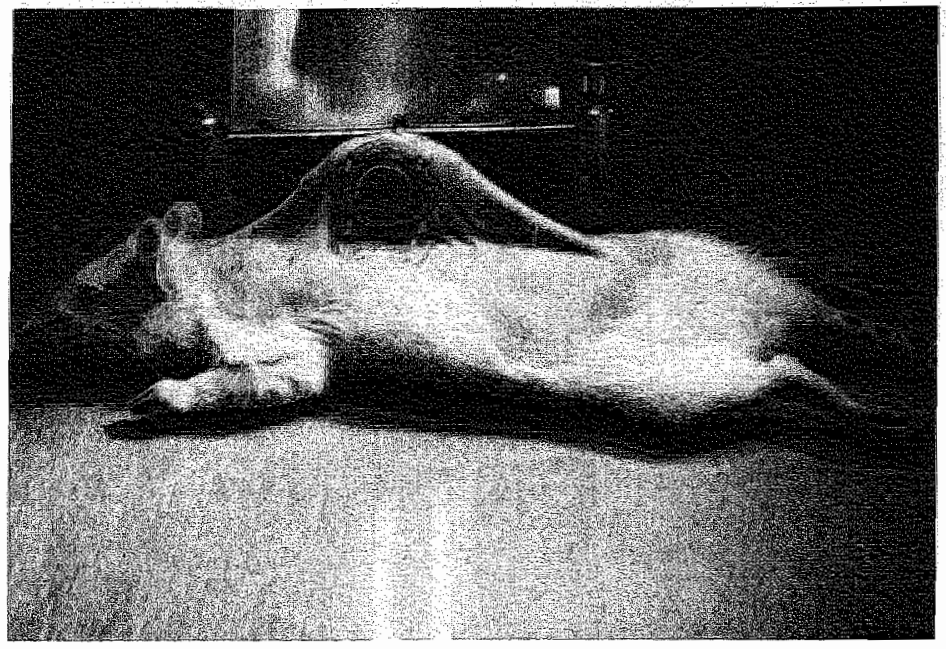

Figure 2.4 A rat immediately after implantation of a dorsal microciculatory chamber

screws. Holding the chamber in place under a pile of sterile gauzes, the rat was flipped over on its right side, turning the $\mathrm{D}$-shaped frame on its axis. The animal was repositioned on the board and openings for the screws on this side were cut with a no. 11 scalpel and the screws were pulled through. On the now facing left side of the skinfold, an outline was made using a dermal punch with a diameter of $15 \mathrm{~mm}$, using the stainless steel pins of the underlying chamber half for orientation. Under microscopic view, a small incision was made in the skin with a no. 11 scalpel down to the cutaneous maximus muscle. Using small forceps and smooth, curved strabismus scissors, the outlined skin section was dissected from the muscle. After this, the stainless steel pins of the first chamber half were pushed through the musele with an 18 gauge needle adaptor. Microbleedings were again stopped with thrombin, fresh saline was put on the preparation and the second chamber half was put in place. Stainless steel nuts were fitted to the screws and the animal was cut loose from the frame. A chamber clamp was used to keep the chamber in place until the two halves were securely fastened together. Sutures were removed from the skin and antimicrobial ointment was applied to the wounds. Excess length of the screws was cut and a drop of commercially available super glue was applied for final securing. Figure 2.4 shows a rat immediately after the implantation procedure. To avoid scratching and nibbling and to improve wound healing, an aluminum cap was placed over the chamber and fixed with stainless steel wire. Immediately after surgery and one day later, rats received a second and third dose of antibiotics. Two to three days after surgery, training was resumed. During the subsequent two weeks, the wound edges were cleaned three times using iodine and saline. Cleaning was carried out under ketamine/xylazine anaesthesia $(5 \mathrm{mg} / \mathrm{kg} ; 1 \mathrm{mg} / \mathrm{kg}$ i.m.). 


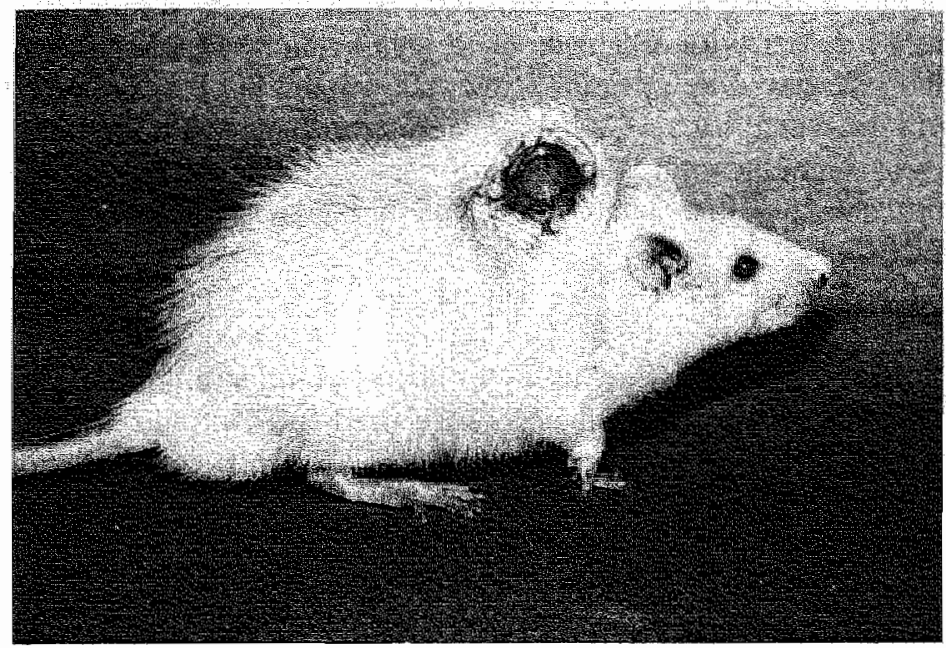

Fig. 2.5 A rat approximately four weeks after implantation of a dorsal microcirculatory chamber. At this age rats were used for experiments. The regrown fur shows some long hair not seen on original rat fur.

Approximately 4 weeks later, rats were used for experiments for the first time.An impression of a mature rat implanted with a dorsal microcirculatory chamber is given by figure 2.5. A preparation was used when it showed good optical clarity and no signs of inflammation, as indicated by presence of an excessive number of collecting venules or disintegration of the tissue.

\subsubsection{Catheters}

\section{Construction of catheters}

Arterial catheters were made of a $6 \mathrm{~cm}$ piece of $\mathrm{PE}-10$ tubing, which was heat-sealed to a $12 \mathrm{~cm}$ piece of PE-50 tubing. A $1 \mathrm{~cm}$ piece of $P E-100$ tubing was heat-sealed to the other end of the PE-50 tubing and a $3 \mathrm{~cm}$ piece of vinyl tubing (TT-89) was slipped over it. This material permits frequent clamping without damaging. Venous catheters were made in a similar way from $6 \mathrm{~cm}$ of $\mathrm{PE}-10$ tubing and $15 \mathrm{~cm}$ of PE-50 tubing. Two rims were made 3 to $4 \mathrm{~cm}$ from the tip of the canula to facilitate securing. In near-boiling water, the PE 10 tubing end of both types of catheters were bent in a U-shape. The length of the PE-10 tubing from the tip to the bend was adjusted to $3 \mathrm{~cm}$.

\section{Implantation of catheters}

Catheters were gas sterilised before use. Prior to implantation, rats were anaesthetised with a mixture of ketamine/xylazine $(5 \mathrm{mg} / \mathrm{kg}, 1 \mathrm{mg} / \mathrm{kg}$ i.m.). One groin was shaven and the animal was fixed dorsal side down on an surgery board with a hole to accommodate the DMC. An incision was made in the shaven 
groin and the femoral artery and vein were freed from the surrounding tissue. After clamping of either vessel with silk sutures, a small hole was cut with ophthalmic scissors and the catheter was advanced into the vessell until the tip reached the abdominal aorta or vena cava. Catheters were secured to the vessels and the underlying muscle with silk sutures and exteriorised and anchored in the neck. They were filled with sterile saline and closed with a metal obturator. Wounds were sutured with 2-0 silk.

\section{Use of catheters}

Venous catheters were used for drug administration, either as bolus injections or by infusion. Arterial catheters were used for continuous registration of mean arterial pressure (MAP) during experiments. To this end the catheter was connected to a pressure transducer (CP 01, CTC, Inglewood, CA, USA), which was callibrated at the beginning of each experimental day, using a mercury manometer. Various types of recorders have been used to register the blood pressure signal. In the haemorrhage experiment, described in chapter 6 , the arterial catheter was also used for blood withdrawal.

\section{Microvascular studies}

\subsubsection{Experimental setup}

A schematic drawing of the experimental setup is given in figure 2.6. A horizontally mounted Leitz Orthoplan microscope (tube magnification $1.25 \mathrm{x}$ ) was used. Through this adaptation, the microscope objective pointed in a horizontal direction, allowing the rats to remain in their natural, ventral side down position during experiments. The preparation was transilluminated with a Xenon lamp (12 V, $100 \mathrm{~W}$ ) equipped with a heat absorbing filter. Wild Leitz VG green and BG 23 blue filters were used for better contrast. A Zeiss Plan 2.5x objective (numerical aperture, NA: 0.08) was used for inspection and mapping of the preparation, individual vessel segments were studied with a Zeiss plan 10x objective (NA: 0.25 ). The microscopic image was directly projected onto a $2 / 3$ inch video camera (Philips LDH 0402/01) and visualised on a video monitor (Sony PVM $122 \mathrm{CE}$ ). On the monitor screen, interline distances were $8 \mu \mathrm{m}$ and $2 \mu \mathrm{m}$ for the $2.5 \mathrm{x}$ and $10 \mathrm{x}$ objectives, respectively. Total magnification on the monitor screen was $420 \mathrm{x}$ for the $10 \mathrm{x}$ objective. The images were stored on videotape with a Philips VHS recorder (VR 6561). A video timer (For.A VTG-33) was connected to the setup for frame coding. A video image shearing device (Intaglietta and Tompkins, 1973) was connected for off-line analysis of the videotapes. 


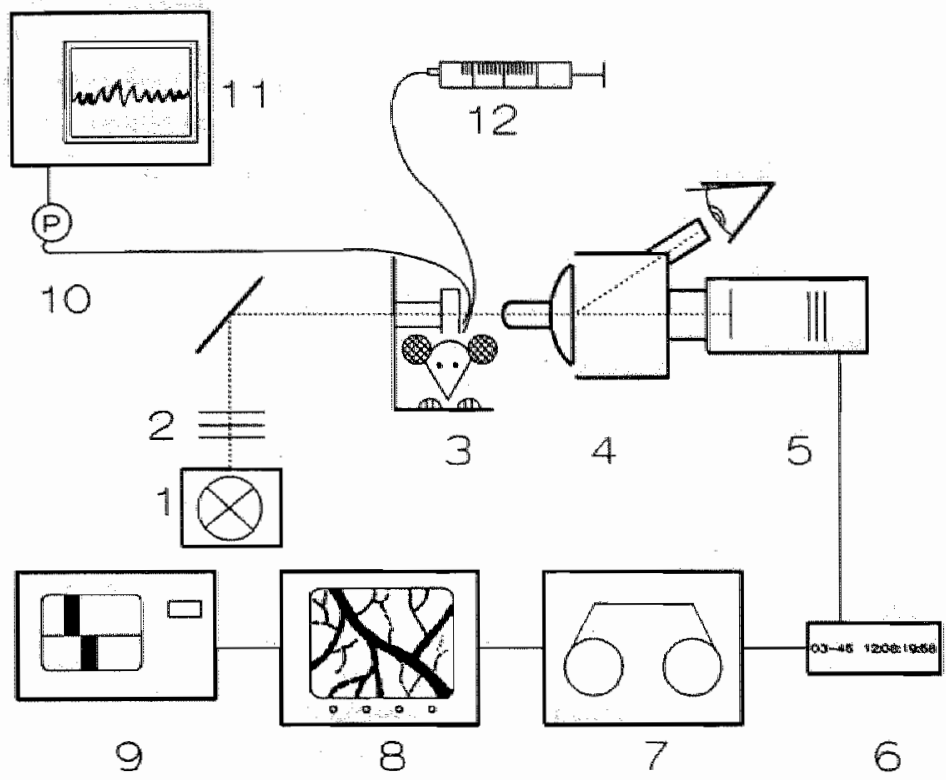

Fig. 2.6 Schematic representation of the experimental sethp. 1 , Xenon lamp $(12 V, 100 W)_{;}$, filter set; 3, microscope stage with conscious rat; 4, microscope; 5, video camera; 6 , video timer; 7 , wideo recorder; 8, video monitor; 9, shearing monitor; 10, pressure transducer; 11, recorder; 12, syringe for drug administration (either as a bolus injection or by an infusion pump).

\subsubsection{General experimental protocol}

At the beginning of each experimental day, a short video recording was made of a micrometer scale for calibration purposes. Next, the aluminum cap was removed from the DMC and the cover slips were cleaned with distilled water and a cotton wool stick. Rats were weighed, put in the restrainer and placed ventral side down in the microscope. The arterial catheter was connected to the pressure transducer for continuous recording of MAP. The venous catheter was extended with an additional piece of PE-50 tubing, allowing drug administration without disturbing the animal, either by bolus injection infusion. After this, rats were allowed to habituate for about half an hour to achieve a stable level of MAP.

For orientation purposes, at the start of the experimental series, a handdrawn map was made of the entire microvasculature in the preparation of each rat, using the $2.5 \mathrm{x}$ objective. Individual vessel segments were selected for investigation using the $10 \mathrm{x}$ objective and marked on the drawing. In the experimental sessions these vessel segments were recorded on tape for about 5 seconds prior to drug administration and at defined time points after injection or initiation of infusion. Details are described in the individual chapters. In general, only one drug was used on each experimental day. 


\subsubsection{Analysis of videotapes}

A video image shearing device (Intaglietta and Tompkins, 1973), built in our own workshop, was used for off-line analysis of microvascular diameters. On the screen of this device, the video image is sheared along a given raster line by delaying the video horizontal synchronisation pulse, thus causing a portion of the video frame to be displaced. The picture itself could be rotated, permitting positioning of the vessel image perpendicular to the shearing direction. After calibration of the system, alignment of the two opposite inner edges of the vessel gives a quantitative measure of the vessel diameter (see fig. 2.6, number 9).

The width of the red blood cell column in a vessel was taken as the vessel lumen size. This means that the actual vessel lumen could have been wider, but in this preparation vascular walls were seldom visible, leaving only the red blood cells as indicators of vessel diameter. In arterioles, the lumen appeared as a black line, in venules, especially in smaller ones, individual erythrocytes were usually visible, making vessel diameter less defined. To determine vessel diameter, 8 measurements taken over a length of $100-150 \mu \mathrm{m}$ of a straight vessel segment, were averaged. In this way, variations caused tapering of the vessel were taken into account.

Arterioles and venules were classified alphanumerically in a functional way according to their branching order. Arterioles with a diameter of over $60 \mu \mathrm{m}$ entering the preparation were classified as A1. At bifurcations, side branches with a diameter similar to the parent vessel were also classified as A1. Clearly smaller side branches were designated A2. This procedure was continued down to A4 vessels. On the venular side a similar scheme was applied, designating draining vessels with a diameter of over $100 \mu \mathrm{m}$ as V1 and smaller venules as V2 to V4. This scheme is visualised on the front cover of this thesis. The number of A4 and V4 vessels that could be analysed was limited in all experiments, and since they did not differ in reaction from the $A 3$ and V3 vessels, they were classified together as A3.A4 and V3.V4 vessels.

\section{Data analysis}

Data were processed with a computer software program (Crunch Interactive Statistical Package, version 3.06, Crunch Software Corporation, San Francisco, CA, USA). The following statistical methods were used to compare data in different experimental groups.

1. The Student's t-test for paired observations to compare values of the same group of rats in two different situations.

2. The Student's t-test for unpaired observations to compare values of two groups of unpaired values. 
3. One-way analysis of variance for multiple group comparisons, followed by the Dunnett's test (Wallenstein et al., 1980) to compare more than two groups of unpaired values.

Data are expressed as means $\pm S E M$. Statistical difference was accepted if $p<0.05$.

\subsection{Drugs used in this thesis}

The drugs listed below were received as kind gifts from the following persons and companies:

Calcium antagonists

Verapamil:

Knoll BV, Amsterdam, the Netherlands

Nifedipine:

Bayer Nederland BV, Mijdrecht, the Netherlands

Felodipine:

B. Meems, Astra Pharmaceutica BV, Amsterdam, the Netherlands

Potassium channel opener

Lemakalim: Dr. R. Buckingham, SmithKline Beecham Pharmaceuticals, Harlow, United Kingdom

$\alpha_{2}$-adrenoceptor agonist
Azepexolle:
Dr. J.C. van Meel, Dr. Karl Thomae GmbH,
Biberach,Germany

ACE-inhibitors

Captopril: $\quad$ Bristol Myers Squibb BV, Woerden, the Netherlands

Enalaprilat: $\quad$ Merck Sharp \& Dohme BV, Haarlem, the Netherlands

Non-peptide angiotensin II receptor antagonist

Losartan: Dr. P.B.M.W.M. Timmermans, Du Pont de Nemours and Company, Wilmington, DL, USA

All other drugs, i.e. the $\alpha$-adrenoceptor antagonists prazosin $\left(\alpha_{1}\right)$ and yohimbine $\left(\alpha_{2}\right)$, and the $\alpha_{1}$-adrenoceptor agonist phenylephrine were purchased from commercial suppliers. 


\section{CHAPTER 3}

\section{A comparison between microvascular network characteristics in striated muscle of conscious adult normotensive and spontaneously hypertensive rats}

\section{1}

\section{Introduction}

Various forms of clinical and experimental hypertension are characterised by an increased resistance in the microcirculation of different vascular beds (Schmid-Schönbein and Chien, 1986). Functional as well as structural mechanisms contribute to an elevated microvascular resistance. Functional factors include increased sensitivity of vascular smooth muscle cells to neural, myogenic and humoral constrictor influences; small arterioles may even completely close to flow (functional rarefaction). Secondly, changes in rheologic parameters can lead to increased blood viscosity and thus elevate vascular resistance. Changes in microvascular network anatomy may influence resistance on a structural basis. Disappearance of existing vessels, possibly after prolonged functional rarefaction, or an incomplete development of the microvascular tree during pathogenesis of hypertension in young subjects leads to a structurally decreased number of microvessels (structural rarefaction).

Rarefaction is generally limited to small precapillary arterioles, while in larger arterioles hypertrophy or hyperplasia of the media leads to a structurally increased thickness of the vessel wall and hence to a narrowed vessel lumen. Furthermore, increased tortuosity, which means increased vessel length within a given tissue mass, also increases microvascular resistance. Resistance $R$ in a single vessel can be described by the "Hagen-Poisseuille law":

$$
R=\frac{8 L \eta}{\pi r^{4}}
$$

Here, $L$ is vessel length, $\eta$ is blood viscosity, and $r$ is diameter. A vascular bed consists of several in series or parallel coupled vessels. Total resistance for a 
number of $\mathbf{n}$ in series coupled vessels is equal to the sum of the individual resistance:

$$
R_{\text {total }}=\sum_{i=1}^{n} R_{i}
$$

For a number of similar parallel coupled vessels, total resistance can be calculated from:

$$
\frac{1}{R_{\text {total }}}=\sum_{i=1}^{m} \frac{1}{R_{i}}
$$

In a network increased length leads to increased resistance. A decreased diameter in any of the vessels also increases resistance. If the number of parallel vessels is decreased, again the result is an increased total resistance.

The spontaneously hypertensive rat (SHR) has been bred as a genetic model for human essential hypertension (Okamota and Aoki, 1963) and is widely used for research in this field. In the initial phase of development of hypertension in SHR, mean arterial pressure is elevated because of an increased cardiac output, while resistance is unchanged. Between the age of 6 and 9 weeks, cardiac output normalises and resistance starts to increase. After an age of 9 weeks, cardiac output is not different from cardiac output in normotensive Wistar-Kyoto (WKY) control rats, but mean arterial pressure is still elevated because of an increased total peripheral resistance (Evenwel et al., 1983). This increase is caused by elevated resistances in probably all vascular beds and has been shown to be especially prominent in liver, spleen, kidneys, brain, and striated muscle of the adult SHR (Evenwel et al., 1983). DeLano and colleagues (1991) recently reported on arteriolar micropressure measurements in different striated muscles of SHR and WKY. In both strains, pressure in feeding arterioles (diameter about $200 \mu \mathrm{m}$ ) was up to $90 \%$ of central blood pressure. Also midway the arteriolar arcade bridge within the muscle (diameter about $100 \mu \mathrm{m}$ ), pressures were still over $70 \%$ of central blood pressure. Furthermore, normalised pressure profiles were similar in both strains. This indicates that in the central arteries of SHR absolute pressure is reduced to a greater degree than in WKY, but that the main pressure reduction still occurs in the microcirculation. This means that the largest absolute resistance increase in SHR striated muscle is located in the microcirculation. Thus, given the large contribution of striated muscle tissue to total body mass, this tissue is an important site of elevated total peripheral resistance in essential hypertension such as occurs in SHR.

The cutaneous maximus muscle in the dorsal skinfold of SHR (Smith et al, 1985) has been used for several pharmacological investigations (Hutchins et al, 
1988; Messing et all, 1991). The muscle extends under the entire surface of the skin and has at least six feeding vessels, one near every extremity, and one midway each side of the body. Perfusion with indian ink revealed that each feeder basically perfuses its own part of the muscle, and that the Al arterioles (see section 2.3.3) form an arcading network with mashes of roughly $1 \mathrm{~cm}$ in cross section. The venular network showed a similar structure. Furthermore, one feeder filled several large draining venules, indicating interconnections with the networks of neighbouring feeders. These observations lead us to the assumption that the cutaneous maximus muscle microvasculature represents a network where $\mathrm{A} 1$ and $\mathrm{V} 1$ and possibly allso $\mathrm{A} 2$ and $\mathrm{V} 2$ vessels form arcades, such as has been described for the spinotrapezius muscle by Engelson and colleagues (1985a,b). In such a network, larger and smaller arcading arterioles and venules form the basic architecture that probably does not change anymore in adult rats. The mashes of the network are filled by asymmetric dichotomous trees of small transwerse arterioles and collecting venules. The density of these vessels may vary, depending on physiological and pathophysiological conditions. The larger vessels in this network serve mainly as a blood distribution system, while the smaller vessels control blood flow through the local capillary network (Oude Vrielink, 1988; Schmid-Schönbein and Zweifach, 1991). In the branching scheme we used (see section 2.3.3), the A1 and A2 arterioles and the $\mathrm{V} 1$ and $\mathrm{V} 2$ venules represent large and small arcading arterioles and venules, respectively. Transverse arterioles and collecting venules are represented by A3.A4 and V3.V4 vessels, respectively. The basic design of the arteriolar and venular networks is similar, but the venular network is possibly more dense (Engelson et al., 1985a). The A1 and V1 arcading vessels are usually paired (personal observation). Although the dorsal microcirculatory chamber is implanted on a defined place on the back of the rat to expose a part of the cutaneous maximus muscle microvasculature, one cannot predict what part of the basic pattern will be covered. For instance, the number of $\mathrm{A} 1$ arterioles or $\mathrm{V} 1$ venules may be zero,one or two.

Data on changes in the microvasculature of the cutaneous maximus muscle that contribute to hypertension in SHR are scarce (le Noble et al., 1990a). In this study, we examined vessel diameters, numbers and lengths of the microvascular network in the cutaneous maximus muscle of SHR and their normotensive counterpart, the Wistar-Kyoto rat (WKY) to determine the nature of the changes that lead to an elevated resistance in this muscle in SHR.

\section{Materials and methods}

\section{2 .1}

Experimental protocol

Male SHR and WKY rats were used in this study. They were prepared for intravital microscopic observations as described in section 2.3.2. After mapping of the microvascular tree, video recordings were started. The entire visible length of the large A 1 and V1 vessels was recorded to document vessel diameter 
and number of side branches. To include as many side branches as possible, constant focussing up and down through the muscle was done at each site of recording. Selected side branches of each branching order were recorded on tape in the same way. The protocol was carried out a second time on the preparation in the vasodilated state. For this purpose, immediately following the first recordings, an infusion of felodipine was started ( $3 \mu \mathrm{g} / \mathrm{kg} / \mathrm{min} ; 10 \mu \mathrm{l} / \mathrm{min}$, stock solution $3 \mathrm{mg} / \mathrm{ml}$ in polyethylene glycol, further dilution with distilled water). As described in chapter 4, felodipine, a dihydropyridine type calcium channel antagonist, is an effective vasodilator in this preparation (Messing et al., 1991). After stabilisation of MAP at a lower level, indicating that vasodilatation was completed, recordings of the same vessels were made to study dilating capacity and possible microvascular recruitment. Arteriolar diameters were measured downstream of each side branch and venular diameters upstream of each side branch. Diameters of the side branches were also measured. From the data on each individual vessel, an average vessel diameter was calculated. Subsequently, vessels were grouped according to branching order (see section 2.3.3) and mean diameters per branching order were calculated. For each branch point, the diameter ratio $R_{D}$ was calculated as the ratio of the main vessel diameter near the side branch and the side branch diameter. The $R_{D}$ walues were used to make a rough division between next order side branches that are part of the basic network, and small transverse arterioles and draining venules that branched directly from first or second order vessels.

\subsubsection{Photography and slide analysis}

On the day following the microscope experiments, slide pictures (Kodak Ektachrome 64) were taken from the muscle preparation with a Nikon F301 camera with a $50 \mathrm{~mm} \mathrm{f} / 1.8$ Nikkor lens, a polarising filter and a Novoflex automatic extension bellow, mounted on a small stage. Conscious rats were put on the stage and lightly restrained by hand by one investigator. The dorsal microcirculatory chamber was gently pushed against a perspex rod that was mounted horizontally on the stage. The rod served to conduct the light from the flash light, which transilluminated the muscle preparation (Metz Mecablitz 32CT3, connected to the camera with a Nikon TTL remote cord SC-23). Between the flash light and the optical rod, a diffusion fillter and a second crossed polarising filter were placed. Pictures were taken by a second investigator. The extension of the bellow was such that the image of the preparation optimally filled the picture frame, yielding a $2.0 \mathrm{x}$ magnification. A regular surgery lamp was used for illumination of the picture field during focusing. A Nikon remote cord $\mathrm{HC}-12 \mathrm{~A}$ was used for shutter release to minimise vibration of the camera. A picture of a resolution test chart taken under the same conditions yielded a resolution of 70 line pairs $/ \mathrm{mm}$. This means a resolution of $14 \mu \mathrm{m}$ on the slide, which is equal to $7 \mu \mathrm{m}$ on the original when taking the $2.0 \mathrm{x}$ magnification into account. Since the muscle preparation had less contrast than the resolution test chart, the resolution on the slide pictures of the cutaneous maximus muscle was estimated to be about $10 \mu \mathrm{m}$.

Slides were projected on a digitising tablet to a total magnification of the 
preparation of $52 x$. A digitising software program (Sigma Scan, version 3.90, Jandel Scientific, Bridgeway Sausalito, CA, USA) was used to measure the length of various vessels. Firstly, the length of each vessel studied by intravital microscopy was determined, and from these lengths and the number of side branches (i.e. the number of diameter measurements), the number of side branches per unit of vessel length was calculated. Secondly, the total length of all A1, A2, V2 and V1 vessels in the preparation was measured, respectively. For $A 1$ and $V 1$ vessels, the tortuosity was also determined by calculating the ratio of the measured vessel length and the length of the straight line between the end nodes of the vessel.

\section{2 .3}

Statistics

Data, expressed as means $\pm S E M$, were analysed with an unpaired $t-$ test for differences between SHR and WKY and with a paired t-test for differences between basal and vasodilated conditions within each rat strain. Statistical significance was accepted when $\mathrm{p}<0.05$.

\section{3}

\section{Results}

Table 3.1 shows that MAP was significantly higher in SHR than in WKY, both before and during infusion of $3 \mu \mathrm{g} / \mathrm{kg} / \mathrm{min}$ felodipine. The blood pressure decrease induced by felodipine was approximately $27 \%$ in both strains. The two groups did not differ in body weight (table 3.1).

Figure 3.1 represents microvascular diameters in the basal (panel a) and vasodilated (panel b) states. A1 and A2 arterioles were smaller in SHR in both states. A3 arterioles and all types of venules did not differ in diameter in either state although V2 venules tended to be wider in SHR.

Figure 3.2 shows the reactivity of the cutaneous maximus muscle microvasculature to felodipine. Dilating capacity was up to $50 \%$ for $\mathrm{A} 3$ arterioles. $\mathrm{A} 1$, but not the other arterioles, showed a significantly larger dilating capacity in SHR; in the dilated state, however, they were still narrower than WKY Al arterioles under

Table 3.I Group comparisons berween Wistar-Kyoto (WKY) and spontaneously hypertensive rats (SHR).

\begin{tabular}{lll}
\hline & WKY $(\mathrm{n}=7)$ & SHR $(\mathrm{n}=10)$ \\
$\begin{array}{l}\text { Mean arterial pressure (mmHg) } \\
\text { basal conditions } \\
\text { vasodilated condition }\end{array}$ & $132 \pm 14$ & $174 \pm 6^{*}$ \\
Body weight (g) & $96 \pm 13^{\text {H }}$ & $126 \pm 6^{* *}$ \\
${ }^{*} \mathrm{p}<0.05$ WKY vs. SHR & $229 \pm 3$ & $236 \pm 4$ \\
${ }^{*}<0.05$ basal vs. vasodilated state & & \\
\hline
\end{tabular}


Table 3.2 Number of side branches per mm of vessell length.

I. Total number of side branches/mm under basal conditions

$\begin{array}{lllll}\text { Parent vessel } & \text { n } & \text { WKY } & \text { n } & \text { SHR } \\ \text { A1 } & 8 & 0.55 \pm 0.10 & 11 & 0.67 \pm 0.08 \\ \text { A2 } & 10 & 0.81 \pm 0.13 & 22 & 1.27 \pm 0.13^{*} \\ \text { A3 } & 8 & 1.30 \pm 0.38 & 10 & 1.32 \pm 0.28 \\ \text { V3 } & 11 & 1.20 \pm 0.38 & 12 & 0.83 \pm 0.62 \\ \text { V2 } & 12 & 1.73 \pm 0.27 & 23 & 2.81 \pm 0.33^{*} \\ \text { V1 } & 8 & 2.07 \pm 0.47 & 11 & 2.13 \pm 0.22\end{array}$

II. Total number of side branches/mm under vasodilated conditions

Parent wessel

A1

A2

A3

V3

$\mathrm{V} 2$

$\mathrm{V} 1$
WKY

$0.61 \pm 0.08$

$0.94 \pm 0.14$

$1.30 \pm 0.38$

$1.30 \pm 0.48$

$1.91 \pm 0.29$

$2.11 \pm 0.47$
SHR

$0.78 \pm 0.08^{\text {HI }}$

$1.43 \pm 0.15^{* * *}$

$1.43 \pm 0.28$

$0.87 \pm 0.63$

$3.02 \pm 0.34^{\text {* } \mathrm{H}}$

$2.23 \pm 0.20$

III. Number of side branches/mm calcullated from data with $\mathbf{R}_{\mathrm{D}}<\mathbf{3 . 0}$

Parent vessel

A. 1

A2

A3

V3

V2

V1
WKY

$0.19 \pm 0.08$

$0.22 \pm 0.07$

n.d.

n.d.

$0.91 \pm 0.15$

$0.64 \pm 0.16$
SHR

$0.20 \pm 0.05$

$0.71 \pm 0.13^{*}$

n.d.

n.d.

$1.51 \pm 0.25^{*}$

$0.49 \pm 0.14$

${ }^{*} p<0.05$ WKY ws. SHR

\#p $<0.05$ basal vs. viasodilated state

$\mathrm{n}$. number of analysed parent vessels

n.d.: not determined

basal conditions. V3 venules in WKY slightly dilated while those in SHR did not show a reaction. Towards the proximal venules, these vessels showed an increasing tendency to constrict, which was strongest in SHR where V1 venulles constricted almost $20 \%$. Only the difference between the V2 venules reached statistical significance.

In table 3.2 different calculations of the number of side branches $/ \mathrm{mm}$ are shown. Under the heading "parent vessel", the vessel type of the parent vessel is indicated. Consequently, vessels that branch from e.g. an A1 arteriole are referred to as A1 side branches. It should be kept in mind that these vessels themselves are higher order vessels. In part I it can be seen that most vessel types had similar numbers of side branches per mm vessel length, only $\mathrm{A} 2$ and $\mathrm{V} 2$ vessels had an increased number of side branches in SHR. In this regard, there were no differences com- 

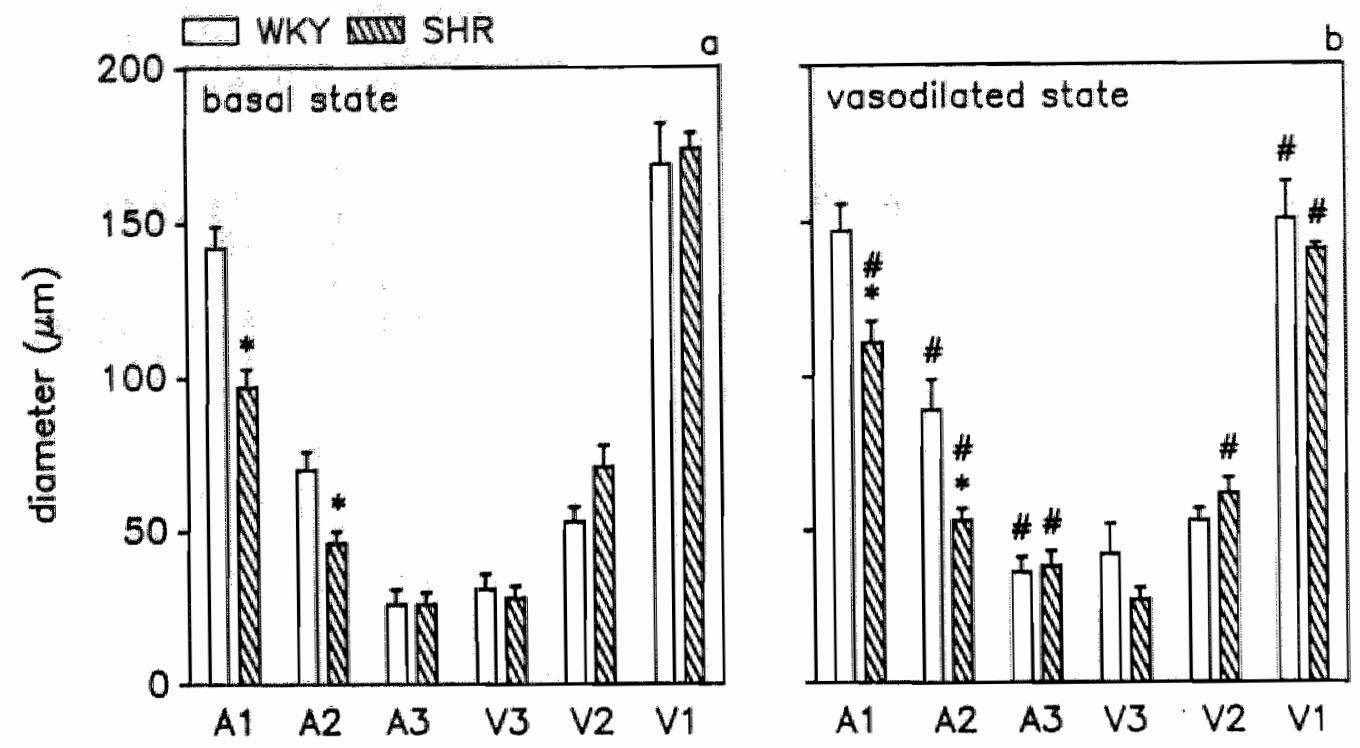

Figure 3.I Mean microvascular diameters in WKY and SHR cutaneous maximus muscle in basal state (panel a) and in vasodilated state during infusion of $3 \mu \mathrm{g} / \mathrm{kg} / \mathrm{min}$ felodipine (panel b). *p<0.05 WKY vs. SHR. " $p<0.05$ basal vs. vasodilated state.

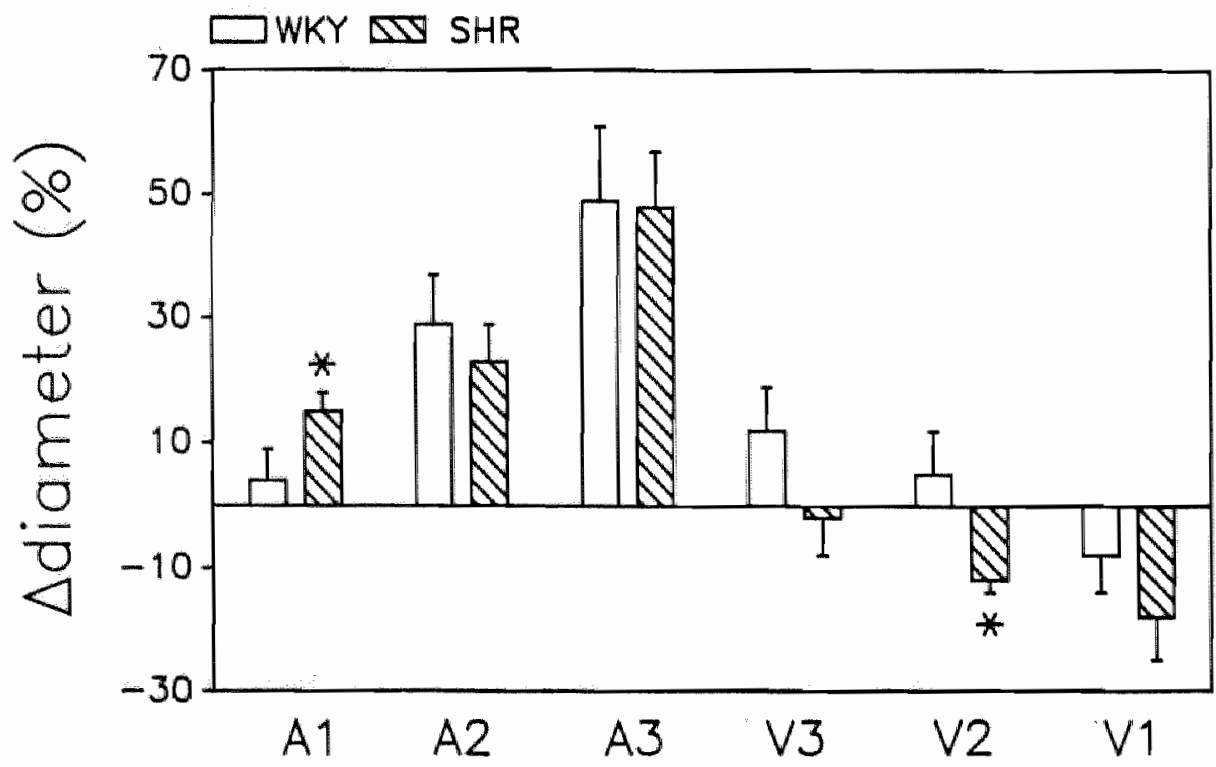

Figure 3.2 Percentual microvasular diameter increase during infusion of $3 \mu \mathrm{g} / \mathrm{kg} / \mathrm{min}$ felodipine. ${ }^{*} p<0.05 W K Y$ ws. SHR 


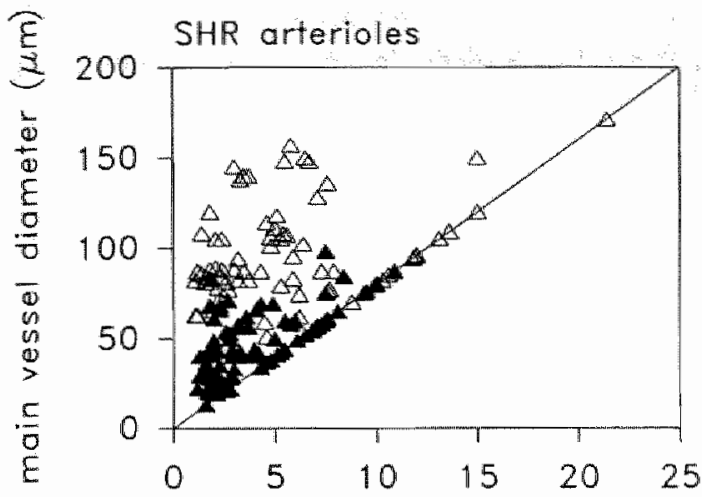

\section{WKY orterioles}

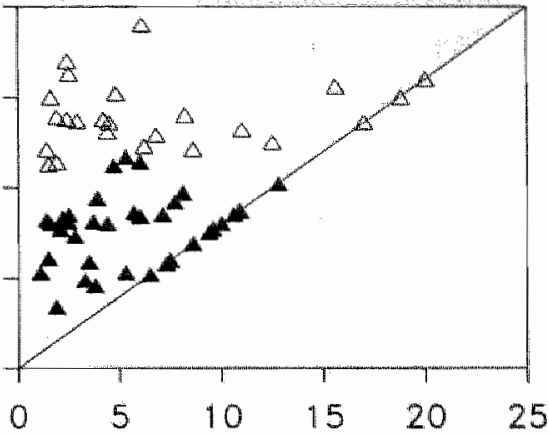

$\frac{E}{3}$
$\frac{1}{0}$
$\frac{1}{0}$
$\frac{E}{0}$
$\frac{0}{0}$
$\overline{0}$
0
0
0
$\frac{5}{0}$
$E$
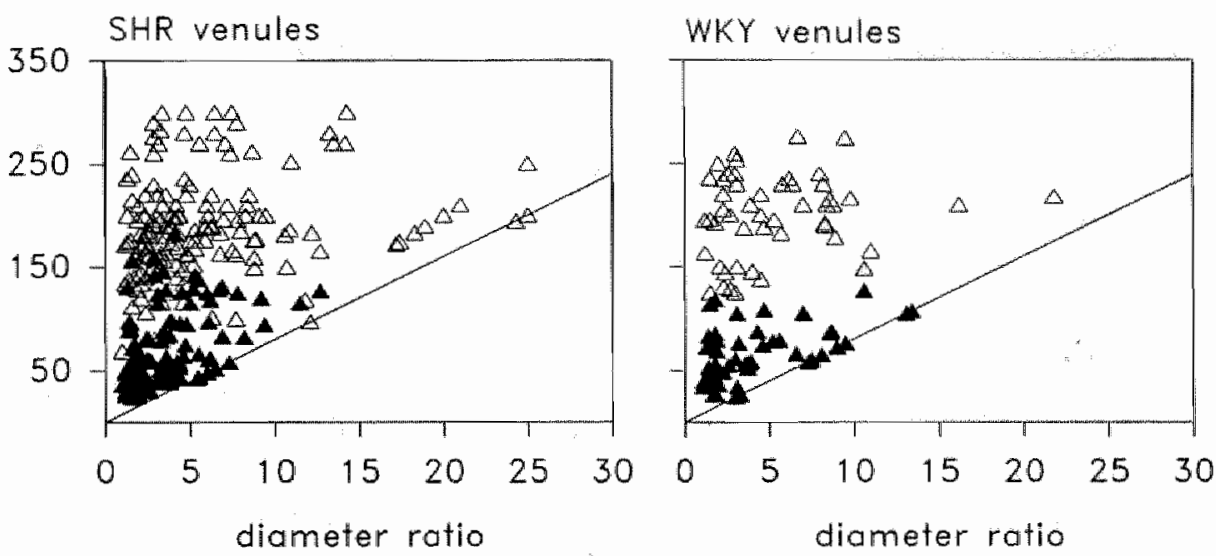

Fig. 3.3 Main vessel diameters of SHR and WKY first order ( $\Delta$ ) and second order ( 4 ) vessels ws. diameter ratio. The angle of the straight lines indicates the detection limit for small vessels of the video system used.

pared to the vasodilated state, as shown in part II. Vasodilation induced microvascular recruitment at the levels of A2, A3 and V3 vessels of SHR but not of WKY.

Fig. 3.3 shows scatter plots of the calculated diameter ratios. $R_{D}$ values varied from 1 to 25 . All intermediate values were found, but the lower values predominated. When calculated for $R_{D}<3.0$, a range that probably excludes "A3 on an $A 1$ "

type side branches (see fig. 3.1), the statistical differences between WKY and SHR number of side branches of larger vessels were similar as calculated for the total number of side branches (table 3.2, part III).

Total vessel lengths are represented in table 3.3. There is a tendency for a decreased Al vessel length in SHR but data were not significantly different from 
WKY. Other vessel lengths were simillar in both strains. Al arterioles in SHR were significantly less tortuous than those in WKY but VI venule tortuosity did not differ between the two strains (table 3.4).

\section{4}

\section{Discussion}

\section{4 .1}

\section{Evaluation of the experimental data}

The present study was designed to compare structural and functional properties of the microvascular network of the intact, striated cutaneous maximus muscle in conscious, spontaneously hypertensive rats (SHR) and their normotensive counterpart, the Wistar-Kyoto rats (WKY) and to examine whether differences in these properties can contribute to the elevated blood pressure in SHR. The investigated microvascular networks mainly differed with respect to the arteriolar vessels. In SHR, A1 and A2 arterioles were about one third narrower while smaller arterioles and all venules had equal lumen sizes. Felodipine, which lowered mean arterial pressure to a similar extent in both strains, significantly dilated the entire arteriolar tree in SHR while in WKY A2 and A3 but not A1 arterioles were dilated. Thus, A1 arterioles were significantly more constricted in SHR than in WKY. Following felodipine administration, venules of increasing lumen size showed an increasing tendency to constrict. This tendency was stronger in SHR than in WKY. Felodipine also caused microvascular recruitment of small vessels that directly branched from large vessels in SHR but not in WKY. This indicates the presence of functional rarefaction. Finally, in SHR, A1 arterioles were less tortuous and A2 and $\mathrm{V} 2$ vessels had a larger number of side branches per $\mathrm{mm}$ of vessel length.

The microvascular measurements were performed on WKY and SHR cutaneous maximus muscle, fixed in a dorsal microcirculatory chamber as described in section 2.2.1. Only clear preparations were used, with no signs of inflammation, as evidenced by an excessive number of collecting venules or disintegration of the tissue. However, small parts of the preparation could be blurred, e.g. by cell debris. Vessels with a diameter down to $8 \mu \mathrm{m}$ could be followed provided they ran relatively superficially in the muscle. The thickness of the muscle tissue is estimated to be 200-300 $\mu \mathrm{m}$, thus small vessels that run at the far side of the preparation cannot be detected. Hence, especially the comparison of A3 and V3 vessels was not made for the total number of these vessells but for the number of visible vessels.

The results of our study have a number of implications for the resistance in the SHR cutaneous maximus muscle network. As described in section 3.1, we assume that this network consists of multiple, relatively large, arcading vessels that play a role in blood flow regulation at the organ level, while smaller asymmetric, dichotomously branching vessels fill the mashes of the network and are involved in local regulation of blood flow (Engelson et al., 1985a,b; Schmid-Schönbein and Zweifach, 1991). A useful property of an arcading network is that pressure along the arcading arterioles is remarkably uniform over the extent of the muscle (Engelson 
Table 3.3 Total versel lengths (mm)

Vessel type

Al

A2.

$\mathrm{V} 2$

V1
WKY

$17 \pm 3$

$14 \pm 2$

$28 \pm 2$

$20 \pm 3$

\section{SHR}

$11 \pm 2$

$14 \pm 1$

$23 \pm 2$

$18 \pm 2$

et al., 1986; DeLano et al., 1991). This ensures similar pressures at the smaller transverse side branches that serve to perfuse distinct local muscle segments. When the microvascular network architecture is homogeneous, alterations seen in the DMC preparation are likely to be true for the whole muscle.

The most important differences were the $30 \%$ smaller A1 and A2 arteriolar diameters in SHR. Given the Hagen-Poisseuille law and assuming no other differences, such a decrease would increase resistance 5-fold in that particular part of the microcirculation. The functional significance of this elevated resistance is clear from the fact that pressure in the feeding vessels at the entrance of striated muscle can be as high as $90 \%$ of central blood pressure (DeLano et al., 1991). The latter authors also showed that normalised pressure is similar in SHR and WKY. Since capillary pressure is normal in SHR, a proportionally equal, but absolutely increased pressure drop has to occur in the SHR arteriolar microvasculature. Our data show that the $A 1$ and $A 2$ arterioles in SHR, striated muscle are a main site of resistance increase (Schmid-Schönbein and Chien, 1986; Bohlen, 1989; Mulvany, 1990). The decreased lumen sizes of $A 1$ and $A 2$ vessels may have a structural basis but our data show that increased sensitivity to vasoconstrictor influences also contributes to this phenomenon. Felodipine in SHR, but not WKY, significantly dilated A.1 arterioles and also induced microvascular recruitment, indicating functional rarefaction in SHR. This involved only small transverse arterioles and collecting venules. However, SHR had a higher number of side branches per $\mathrm{mm}$ length of $\mathrm{A} 2$ arterioles. Also $\mathrm{A} 1$ arterioles were less tortuous. These two phenomena counteract the resistance increase caused by the smaller A1 and A2 lumen sizes. A2 vessel lengths were similar in WKY and SHR. On the basis of th similar number of $\mathrm{A} 2$ arterioles per $\mathrm{mm}$ length of $\mathrm{Al}$ arterioles, this would imply that $\mathrm{A} 2$ arterioles are longer in SHR. Thus, the basic arcading arteriolar network in SHR is likely to be composed of shorter A1 arteriolar segments and longer A2 arteriolar segments, indicating an increased relative contribution of $A 2$ vessels. This would further decrease the average diameter of the total network, contributing to a resistance increase. The decrease in diameter will increase resistance most strongly, since it appearce as the inverse fourth power in the Hagen-Poiseuille law.

A number of conclusions can be drawn from the scatter plots in fig. 3.3. Firstly, the angle of the lines that connect the lower points of each scatter cloud indicates 
Table 3.4 Tortuosity of large vessels

$\begin{array}{lcccc}\text { vessel type } & \mathbf{n} & \text { WKY } & \mathbf{n} & \text { SHR } \\ \text { A1 } & 12 & 1.20 \pm 0.05 & 15 & 1.09 \pm 0.01^{*} \\ \text { V1 } & 7 & 1.19 \pm 0.08 & 12 & 1.18 \pm 0.04 \\ \text { *based on comparable vessel lengths (mm) } & & & \\ \text { A1: } 8.8 \pm 0.6(W K Y) \text { and } 8.6 \pm 0.7(\mathrm{SHR}) & & \\ \text { V1: } 9.3 \pm 0.5(W K Y) \text { and } 9.2 \pm 0.5(\mathrm{SHR}) & \\ \text { "p<0.05 WKY vs. SHR }\end{array}$

the diameter of the smallest detectable vessel. This shows to be about $8 \mu \mathrm{m}$, which is in good agreement with the resolution determined from the monitor screen (see section 2.3.1). Secondly, for all vessel types side branches with an $R_{D}$ of about 1 exist, which means that parent vessels divide into two similar branches with diameters comparable to the parent vessel: At such points, e.g. an Al arteriole yields two Al arterioles. Furthermore, the scatter clouds are densest for the lower $R_{D}$ values, but also high $R_{D}$ values were found, indicating that, for instance, an $A 3$ arteriole may branch directly from an $\mathrm{Al}$ arteriole. As described in the introduction of this chapter, it is likely that first and possibly second order vessels form an arcading network that has a blood distributing function, while smaller vessels regulate local blood flow. Our data indicate that these small vessels may branch in a regular way from higher order vessels, or directly from large low order vessels. When $\mathbf{R}_{\mathrm{D}}<3.0$ is taken as a range that probably includes only next order side branches (table 3.2, part III), the statistical differences between WKY and SHR are the same as for those calculated from the total number of side branches. Thus, in both strains about $25 \%$ of the $A 1$ and $V 1$ side branches have an $R_{D}<3.0$ and can be designated as "real" $\mathrm{A} 2$ and V2 vessels that are probably part of the arcading network, while the remainder are smaller vessels that mainly serve to fill the mashes and regulate local blood flow. SHR have an increased number of A2 side branches and about half of them have an $R_{D}<3.0$. However, in WKY, that already have a lower number of $A 2$ side branches, only $25 \%$ has an $R_{D}<3.0$. This could suggest that the average A3 arteriolar diameter in WKY is smaller in WKY than in SHR. The explanation is that A2 arterioles in SHR are smaller, but A3 arterioles are not (fig. 3.1). Therefore, in SHR $R_{D}$ for $A 2$ side branches will more often be smaller than 3.0.

The density of V3 venules is increased in SHR as indicated by the increased number of side branches per $\mathrm{V} 2$ venule length. We observed that in preparations we had to discard because of extensive neovascularisation, the newly formed vessels were always mainly small venules. Thus, it is suggested that in the case of 
disturbances, like hypertension or inflammation, small venules proliferate, increasing the draining capacity of the venular bed. In SHR, felodipine induced a more pronounced venular constriction than in WKY. Recruitment of blood from capacitance vessels is a mechanism to counteract a fall in blood pressure. Since in SHR local blood volume has been shown to be decreased (Evenwel et al., 1983), constriction of venular capacitance vessels may be stronger in this rat strain.

\subsubsection{Comparison with reports in the literature}

We showed that several microvascular alterations occur in the SHR cutaneous maximus muscle microvasculature. Not all of these are likely to increase resistance, but it is clear that the decreased diameters of large arterioles is the main factor that elevates resistance in this tissue. Lumen narrowing of large arterioles has been found in SHR cutaneous maximums muscle before (le Noble et al., 1990a) and also in SHR spinotrapezius muscle (Engelson et al., 1986), small intestine (Bohlen, 1983; Meininger et al., 1986), where small precapillary arterioles were also narrowed, and in brain cortex (Harper and Bohlen, 1984). Similarly, in spinotrapezius muscle of Dahl-hypertensive rats large arterioles had a decreased diameter (Boegehold and Kotchen, 1990b). Lumen narrowing may have a structural as well as functional basis. Our technique did not allow direct structural measurements, but in the preparation used functional narrowing was shown to play a role in the larger arterioles. Engelson and colleagues (1986) found a structural component in lumen narrowing in SHR spinotrapezius muscle, but this was absent in the same muscle of Dahl-hypertensive rats (Boegehold and Kotchen, 1990b) and also in SHR cerebral cortex arterioles (Harper and Bohlen, 1984) and gracilis muscle (Prewitt et al., 1982). Indeed, structural narrowing is usually more prominent in vessels proximal to the microcirculation (Schmid-Schönbein and Chien, 1986), although it has been found in SHR mesenteric arterioles down to $30 \mu \mathrm{m}$ in diameter (Henrich et al., 1978).

In experimental, secondary forms of hypertension, different mechanisms are involved in blood pressure elevation. In two kidney, one clip (2KIC) hypertension, activation of the renin-angiotensin system leads to increased levels of angiotensin II. In one kidney, one clip ( $1 \mathrm{~K} 1 \mathrm{C})$, reduced renal mass, and salt-sensitive forms of hypertension, blood pressure is elevated because of volume loading. In genetic, primary types of hypertension, an increased sympathetic activity may play a role. Differences in etiology of hypertension are reflected in differences found in microvascular alterations. The muscle most intensively studied is the rat cremaster muscle. Constriction of large cremaster arterioles was found in $1 \mathrm{~K} 1 \mathrm{C}(\mathrm{Meininger} \mathrm{et}$ al., 1984; Hashimoto et al., 1987), 2K1C(Meininger et al., 1984; Ono et al., 1989), and deoxycorticosterone-salt (DOCA) hypertensive rats (Meininger et al., 1984). The latter study, and one report on 1K1C hypertension (Hashimoto et al,, 1987) presented decreased diameters of small arterioles as well. However, large arteriolar diameters were not changed in the cremaster of SHR. In 1974, Hutchins and Darnell published this finding, but also reported that at the level of small 
arterioles a $50 \%$ rarefaction occurred, while at the same time the diameter of the remaining vessels was increased by $30 \%$ rather than decreased. These results were confirmed by other investigators (Chen et al., 1981; le Noble et al., 1990b). In coarctation hypertension, the large feeding arteriole was not changed in diameter but all other arterioles were constricted (Stacey: and Prewitt, 1989) and small arteriolar rarefaction was present (Stacey and Prewitt, 1989; Boegehold et al., 1991b). Likewise rarefaction occurred in all hypertensive models mentioned above, and also in rats with reduced renal mass hypertension (Lombard et al., 1989; Hansen-Smith et al., 1990). Furthermore, rarefaction was observed in gracilis muscle of SHR (Prewitt et al., 1982), IK1C (Prewitt et al., 1984), and Dahlhypertensive rats (Boegehold and Kotchen, 1990a), and in the mesentery (Henrich et al., 1978) and ventral abdominal skin (Haack et al., 1980) of SHR. In the latter two studies, the diameters of the remaining small arterioles were increased, like in the cremaster muscle (Hutchins and Darnell, 1974; Chen et al., 1981; le Noble et al., 1990b), but in the gracilis muscle of the $1 \mathrm{KlC}$ model (Prewitt et al., 1984) these diameters were decreased. Data on rarefaction in the SHR pial microvasculature are conflicting (Sokolova et al., 1985; Weber et al., 1990). In man, rarefaction has been shown to occur in the conjunctiva (Harper et al., 1978; Sullivan et al., 1983) and in skeletal muscle (Henrich et al., 1988). Thus, different mechanisms may contribute to an increased resistance in individual microvascular beds.

A part of the discrepancies found between the mentioned forms of hypertension and individual preparations may be explained by differences in age of the rats used and different durations and types of hypertension. Furthermore, it is important to realise that in SHR hypertension develops in a growing organism with an immature vascular system, while in the other experimental models hypertension is superimposed on a vasculature that has been allowed normal growth. However, comparison of the literature on this subject does not allow to conclude that the importance of either mechanism changes during the development of hypertension. On the other hand, it is evident that microvascular alterations are functional at the early stage of hypertension and become structural in the established state, as has been shown for the cremaster muscle in $1 \mathrm{~K} 1 \mathrm{C}$ (Hashimoto et al., 1987), 2K1C (Ono et al., 1989) and reduced renal mass hypertension (Lombard et al., 1989) as well as for the gracilis muscle in IK1C (Prewitt et al., 1984) and spontaneous hypertension (Prewitt et al., 1982). Structural changes in the cremaster muscle during coarctation hypertension, however, were limited to rarefaction of distal arterioles (Stacey and Prewitt, 1989; Boegehold et al., 1991b), while structural changes of larger arterioles were absent. Since pressure in the cremaster muscle was not elevated by coarctation (Boegehold et al., 1991b), it is indicated that part of the microvascular changes in hypertension are not pressure-mediated but depend upon neurogenic, humeral, or flow-related mechanisms.

Both microvascular rarefaction and constriction increase resistance. Using a mathematical model of the hamster cheek pouch microvasculature, Greene and colleagues (1989) calculated a $21 \%$ resistance increase after $42 \%$ rarefaction and a 
$75 \%$ resistance increase after $30 \%$ decrease in vascular diameter, both at the level of the A3 arterioles. Similar rarefaction or constriction at the level of A4 arterioles were relatively ineffective. Furthermore, as has been cited above, the main alterations in the spinotrapezius (Engelson et al., 1986; Boegehold and Kotchen, 1990b) and gracilis muscles (Prewitt et al., 1982, 1984; Boegehold and Kotchen, $1990 \mathrm{a})$ are of a different nature (constriction vs. rarefaction, respectively) but nevertheless, resistance in both muscles was found to be increased to the same extent (Boegehold et al., 1991a). Since the alterations found in the two muscle types were similar in different forms of hypertension, it is likely that mechanisms of resistance increase are tissue specific. 


\section{CHAPTER 4}

\section{Microvascular actions of calcium antagonists}

\subsection{Introduction}

Recent studies have localised an important part of the increased vascular resistance in several forms of clinical and experimental hypertension in the microvasculature (Zweifach, 1983; Schmid-Schönbein and Chien, 1986; Bohlen, 1989). Thus, constriction and closure of small arterioles contribute importantly to the rise of vascular resistance during hypertension.

The mechanisms of diameter control differ for the various segments of the vascular tree (Bohr and Webb, 1986; Grega and Adamski, 1987; Bohlen, 1989). At the level of the relatively large arterioles and arteries both neural and endocrine factors strongly influence vascular diameter, whereas microvascular diameter may depend more on myogenic mechanisms ((Folkow et al., 1989). Myogenic activity, in fact, is responsible for a major component of basal tone in the resistance section of most vascular beds (Johansson, 1989). The mechanisms underlying myogenic tone are still poorly understood, but recent data suggest an important role for vascular smooth muscle calcium currents (Laher and Bevan, 1989; Nordlander, 1989; Struyker Boudier et al., 1990c).

The differential control of diameters in the various segments of the vascular tree has profound implications for the mode of action of vasodilator drugs. Drugs interfering with sympathetic control of vascular tone may act predominantly on larger arterioles (Faber, 1988), whereas agents interfering with myogenic tone may have a primary site of action in the microvessels. A preparation of the intact cutaneous maximus muscle has recently been developed that allows examination of drug induced microvascular diameter changes in conscious rats (Smith et al., 1985; Hutchins et al., 1988). In the present study we analysed the microvascular sites of action of different calcium antagonists. We specifically addressed the hypothesis that blockade of vascular smooth muscle cell calcium influx inhibits in vivo myogenic microvascular tone. 


\subsection{Materials and methods}

Male SHR were implanted with a DMC and catheters as described in section 2.2 and used for intravital microscopy as described in section 2.3. This chapter is a report on the first experiments carried out in our laboratory with the present model. Since initially some difficulties were met to let the rats get used to being restrained, a light ketamine anaesthesia $(10 \mathrm{mg} / \mathrm{kg}$ i.m., small additional i.v. doses if necessary) was used in this study.

Slow $0.1 \mathrm{ml}$ i.v. bolus injections of verapamil $(30-300 \mu \mathrm{g} / \mathrm{kg})$, nifedipine and felodipine (the latter two 3-30 $\mu \mathrm{g} / \mathrm{kg}$ ) were administered. Each drug was used on a different day, while doses were given in a cumulative manner at 45 to $60 \mathrm{~min}$ intervals. Verapamil was dissolved in saline; nifedipine and felodipine were dissolved in a mixture of polyethylene glycol, ethanol and distilled water (stock solution 15:15:100, subsequent dilutions with distilled water). Solvents were used for control experiments. The effects on microvascular diameters were investigated by taking video recordings shortly before drug injection and $2,5,10,20$, and 30 min afterwards. Videotapes were analysed as described in section 2.3. Maximal deviations from baseline values were taken as the drug effect. Simultaneously, the effects on microvascular vasomotion were examined. Vasomotion refers to spontaneous, oscillatory diameter changes, a common phenomenon in many microvascular preparations. To this end 1 to $2 \mathrm{~min}$ long recordings of diameters of vessels exhibiting vasomotion were analysed for vasomotion amplitude and frequency (cycles/min). Amplitude was determined by measuring the vessel diameter at each subsequent maximum and minimum. Next, the averages of the maxima and minima were determined and the amplitude was calculated as mean maximum minus mean minimum times 0.5 .

Statistical analysis of the data was performed as described in section 2.4 , using the analysis of variance (ANOVA) for multiple group comparisons.

\subsection{Results}

Table 4.1 summarises the number of animals and blood vessels used in each experimental group, as well as baseline values for blood pressure and diameters. There were no statistically significant differences in pre-injection values for the various groups. Venular diameters ranged from $147 \pm 27 \mu \mathrm{m}$ (V1) to $29 \pm 3$ $\mu \mathrm{m}$ (V3.V4). Since no significant venular diameter changes were observed following the administration of the calcium antagonists, venular diameters are not included in the rest of the data.

Figure 4.1 shows the effects of two doses of felodipine. MAP decreased in a dose-dependent manner. Maximum decreases were observed within 3 min and effects lasted for 5-10 min. The A1 vessel was dilated in a dose-dependent manner, while this effect outlasted the decrease in MAP. With the higher doses diameter increases were observed up to $30-60 \mathrm{~min}$. The A3 vessel showed vasomotion. 
Table 4.I Baseline wallues for MAP and arteriolar diameters (Ø) in the various experimental groups.

\begin{tabular}{|c|c|c|c|c|c|c|c|c|}
\hline $\begin{array}{l}\text { Treatment } \\
(\mu \mathrm{g} / \mathrm{kg})\end{array}$ & $\mathbf{n}$ & $\begin{array}{l}\text { MAP } \\
(\mathrm{mm} H \mathrm{H})\end{array}$ & n & 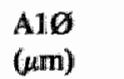 & n & $\begin{array}{l}\mathrm{A} 20 \\
(\mu \mathrm{m})\end{array}$ & $\mathbf{n}$ & $\begin{array}{l}\text { A3.A40 } \\
(\mu \mathrm{m})\end{array}$ \\
\hline \multicolumn{9}{|l|}{ Verapamil } \\
\hline 0 & 10 & $169 \pm 9$ & 8 & $92 \pm 8$ & 16 & $47 \pm 3$ & 10 & $23 \pm 3$ \\
\hline 30 & 8 & $169 \pm 8$ & 7 & $85 \pm 7$ & 12 & $50 \pm 4$ & 18 & $21 \pm 2$ \\
\hline 100 & 8 & $159 \pm 8$ & 8 & $83 \pm 6$ & 12 & $50 \pm 4$ & 16 & $19 \pm 2$ \\
\hline 300 & 7 & $165 \pm 12$ & 7 & $88 \pm 9$ & 12 & $51 \pm 5$ & 5 & $27 \pm 4$ \\
\hline \multicolumn{9}{|l|}{ Nifedipine } \\
\hline 0 & 9 & $189 \pm 4$ & 10 & $84 \pm 6$ & 13 & $45 \pm 4$ & 16 & $17 \pm 2$ \\
\hline 3 & 9 & $187 \pm 1$ & 8 & $101 \pm 12$ & 16 & $55 \pm 5$ & 17 & $19 \pm 2$ \\
\hline 10 & 9 & $189 \pm 4$ & 8 & $103 \pm 12$ & 16 & $57 \pm 5$ & 17 & $18 \pm 2$ \\
\hline 30 & 8 & $181 \pm 5$ & 6 & $95 \pm 10$ & 11 & $50 \pm 5$ & 19 & $15 \pm 1$ \\
\hline \multicolumn{9}{|l|}{ Felodipine } \\
\hline 0 & 9 & $189 \pm 4$ & $10^{\circ}$ & $84 \pm 6$ & $\mathbb{1 3}$ & $45 \pm 4$ & 16 & $17 \pm 2$ \\
\hline 3 & 7 & $183 \pm 8$ & 8 & $99 \pm 8$ & 13 & $51 \pm 4$ & 14 & $20 \pm 2$ \\
\hline 10 & 8 & $179 \pm 6$ & 9 & $99 \pm 7$ & 15 & $53 \pm 4$ & 15 & $21 \pm 3$ \\
\hline 30 & 6 & $179 \pm 4$ & 7 & $92 \pm 12$ & 12 & $53 \pm 4$ & 8 & $2.1 \pm 4$ \\
\hline Saline & 7 & $154 \pm 8$ & 10 & $87 \pm 8$ & 13 & $52 \pm 6$ & 6 & $25 \pm 4$ \\
\hline
\end{tabular}

Already after a dose of $10 \mu \mathrm{g} / \mathrm{kg}$ vasomotion had completely stopped, whereas the higher dose blocked vasomotion as well as increased resting diameter.

The dose-dependent MAP reduction during the administration of the three calcium antagonists is summarised in figure 4.2. Figure 4.3 shows the effects on arteriolar diameters. Each vessel category dilated in a dose-dependent manner following verapamil, nifedipine or felodipine (panels a through $\mathrm{c}$, respectively).

Vasomotion was observed in approximately $60 \%$ of the A3 and A4 vessels. It was rarely seen at the level of A1 and A2 vessels or venules. Table 4.2 summarises the effects of the three agents on vasomotion amplitude and frequency. Vasomotion inhibition seems an "all-or-none" phenomenon. As an example, the highest dose of verapamil stopped vasomotion in 3 vessels and left it intact in 3 other vessels. The dihydropyridines were more effective than verapamil in blocking vasomotion. 


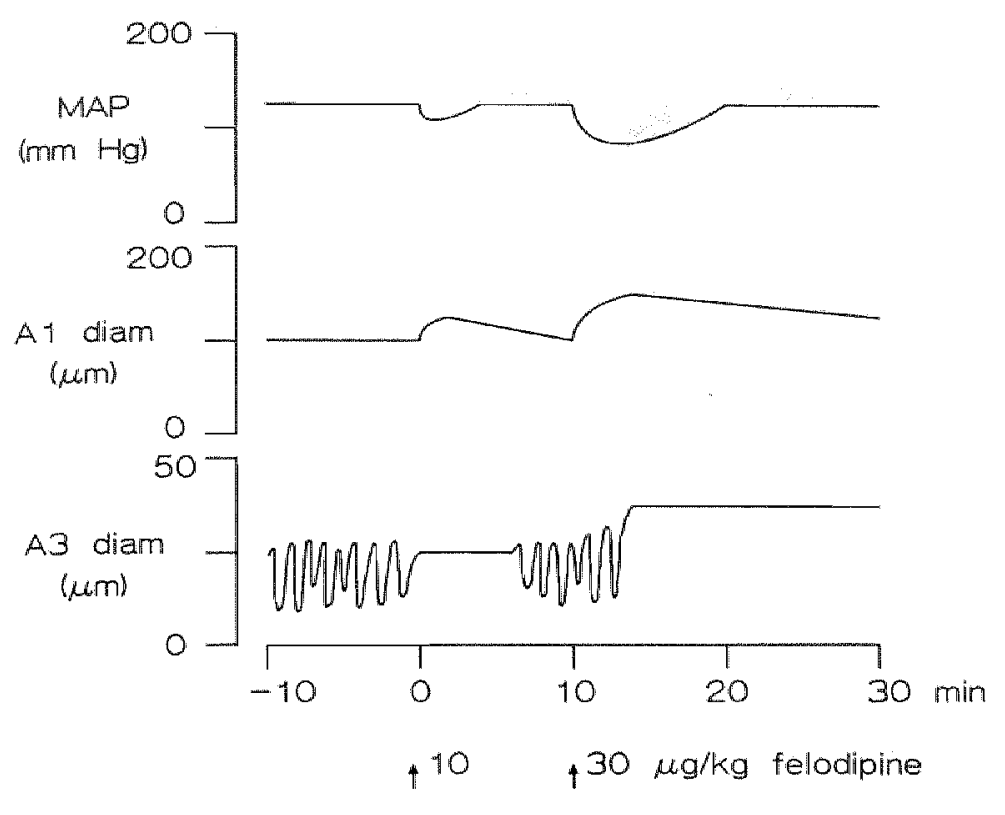

Figure 4.I Effects of two doses of felodipine on MAP and diameter of an AI and an A3 arteriole in SHR. Note the thythmic diameter diameter changes of the A3 arteriole

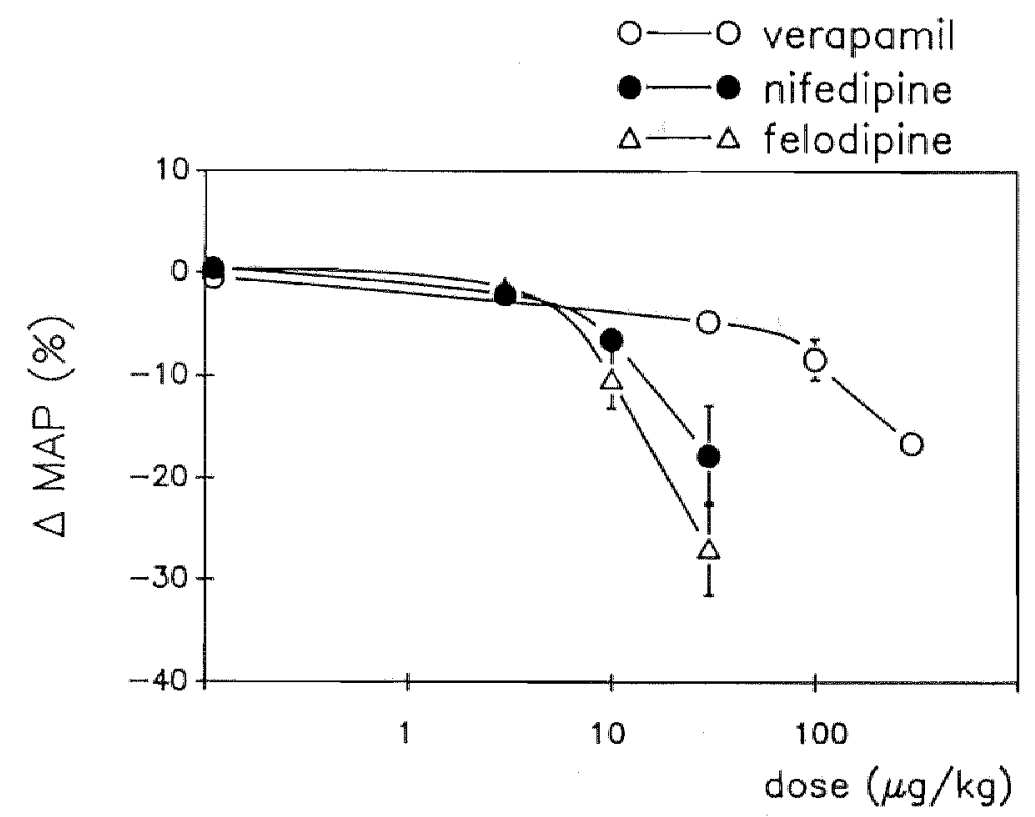

Figure 4.2 Effects of different doses of the calcium antagonists on MAP 

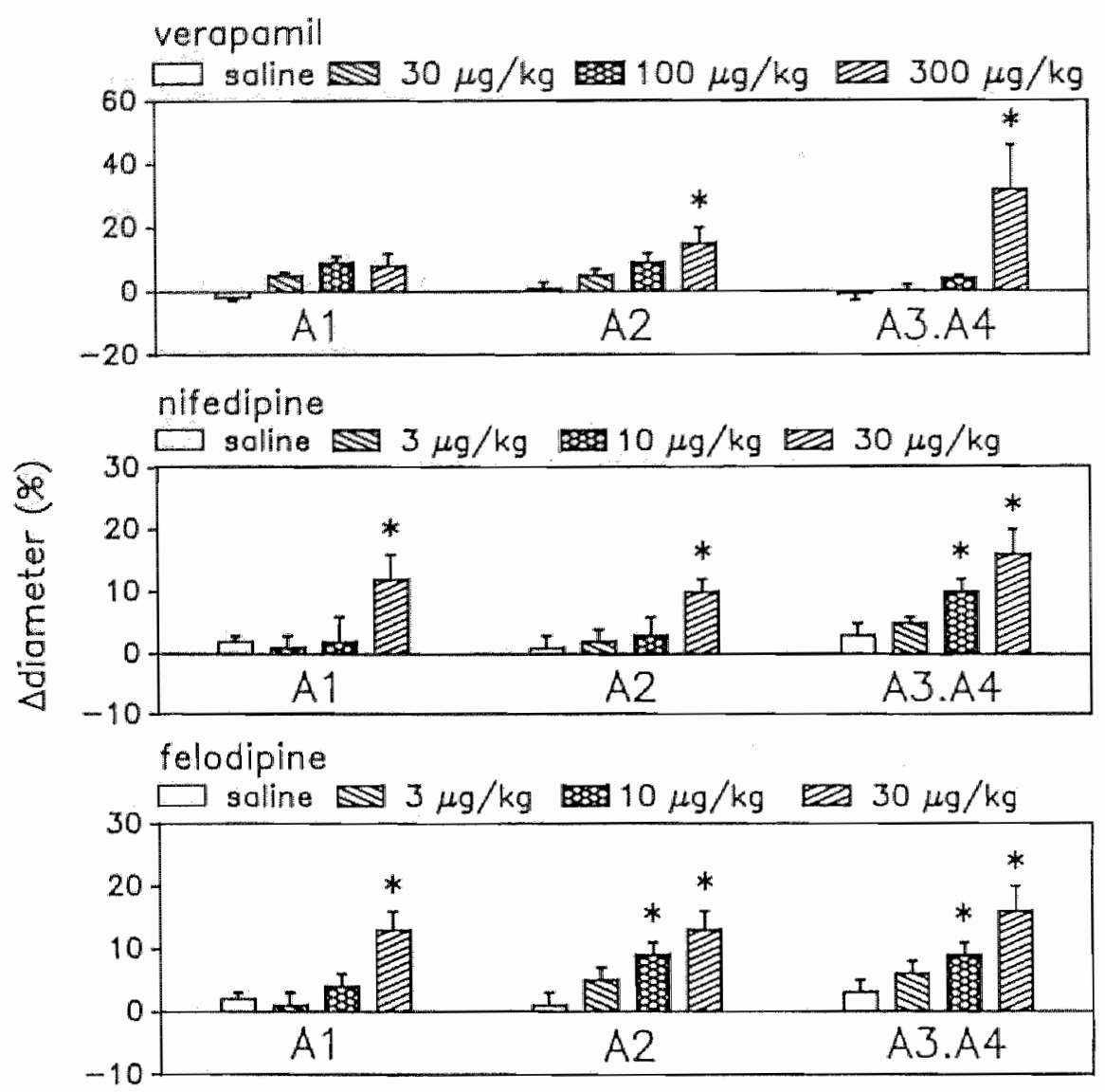

Figure 4.3 Effects of different doses of verapamil, nifedipine and felodipine on arteriolar diameters

\subsection{Discussion}

The present study demonstrates that treatment of intact SHR with verapamil or dihydropyridine-like calcium antagonists causes a significant increase in small arteriolar diameter. Venular diameters were not affected. In addition, the calcium antagonists strongly inhibit the spontaneous rhythmic changes in precapillary arteriolar diameter. The microvessels studied are part of a striated muscle located subcutaneously on the back of the rats. Although conclusions from one microvascular bed may not always be taken to be representative of each microvascular bed, we are confident about the relevance of our findings with respect to the control of vascular resistance in our animal model. Striated muscle 
Table 4.2 Vasomation amplitude and frequency of $A 3$ and A4 wessels before and 2 miwutes after drug administration.

\begin{tabular}{|c|c|c|c|c|c|}
\hline \multirow{2}{*}{$\begin{array}{l}\text { Treatment } \\
(\mu \mathrm{g} / \mathrm{kg})\end{array}$} & \multirow[t]{2}{*}{$\mathbf{n}$} & \multicolumn{2}{|c|}{ Amplitude $(\mu \mathrm{m})$} & \multicolumn{2}{|c|}{ Frequency (cycles/min) } \\
\hline & & Before & After & Before & After \\
\hline \multicolumn{6}{|l|}{ Verapamil } \\
\hline 0 & 7 & $4.4 \pm 0.5$ & $4.6 \pm 0.6$ & $3.0 \pm 0.4$ & $3.6 \pm 0.5$ \\
\hline 30 & 8 & $4.5 \pm 0.6$ & $3.9 \pm 0.8$ & $3.0 \pm 0.6$ & $2.9 \pm 0.4$ \\
\hline 100 & 7 & $4.9 \pm 0.4$ & $4.1 \pm 0.6$ & $2.8 \pm 0.5$ & $2.5 \pm 0.5$ \\
\hline 300 & 6 & $4.3 \pm 0.6$ & $\begin{array}{l}0(n=3) \\
3.9 \pm 0.8(n=3)\end{array}$ & $3.3 \pm 0.3$ & $\begin{array}{l}0(\mathrm{n}=3) \\
3.2 \pm 0.7(\mathrm{n}=3)\end{array}$ \\
\hline \multicolumn{6}{|l|}{ Nifedipine } \\
\hline 0 & 9 & $4.9 \pm 0.6$ & $4.6 \pm 0.7$ & $3.2 \pm 0.4$ & $2.8 \pm 0.3$ \\
\hline 3 & 7 & $5.0 \pm 0.7$ & $4.3 \pm 0.7$ & $2.9 \pm 0.5$ & $2.6 \pm 0.6$ \\
\hline 10 & 5 & $5.0 \pm 0.8$ & $\begin{array}{l}0(n=2) \\
4.9 \pm 1.6(n=3)\end{array}$ & $2.3 \pm 0.2$ & $\begin{array}{l}0(n=2) \\
2.8 \pm 0.6(n=3)\end{array}$ \\
\hline 30 & 6 & $4.7 \pm 1.1$ & 0 & $1.9 \pm 0.4$ & 0 \\
\hline \multicolumn{6}{|l|}{ Felodipine } \\
\hline 0 & 9 & $4.9 \pm 0.6$ & $4.6 \pm 0.7$ & $3.2 \pm 0.4$ & $2.8 \pm 0.3$ \\
\hline 3 & 4 & $4.1 \pm 1.2$ & $4.2 \pm 0.9$ & $3.1 \pm 0.5$ & $2.6 \pm 0.3$ \\
\hline 10 & 7 & $4.5 \pm 0.6$ & $\begin{array}{l}0(n=2) \\
4.4 \pm 0.5(n=5)\end{array}$ & $2.9 \pm 0.4$ & $\begin{array}{l}0(n=2) \\
1.9 \pm 0.4(n=5)\end{array}$ \\
\hline 30 & 8 & $5.0 \pm 0.5$ & $\begin{array}{l}0(n=7) \\
5,0(n=1)\end{array}$ & $2.3 \pm 0.3$ & $\begin{array}{l}0(n=7) \\
2.0(n=1)\end{array}$ \\
\hline
\end{tabular}

represents a major source of resistance increase in SHR (Evenwel et al., 1983). Furthermore, within striated muscles small arterioles are the primary sites of resistance control (Zweifach, 1983; Schmid-Schönbein and Chien, 1986; Bohlen, 1989; le Noble et al., 1990a, b).

Our findings confirm and extend previous studies showing a vasodilator effect of calcium antagonists primarily at the arteriolar and not the venular level (Cauvin et al., 1983; Nyborg and Mulvany, 1984; Julou and Freslon, 1986; Struyker Boudier et al., 1990c). The present study suggests a strong effect of all three agents used on the smallest, precapillary arterioles. In this respect, calcium antagonists differ from other vasodilators, such as $\alpha_{1}$-adrenoceptor blockers (Faber, 1988; chapter 6), ACE-inhibitors (Wang and Prewitt, 1990; chapter 7) or hydralazine (Hutchins et al., 1988) which do not dilate small, precapillary arterioles, but rather act at the level of the larger arterioles and arteries. Alpha ${ }_{2}$-adrenoceptor blockers (Faber, 1988; chapter 6) and potassium channel openers (Struyker Boudier et al., 1990b; chapter 5) show a pattern of small arteriolar vasodilatation similar to that of the calcium antagonists. The consequences of this heterogeneity in microvascular action of different vasodilator substances are large. From a haemodynamic point of view the site of action in the arteriolar tree has different consequences. The large 
arteriolar and arterial wall predominantly determine the compliance properties of the arterial system (Safar et al., 1986; O'Rourke, 1990). On the other hand, the smaller arterioles are major sites of resistance control in the circulatory system. By increasing small arteriolar diameter vasodilators influence peripheral vascular resistance and diastolic as well as systolic pressure.

The effects of the calcium antagonists on small arteriolar diameter outlasted the fall in blood pressure. This seems contradictory to the importance of small arterioles in the control of vascular resistance and blood pressure. However, blood pressure is not only determined by vascular resistance, but also by cardiac output. Investigations carried out by others in our laboratory on intact SHR have shown that both verapamil and dihydropyridines activate baroreceptor reflexes and thereby cause an acute rise in sympathetic nerve activity (Nievelstein et al., 1985). We generally noted increases in heart rate immediately following calcium antagonist administration (data not shown). Thus, a primary, drug-induced peripheral vasodilatation may not be parallelled by a drop in blood pressure due to reflex compensatory mechanisms. The reflex activation of the heart brings blood pressure back to its pre-injection values before peripheral vasodilatation has waned.

A further haemodynamic consequence of a relatively long-lasting and strong small arteriolar effect of calcium antagonists is an increased microvascular fluid extravasation. In a recent elegant series of studies, Gustafsson and co-workers $(1987,1988,1989)$ showed that the more pronounced inhibition of vascular tone in pre- rather than in postcapillary resistance vessels following felodipine is associated with an increased capillary hydraulic pressure and fluid filtration from blood to tissue. Although we did not measure microvascular fluid exchange in this study our data point in the same direction. These observations may explain the clinical phenomenon of peripheral oedema formation during calcium antagonist treatment of hypertension.

A final consequence of the microvascular heterogeneity in vasodilator drug action relates to the mechanisms regulating peripheral vascular resistance. The resistance to blood flow depends on (1) smooth muscle activity, (2) characteristics of the blood itself, such as its viscosity, and (3) structural characteristics of the vascular bed, such as the number, length and radius of blood vessels (Bohr and Webb, 1986; see also section 3.1). Vasodilator drug action has thus far almost exclusively been aimed at the first factor. Smooth muscle activity is determined by external nervous and endocrine influences and by more locally derived factors, such as metabolites and myogenic responses (Bohr and Webb, 1986; Johansson, 1989). The degree of contribution of each of these factors to resistance control differs per vascular bed as well as per segment within a vascular bed (Bohr and Webb, 1986; Grega and Adamski, 1987).

The results of the present study give support to the hypothesis that vascular smooth muscle cell calcium influx is an important cellular mechanism in myogenic activity. Myogenic activity is based both on a tonic and an oscillatory contraction (Johansson, 1989). In vivo, the latter occurs spontaneously in small arterioles (Colantuoni et al., 1984; le Noble et al., 1990a; this study). Previous studies by 
Colantuoni et al (1984) and De Clerck et al (1989) as well as the present study indicate that spontaneous vasomotion is blocked by calcium antagonists before basal tone is affected. In isolated rat arteries, vasomotion can be induced by entrancing vascular smooth muscle cell calcium influx (Lamb et all., 1985; Boonen and De Mey, 1990). The oscillatory contractile activity varies inversely with the potassium and directly with the calcium concentration in the bath solution. In view of the known existence of cytosolic calcium oscillators coupled to cell membrane potassium channels (Berridge and Galione, 1988), vasomotion may depend on the oscillatory activity of the calcium-dependent potassium current.

The physiological stimuli of this oscillator as well as its sensitivity to drugs other than calcium antagonists remain to be established. One intriguing aspect is that this oscillator seems much more active in spontaneously hypertensive rat blood vessels than in vessels from normotensive control groups both in vitro (Mulvany and Nyborg, 1980; Lamb et al., 1985; Boonen and De Mey, 1990) and in vivo (le Noble et al., 1990a).

In conclusion, the major sites of vascular action of calcium antagonists of various chemical structures are the small, precapillary arterioles. These are the arterioles that determine to an important degree the increased resistance in spontaneous hypertension in the rat. In addition, calcium antagonists seem to interfere with the myogenic control of the tone and diameter of these small arterioles. 


\section{CHAPTER 5}

\section{Preferential small arteriolar vasodilatation by the potassium channel opener lemakalim in conscious spontaneously hypertensive rats}

\section{$5.1 \quad$ Introduction}

Membrane potassium channels are present in arterial smooth muscle (Cook, 1990; Edwards and Weston, 1990). Lemakalim (BRL 38227; the transenantiomer of cromakalim) is a member of a novel class of agents that increase potassium conductance through $\mathrm{K}^{+}{ }_{\text {ATP }}$ channels and hyperpolarise smooth muscle (Edwards and Weston, 1990). Hyperpolarisation of arterial smooth muscle is believed to be the primary mechanism of the vasorelaxant and hypotensive activity of potassium channel openers (Nelson et al., 1990). Indeed, these agents have vasodilator activity in various vascular beds in mammalian species, including humans (Clapham and Buckingham, 1988; Webb et all, 1989). Although the vasorelaxant properties of potassium channel openers are well documented in different isolated artery preparations, their in vivo sites of action are still virtually unexplored. Since small arteries and arterioles are the dominant sites of control of vascular resistance and of increased resistance in hypertension (Schmid-Schönbein and Chien, 1986; Bohlen, 1989; Mulvany, 1990), an important microcirculatory site of action may be hypothesised. The purpose of the present study was to define the microvascular sites of action of lemakalim. Responses to lemakalim were studied in SHR that were provided with chronic dorsal microcirculatory chambers that allow the direct observation of microvessels in intact striated muscle of conscious animals. 
Male SHR were implanted with a DMC and catheters as described in section 2.2 and used for intravital microscopy as described in section 2.3.

Lemakalim was dissolved in $0.9 \% \mathrm{NaCl}$ (saline). Controll solutions consisted of saline. Lemakalim $(10,30$ and $100 \mu \mathrm{g} / \mathrm{kg})$ was given in a randomised way on different days as slow $(15-30 \mathrm{sec})$ i.v. bolus injections of $0.1 \mathrm{ml}$ of the drug solution. Effects were calculated as the difference from the pre-injection value. Statistical analysis was performed with an analysis of variance (ANOVA) for multiple group comparisons as described in section 2.5 .

\subsection{Results}

Experiments were performed in 6 SHR with a total of $10-16$ vessels per vessel type. Table 5.1 summarises the baseline values for blood pressure and vascular diameters. Figure 5.1 shows the effects of increasing doses of lemakalim on MAP in conscious SHR. MAP decreased rapidly in a dose dependent manner. Maximum decreases in MAP were observed within $10 \mathrm{~min}$. MAP returned gradually towards control values within 30-90 min. The effects on MAP reached statistical significance during the 30 and $100 \mu \mathrm{g} / \mathrm{kg}$ doses of lemakalim.

The effects of lemakalim on arteriolar and venular diameters are summarised in figure 5.2. Arteriolar diameters (panel a) increased dose-dependently within 10 min. The maximum effects were observed between 5-15 min and reached statistical significance for the A1 vessels during $100 \mu \mathrm{g} / \mathrm{kg}$; for the A2 vessels during 30 and $100 \mu \mathrm{g} / \mathrm{kg}$ and for the A3/A4 vessels at all doses administered. Venular diameters (panel b) were not significantly affected by any of the doses of lemakalim.

Table 5.1 Baseline values for MAP ( $\mathrm{mmHg}$ ), and vascular diameters $(\mu \mathrm{m})$ in the experimental group

$\begin{array}{lcc}\text { MAP } & \mathrm{n} & \\ \text { A1 } & 6 & 164 \pm 5 \\ \text { A2 } & 10 & 95 \pm 7 \\ \text { A3.A4 } & 14 & 47 \pm 4 \\ \text { V3.V4 } & 11 & 21 \pm 3 \\ \text { V2 } & 11 & 30 \pm 3 \\ \text { V1 } & 16 & 56 \pm 6 \\ & 10 & 128 \pm 12\end{array}$




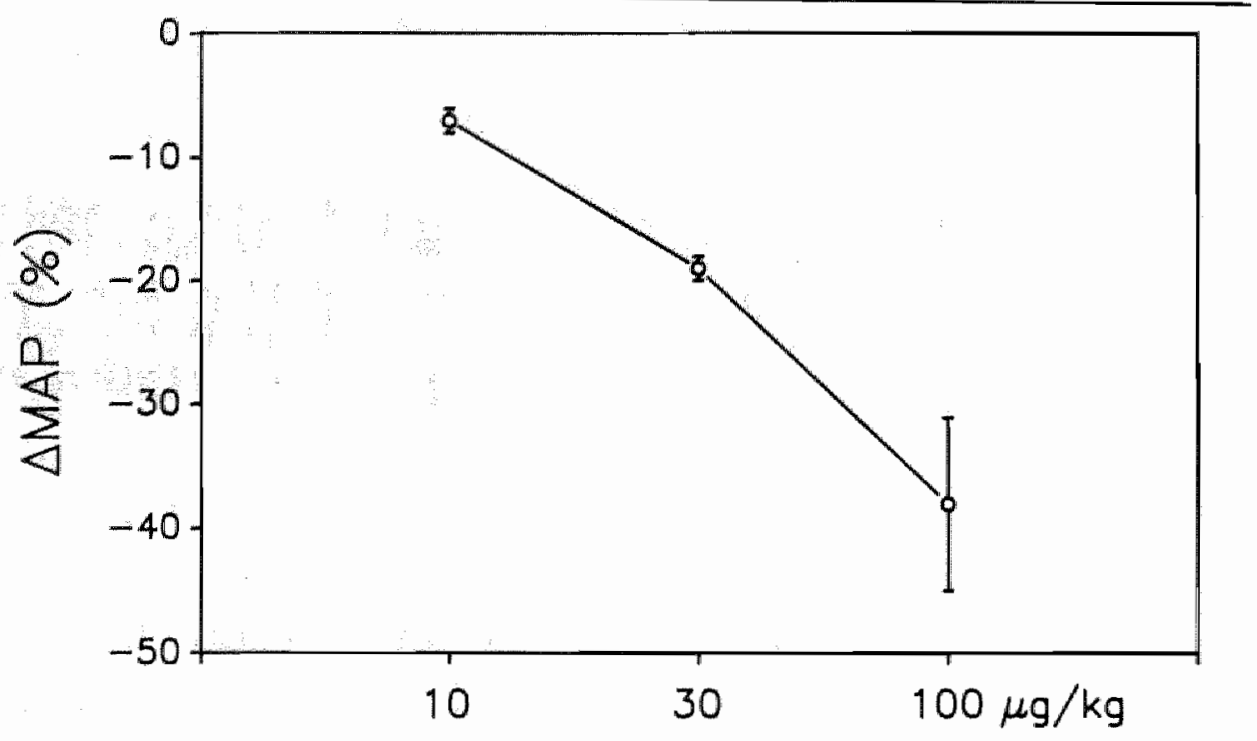

Figure 5.1 Effects of increasing doses of lemakalim on MAP.

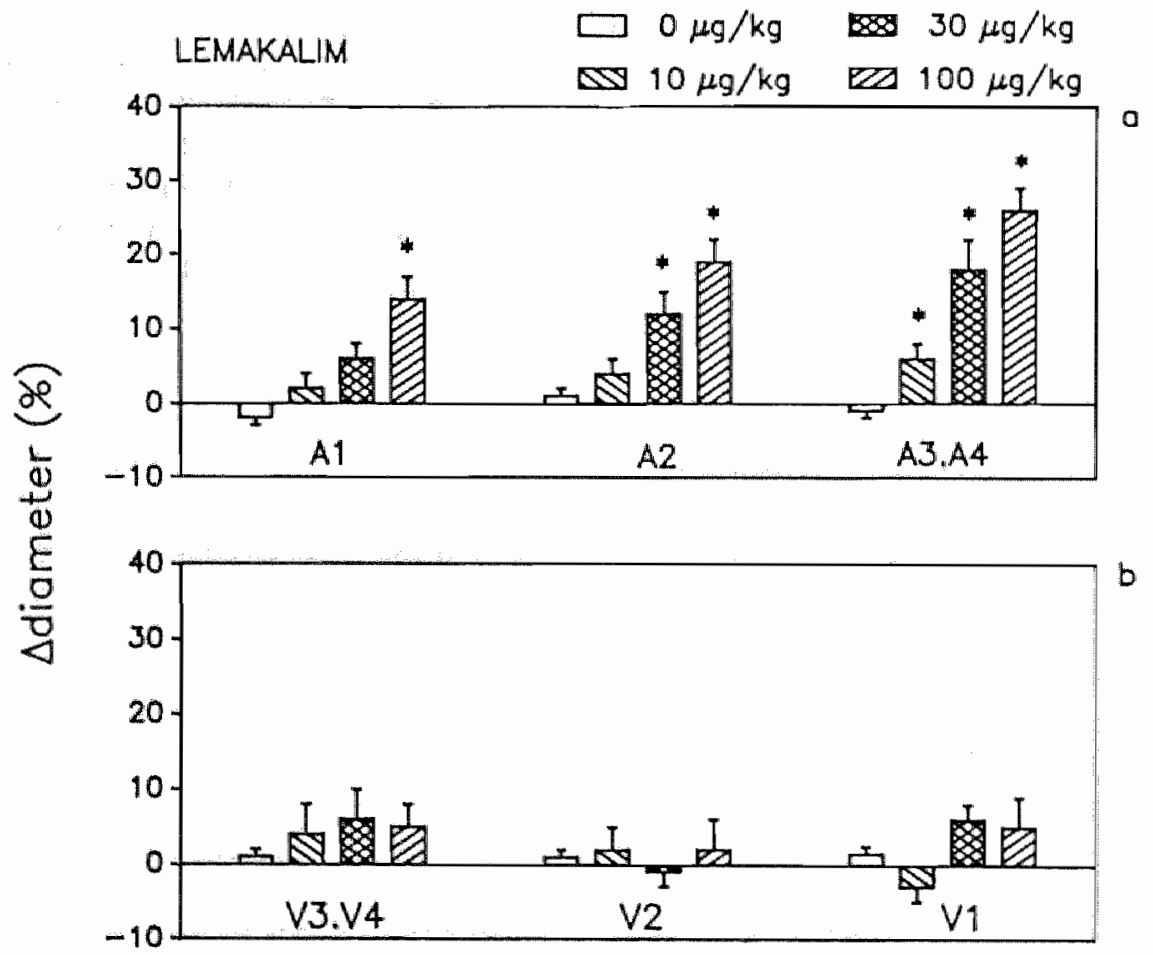

Figure 5.2 Effects of increasing doses of lemakalim on arteriolar (panel a) and venular (panel b) diameters. 
Results of the present study show that lemakalim preferentially dilates small arterioles in conscious SHR. They are dilated at doses lower than those needed to dilate large arterioles (figure 5.2a). It has only negliable effects on venules (figure 5.2b). The animal model used does not allow the observation of even larger arterioles or venules. However, previous studies (Schmid-Schönbein and Chien, 1986; Bohlen, 1989; Mulvany, 1990) have shown that an important part of basal vascular resistance and increased resistance in hypertension is localised in arterioles with diameters of $100 \mu \mathrm{m}$ or less. Therefore, the choice of our model seems highly relevant for the study of the site of action of drugs that lower blood pressure primarily through vasorelaxation.

Vasodilator antihypertensive drugs have a marked heterogeneity with respect to their microvascular sites of action. Lemakalim, like calcium channel antagonists (chapter 4, Messing et al., 1991) preferentially dilates small arterioles. In contrast, $\alpha_{1}$-adrenoceptor antagonists (chapter 6, Messing et al., 1990) have little effect on the smallest arterioles and dilate larger arterioles. Angiotensin-converting enzyme inhibitors have no effect on microvascular diameter (chapter 7). This heterogeneity has important implications for understanding mechanisms of control of vascular tone. Vascular tone is the result of a complex interplay between basal structural properties of the vessel wall and physical forces exerted on the wall on the one hand and external influences, such as hormones, neurotransmitters or locally (endothelium) derived substances on the other. Our data suggest that small arterioles may be preferentially under the control of factors that affect membrane potential. Potassium channels and voltage-dependent calcium channels may be important representatives of these electrical forms of control. Large arterioles and arteries, on the other hand, seem to be more sensitive to extrinsic forms of control, such as meurotransmitters or circulating hormones (Messing et al., 1991). The differential role of physical and endothelium-derived factors is still not known.

A final important consequence of our observations is related to the potential therapeutic use of potassium channel openers. Potassium channel openers have been shown to increase the nutritive flow even in severely ischemic striated muscle, in contrast to other vasodilators (Angersbach and Nicholson, 1988). The preferential dilatation of small arterioles may explain why in situations of severe reduction of the conductance through the feeding arteries and arterioles, potassium channel openers are still able to enhance flow. In case of a more generalised vasodilatation blood flow to non-ischaemic parts of the circulation can be enhanced at the expense of flow to the ischaemic vasculature, a phenomenon referred to as steal effect. This can be avoided by preferential dilatation of the vasculature distal to the occlusion. Thus, apart from hypertension the treatment of chronic occlusive arterial disease may be an attractive future area of therapeutic application of potassium channel openers. 


\section{CHAPTER 6}

\section{Alpha-adrenergic reactivity of striated muscle microvessels in conscious spontaneously hypertensive rats}

\subsection{Introduction}

Alpha-adrenergic mechanisms pllay an important role in microvascular tone regulation. It is known that $\alpha$-adrenoceptors exist as two subtypes, the $\alpha_{1}$ - and $\alpha_{2}$-subtype, as determined by their sensitivity to different $\alpha$-adrenergic agonists and antagonists. These subtypes may be of importance for the differential regulation of microvascular tone. Firstly, the $\alpha_{1}$ - and $\alpha_{2}$-subtypes are distributed unevenly through the microvascular tree (Faber, 1988b). Most importantly, $\alpha_{1}$-receptors are located only in larger arterioles, while the $\alpha_{2}$-subtype is located throughout the arteriolar microvasculature. Secondly, the two subtypes differ greatly in sensitivity to variations in factors like myogenic tone (Faber and Meininger, 1990), pH (McGillivray-Anderson and Faber, 1990; Chen and Shepherd, 1991), oxygen tension (McGillivray-Anderson and Faber, 1991) and temperature (Faber, 1988a). In general, the $\alpha_{2}$-adrenoceptor seems to be more sensitive to variations in local environment than the $\alpha_{1}$-subtype. Thirdly, each type is thought to be coupled in a different way to postreceptor mechanisms that lead to an increase of intracellular calcium concentrations, and hence to vascular smooth muscle contraction (Minneman, 1988).

In this study, we addressed the question of $\alpha$-adrenergic microvascular reactivity in conscious hypertensive rats. So far, data on this subject are scarce. Furthermore, discrepancies arise when in vivo and in vitro data on larger vessels are compared, especially regarding the $\alpha_{2}$-subtype. Alpha $a_{2}$-adrenergic responses are difficult to evoke e.g. in dog and rat mesenteric arteries in vitro, while comparable in vivo experiments show clear responses (Daniel et al., 1991). Also, vessels that possess $\alpha_{2}$-adrenoceptors as shown by receptor binding may not show $\alpha_{2}$-adrenergic reactivity in vitro, as Shi and co-workers found in canine aorta and mesenteric vessels (1990). Lastly, in acute preparations of anaesthetised animals, microvascular reactivity may be altered compared to the real in vivo situation (Nishigaki et al., 1991).

We used the intact striated muscle preparation of the dorsal cutaneous maximum muscle of conscious spontaneously hypertensive rats, as originally developed by Smith et al (1985). This preparation allows microvascular observations in conscious 
rats that have recovered from surgery. The first aim of this study was to determine the distribution of $\alpha$-adrenergic reactivity in rat striated muscle microvessels. We used specific $\alpha_{1}{ }^{-}$and $\alpha_{2}$-adrenergic agonists and antagonists for this purpose and assessed microvascular diameter changes induced by these drugs. Secondly, to determine whether there was any contribution of blood pressure changes to the microvascular effects observed we investigated the effects of graded haemorrhage on the same preparation and parameters.

\section{2}

\section{Materials and methods}

\section{Determination of $\alpha$-adrenergic reactivity}

Male SHR were implanted with a DMC and catheters as described in section 2.2, and used for intravital microscopy as described in section 2.3.

Video recordings were made before drug administration to obtain baseline diameters. Subsequently, the selective $\alpha$-adrenoceptor agonists phenylephrine $\left(\alpha_{1}\right)$ or azepexole $\left(\alpha_{2}\right)$ were infused in an cumulative manner $(1,3,10 \mu \mathrm{g} / \mathrm{kg} / \mathrm{min}$ and $30,100,300 \mu \mathrm{g} / \mathrm{kg} / \mathrm{min}$, respectively; each dose $10 \mu \mathrm{l} / \mathrm{min}$ ). Each dose was infused for approximately $15 \mathrm{~min}$. After $5 \mathrm{~min}$, when blood pressure had stabilised, video recordings of the selected vessel segments were started. After the last agonist dose, MAP was allowed to return to baseline values. After MAP had been stable for at least $10 \mathrm{~min}$, a bolus injection of the corresponding antagonist was given (prazosin $\left(\alpha_{1}\right): 0.1 \mathrm{mg} / \mathrm{kg}$; yohimbine $\left(\alpha_{2}\right): 1 \mathrm{mg} / \mathrm{kg}$; each dose $\left.0.1 \mathrm{ml}\right)$. Again, video recordings were taken during the stable phase of blood pressure reduction. Prazosin was dissolved in distilled water to a concentration of $1 \mathrm{mg} / \mathrm{ml}$, further dilutions were made with saline. All other drugs were dissolved in saline, which allso was used for control experiments. Experiments on the two $\alpha$-adrenoceptor subtypes on individual rats were performed in random order.

\subsubsection{Haemorrhage experiment}

The experimental setup as described in section 2.3 was used. The protocol for inducing a graded haemorrhage was as follows. After registration of baseline values, 5 individual samples of $1 \mathrm{ml}$ blood were withdrawn from the arterial catheter, separated by recovery periods of $20 \mathrm{~min}$ (Lombard and Roman, 1990). At the end of each 20 min period, video recordings were taken. At the end of the experiments, rats were killed by an i.v. overdose of pentobarbital.

\section{2 .3}

\section{Statistics}

Effects were calculated as percentual differences from pre-injection values and are expressed as mean \pm SEM. Data were analysed with an analysis of variance (ANOVA) for multiple group comparisons, except for antagonist data, where a paired t-test was used (see section 2.4). Statistical significance was accepted if $\mathrm{p}<0.05$. 
Table 6.1 Baseline values of MAP (mmHg) and microvascular diameter ( $\mu \mathrm{m}$ ) in the individual experimental groups.

\begin{tabular}{llllll}
\hline Drug & Phenylephrine & Prazosin & Azepexole & Yohimbine & Haemorrhage \\
n & 7 & 7 & 7 & 7 & 5 \\
MAP & $160 \pm 6$ & $159 \pm 3$ & $144 \pm 5$ & $140 \pm 3$ & $167 \pm 7$ \\
n & 11 & 11 & 10 & 10 & 8 \\
A1 & $83 \pm 8$ & $78 \pm 7$ & $85 \pm 9$ & $80 \pm 8$ & $84 \pm 5$ \\
n & 10 & 13 & 10 & 10 & 10 \\
A2 & $57 \pm 7$ & $55 \pm 6$ & $57 \pm 6$ & $55 \pm 6$ & $41 \pm 3$ \\
n1 & 11 & 11 & 11 & 11 & 22 \\
A3.A4 & $20 \pm 2$ & $22 \pm 3$ & $23 \pm 3$ & $23 \pm 4$ & $21 \pm 1$ \\
n & 15 & 15 & 11 & 10 & 12 \\
V3.V4 & $33 \pm 4$ & $33 \pm 4$ & $31 \pm 5$ & $27 \pm 3$ & $28 \pm 2$ \\
n & 16 & 16 & 16 & 16 & 21 \\
V2 & $77 \pm 8$ & $76 \pm 8$ & $73 \pm 8$ & $69 \pm 18$ & $55 \pm 4$ \\
n & 10 & 6 & 7 & 7 & 5 \\
V1 & $157 \pm 17$ & $141 \pm 30$ & $150 \pm 21$ & $147 \pm 27$ & $130 \pm 18$ \\
& & & & & \\
\hline
\end{tabular}

6.3

\section{Results}

Baseline values for MAP and vessel diameters are given in table 6.1. There were no statistically significant differences in baseline values between different groups of either group of experiments (ANOVA).

The effects of the agonists on MAP are given in fig. 6.1, showing a clear dosedependent relationship between agonist dose and blood pressure increase. Maximal increases for each dose were reached within $5 \mathrm{~min}$ after initiation of the infusion. Similarly, MAP rapidly returned to baseline values after termination of the infusion. Fig. 6.2 shows the blood pressure lowering effect of the antagonists. Maximal decreases were reached within $10 \mathrm{~min}$ and were stable for at least $30 \mathrm{~min}$ thereafter. In all cases, saline had no effect. 


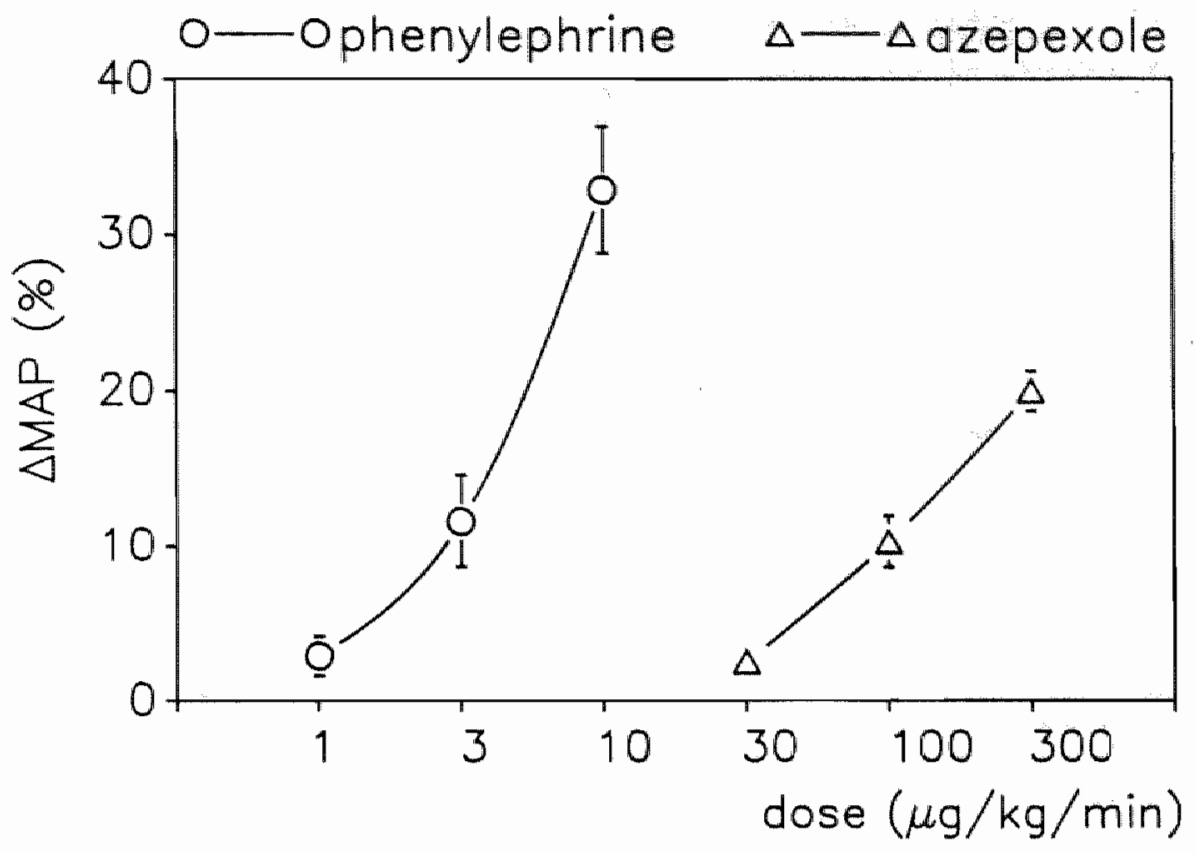

Figure 6.1 Effects of $\alpha$-adrenergic agonists on MAP.

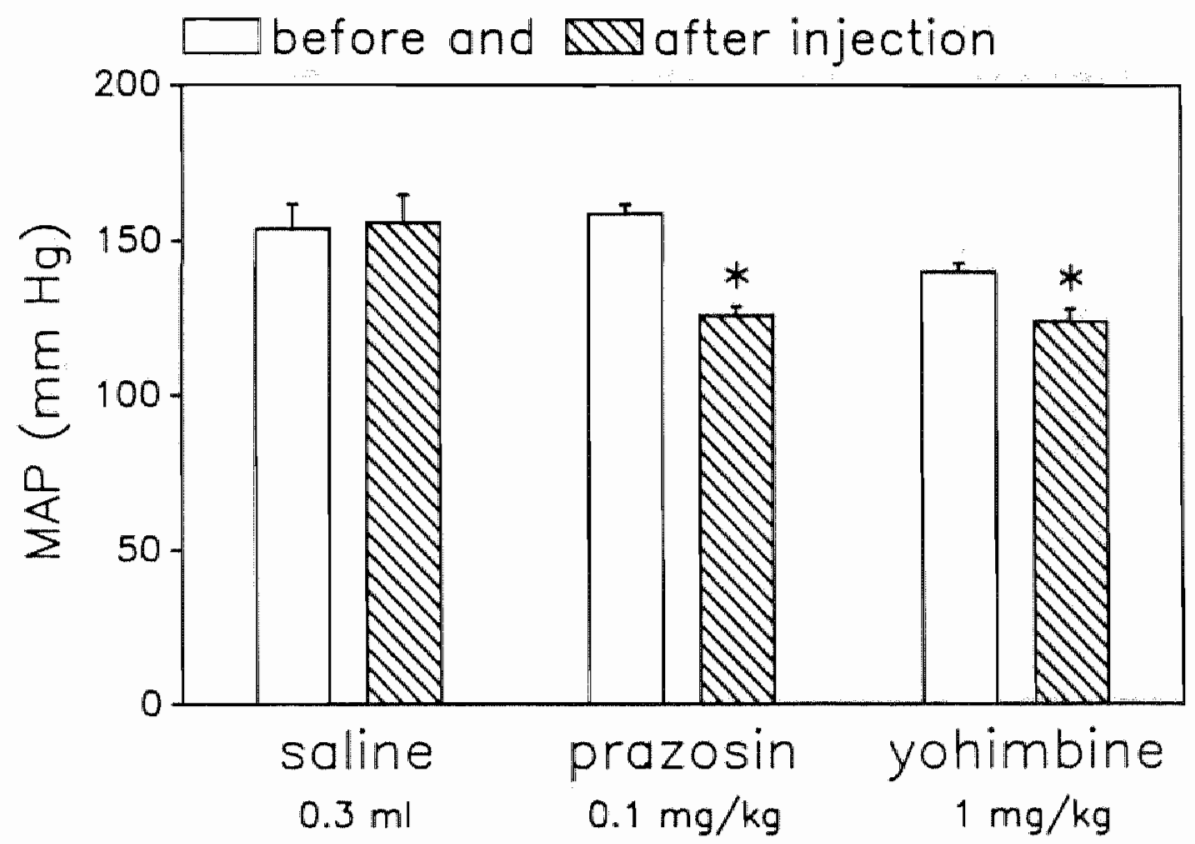

Figure 6.2 Effects of $\alpha$-adrenergic anragonists on MAP. 


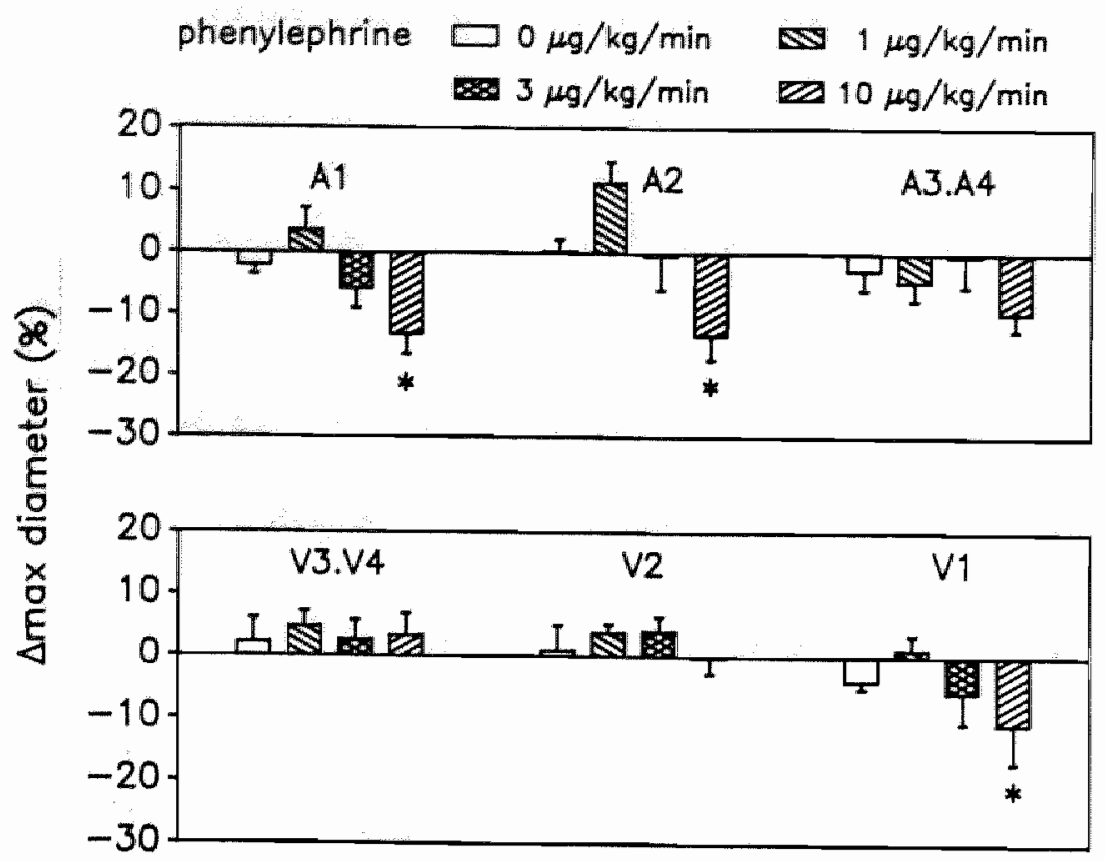

Figure 6.3 Effects of different doses of phenylephrine on microvascular diameters.

Fig. 6.3 shows the effects of phenylephrine on diameter changes of the individual vessel types. Only the larger vessels (A1, A2, V1) were constricted. Azepexole (fig. 6.4) constricted the entire arteriolar vasculature and caused also a significant constriction of the smallest venules (V3.V4), but not the V1. The antagonists caused differential dilatations (fig. 6.5). Prazosin dilated larger vessels (A1,A2, V1, V2) and yohimbine induced dilatation at all arteriolar levels, but had no effect on the venular vessels.

Blood pressure in the haemorrhage experiment is shown in fig. 6.6. MAP initially remained stable, but haemorrhage caused a significant fall in MAP after 5 $\mathrm{ml}$ bllood had been withdrawn. The effects on microvascular diameters are shown in fig. 6.7. There was no significant change in diameter of A1 and A2 vessels, but A3.A4 arterioles significantly dilated after $5 \mathrm{ml}$ of blood withdrawal. On the venular side, V2 and V3.V4 vessels significantly constricted after 4 to $5 \mathrm{ml}$ of blood withdrawal, while V1 venules tended to do so. 


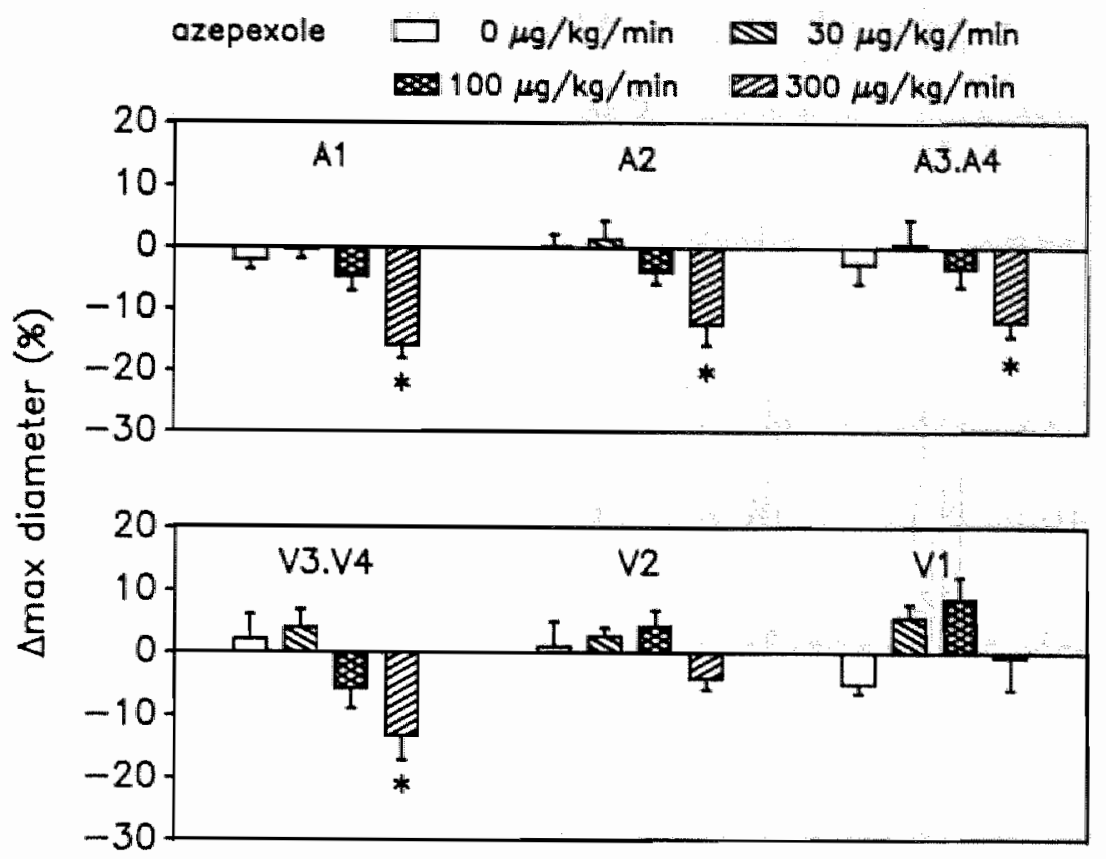

Figure 6.4 Effects of different doses of azepexole on microvascular diameters.

\section{4}

\section{Discussion}

The present study was aimed at an analysis of the $\alpha$-adrenergic reactivity of striated muscle microvessels of conscious rats, using selective $\alpha_{1}$ - and $\alpha_{2}$-adrenergic agonists and antagonists. The specificity of the effects of the antagonists was verified by comparing their effects with those induced by haemorrhage, a non-pharmacological way of blood pressure reduction. In vivo experiments were performed on the cutaneous maximus muscle of intact conscious SHR and the results suggest a distinct pattern of $\alpha$-adrenoceptor subtype distribution. Only the larger arterioles and venules showed $\alpha_{1}$-adrenergic reactivity while $\alpha_{2}$-adrenergic reactivity was essentially restricted to the arteriolar vasculature. A haemorrhage induced effect on microvascular diameter was only seen at a much higher degree of blood pressure decrease as compared to $\alpha$-antagonist induced effects.

We are the first to report on microvascullar distributions of $\alpha$-adrenergic reactivity in the intact striated muscle of conscious SHR. Studies by others on anaesthetised models or isolated vessels yielded comparable results. Large arterioles are reported to show both $\alpha_{1}$ - and $\alpha_{2}$-adrenergic reactivity in the canine epicardium (Heusch et al., 1984; Chilian, 1991), rat cremaster muscle (Faber, 1988b), and human subcutaneous (Nielsen et al., 1990b), omental (Nielsen et al., 1990a), colon, pericardial fat and skeletal muscle (Nielsen et al., 1991). Small arterioles seem to 


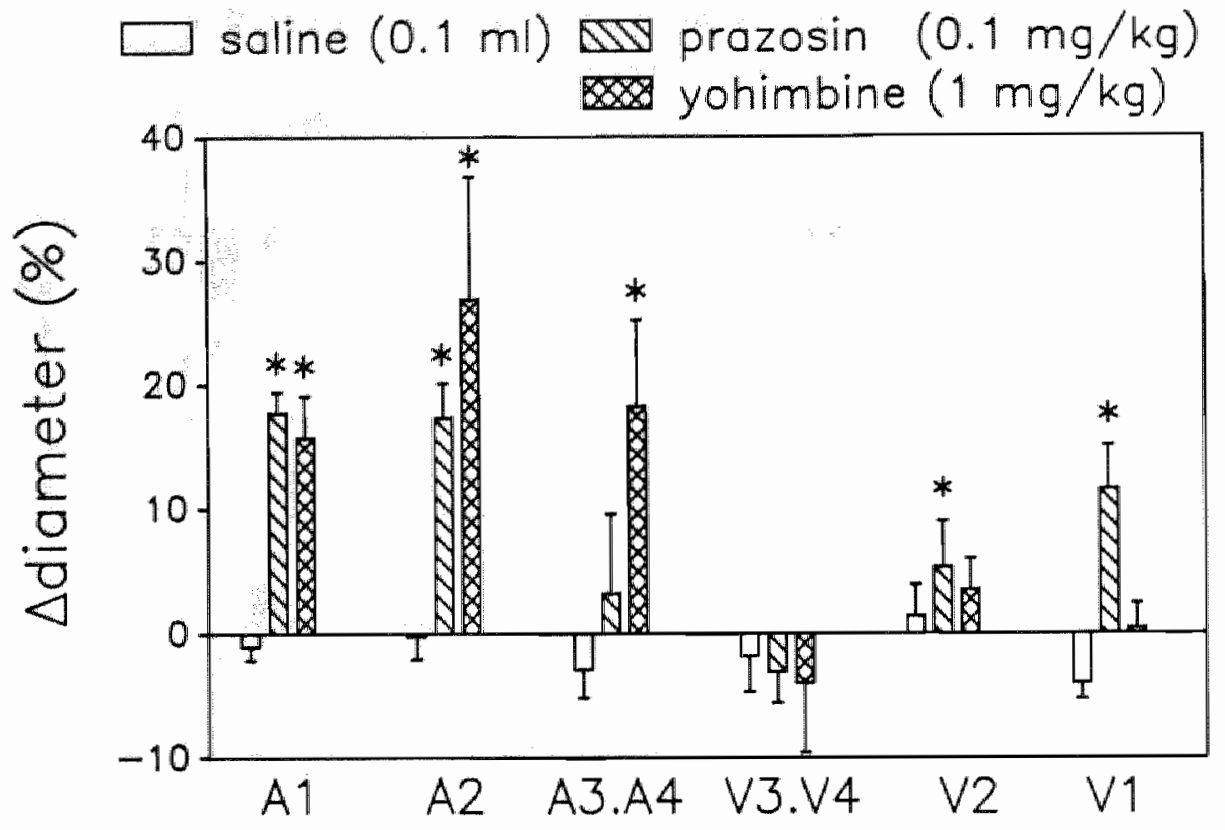

Figure 6.5 Effects of $\alpha$-adrenergic antagonists on microwascular diameter.

be predominantly subserved by $\alpha_{2}$-adrenoceptors as has been shown in rat cremaster muscle (Faber, 1988b) and acral cutaneous microcirculation (Willette et al., 1991) and human omental (Nielsen et al., 1990a) and subcutaneous arterioles (Nielsen et al., 1989). Data on larger arteries, e.g. canine epicardial arteries (Heusch et al., 1984; Chilian, 1991) and various human arteries (Nielsen et al., 1989) show a predominance of $\alpha_{1}$-adrenergic reactivity in these vessels. Thus, while $\alpha_{\rrbracket}$-adrenoceptors might predominate on arteries and $\alpha_{2}$-adrenoceptors on small precapillary arterioles, small arteries and large arterioles might be subserved by a mixed population of $\alpha_{1}$ - and $\alpha_{2}$-adrenoceptors. Similarly, large venules and veins are also reported to possess both $\alpha$-adrenoceptor subtypes (De Mey and Vanhoutte, 1981; Faber, 1988b). In our preparation, however, large venules only showed $\alpha_{1}$-adrenergic reactivity so a transition of a pure $\alpha_{1}$ - to a mixed $\alpha_{1}$ - and $\alpha_{2}$ adrenoceptor population may exist in venules.

The present data support the hypothesis that a varying distribution of $\alpha$-adrenoceptors along the vascular tree is involved in differential tone regulation of distinct segments of the microvasculature. Different microvascular levels have been shown to differ in sensitivity to neural (Ohyanagi et al., 1991), myogenic (Faber and Meininger, 1990) and physical and humoral factors (Faber and McGillivray, 1988). This is valid for arterioles as well as venules (Marshall, 1991) although the sensitivity of venules and veins to neura $\rrbracket$ influences (Marshall, 1982) and also to $\alpha$ adrenergic antagonists (D'Oyley and Pang, 1990) seems to be smaller than arterio- 


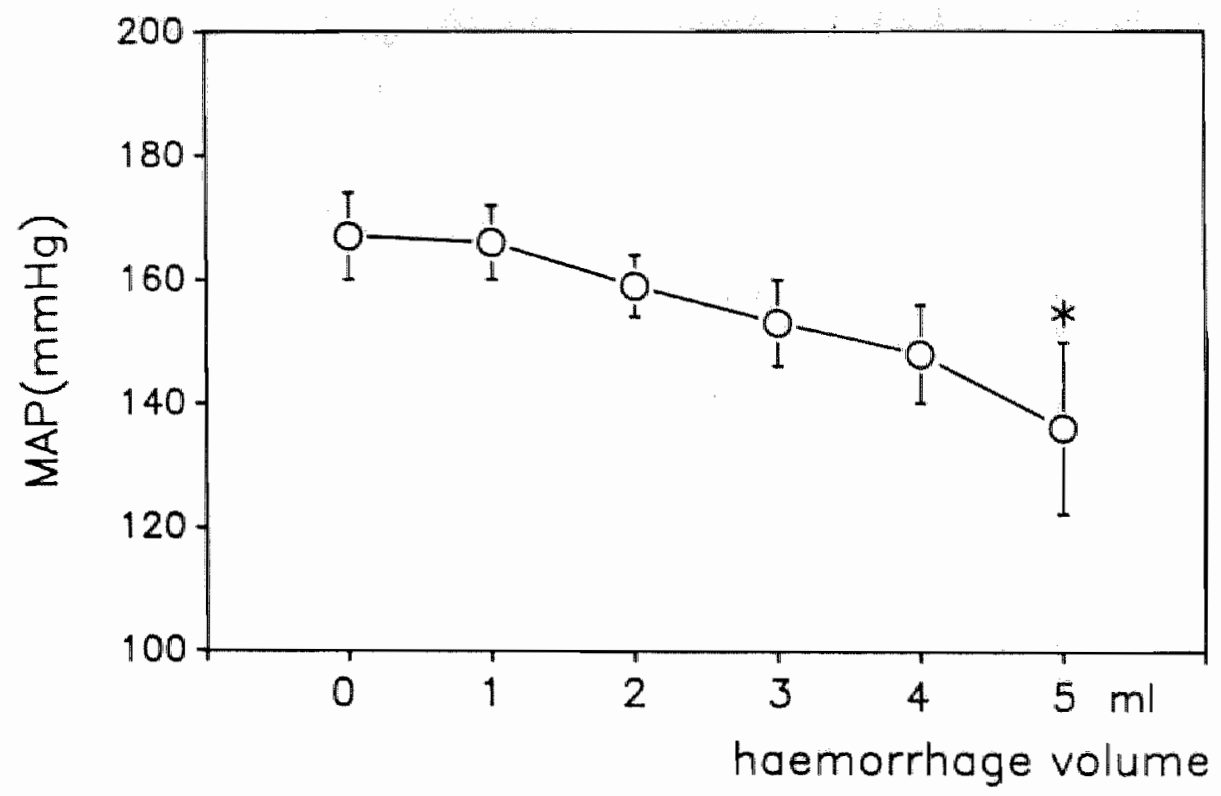

Figure 6.6 Effects of graded haemorthage on $M A P$.

lar sensitivity because of lack of noradrenergic nerve fibres.

The effects of haemorrhage on microvascular diameter were different from those of $\alpha$-adrenergic antagonists. This is most strikingly evident for prazosin. Baseline MAP and the degree of blood pressure decrease were very similar in the two groups, but the effects on microvascular diameters were almost completely opposite. Haemorrhage had no effect on $\mathrm{A} 1$ and $\mathrm{A} 2$ arterioles and caused a dilatation of A3.A4 arterioles. Prazosin had opposite effects, it dilated A1 and A2 arterioles, but had no effect on A3.A4 arterioles. On the venular side, haemorrhage caused constrictions, while prazosin caused dilatations. Yohimbine, like haemorrhage, caused a dilatation of A3.A4 arterioles, while prazosin did not. This is even more an indication of the drug specific microvascular effects of the $\alpha$-adrenergic drugs.

The results of the haemorrhage experiment show that conscious SHR actively try to counteract the effects of blood loss. The initial blood withdrawals had little effect on MAP, while the same protocol carried out on anaesthetised SHR (Lombard and Roman, 1990) immediately caused a fall in blood pressure. Conscious SHR initially managed to keep MAP relatively constant with no changes in microvascular diameter. Constrictions in other vascular beds or upstream vessels, reflex regulation of venous capacitance or fluid gain from the tissue space can explain this observation. It indicates that the striated muscle microvasculature does not play an important role in counteracting haemorrhagic shock. Therefore, the arteriolar dilatations seen in the second half of the experiment are most likely due to increased concentrations of tissue metabolites, which especially inhibit $\alpha_{2}$-adrenergic tone (McGillivray-Anderson and Faber, 1990; Chen and Shepherd, 1991). During haemorrhage 


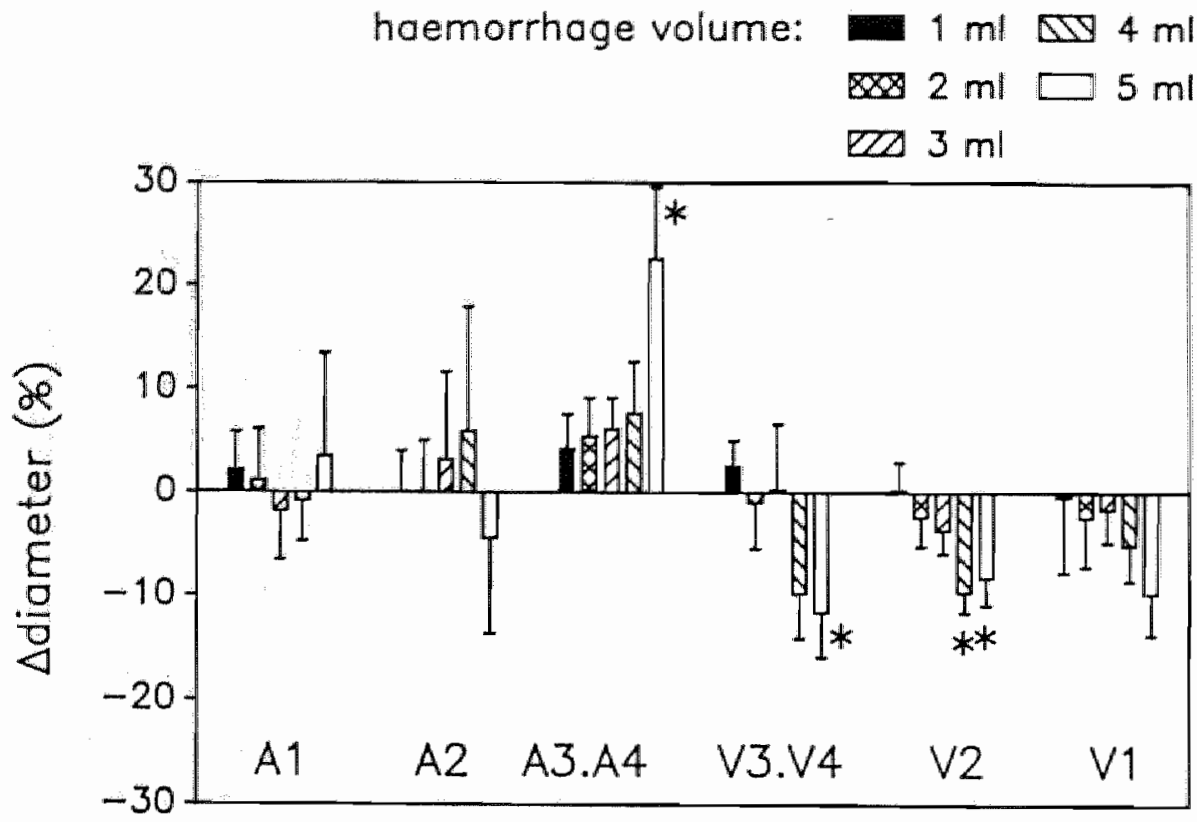

Figure 6.7 Effects of graded heamorrhage on microwascular diameter. Each cluster represents the effects of 5 succesive $1 \mathrm{mi}$ blood withdrawals.

tissue metabolites may accumulate due to impaired blood supply or plugging of arterioles by cellular blood components. This explains arteriolar dilatation (Torres Filho et al., 1989; this study) with a simultaneous decrease in laser Doppler flow and increased vascular resistance (Lombard and Roman, 1990). Torres Filho and co-workers (1989), who studied the anaesthetised cat haemorrhagic sartorius muscle, also observed dilatations of large arterioles while small arterioles slightly constricted, this being in accordance with the theory of a predominance of $\alpha_{2}$ adrenoceptors in the distal part of the arteriolar microvasculature. The venular constriction induced by haemorrhage can easily be explained by the recruitment of blood volume from the capacitance space of the venous side of the circulation.

From a therapeutical point of view, the results of our study have important implications for treatment of diseases where $\alpha_{2}$-adrenoceptors are involved; the $\alpha_{2}$ adrenoceptor can be used as a means for drug targeting (Benjamin and Vallance, 1991). In hypertension, blood pressure is increased due to microvascular resistance increase (Schmid-Schönbein and Chien, 1986), indicating that the arterioles which posses $\alpha_{2}$-adrenoceptors, but not the arteries, are involved. Selective postsynaptic $\alpha_{2}$-adrenoceptor antagonists would specifically dilate the microvessels involved and thus lower blood pressure. Such a treatment would also be profitable in the treatment of primary Raynaud's phenomenon, where disturbances in $\alpha_{2}$-adrenoceptor regulation are thought to be a cause of the disease (Coffman, 1991). 


\section{CHAPTER 7}

\section{On the role of angiotensin II in striated muscle microvascular tone in conscious spontaneously hypertensive rats}

The regulation of microvascular tone depends on an interplay of several humoral, neural and myogenic mechanisms as well as structural properties of the microvascular system. In hypertension resistance in many vascular beds is increased, mainly due to an elevated resistance at the level of the arteriolar microvessels (Schmid-Schönbein and Chien, 1986; Bohlen, 1989; Mulvany, 1990). The renin-angiotensin system (RAS) plays an important role in cardiovascular homeostasis and the biological mediator of the RAS, angiotensin II (AII) can therefore be expected to contribute substantially to microvascular tone regulation. However, data on this subject show regional and segmental differences in the vasoconstrictor potency of AII. In in vitro studies AII readily constricts femoral and cerebral arteries, but mesenteric arteries react to a lesser extent (Juul et al., 1987). Even vessels from one organ may differ, for instance the retinal artery of the bovine eye did and the posterior ciliary artery did not constrict to AII (Nyborg et al., 1990). In in vivo studies, segmental differences have been reported. In rat cremaster muscle, small precapillary arterioles were strongly constricted by AII, while larger arterioles, situated immediately proximal to these vessels hardly reacted (Vicaut et al., 1989). Studies in the hamster cheek pouch also showed segmental differences, that were even augmented after induction of renovascular hypertension (Myers et al., 1988). Furthermore, in in vivo studies regional and segmental differences in the action of AII may be confused by the augmentation of sympathetic constriction (Seidelin et al., 1991) and also by vasodilator actions of degradation products of AII, such as have been reported in rabbit brain arterioles (Haberl et al., 1991).

Various drugs have been developed that antagonise the RAS at different points. An important drug class in this regard are the angiotensin converting enzyme (ACE) inhibitors, which block the formation of AII from AI by ACE. Simultaneously, however, they inhibit the breakdown of bradykinin, a vasodilatory polypeptide, while AII can also be formed by ACE-independent pathways (Dzau, 1990). These two phenomena possibly confuse the effects of ACE-inhibitors, but 
nevertheless they are widely used for research and therapeutic purposes. Another drug type is the recently developed nonpeptide AII receptor antagonist DuP 753, now named losartan. This is a highly selective, competitive antagonist without agonistic effects (Wong et all, 1989). This makes losartan a more selective tool for investigation of the actions of the RAS than ACE-inhibitors,

In the present study we investigated the contribution of AII to microvascular tone in an intact striated muscle preparation in conscious spontaneously hypertensive rats (SHR), thus avoiding influences of anaesthesia and acute surgery. The dorsal microcirculatory chamber model, exposing the cutaneous maximus muscle (Smith et al., 1985) was chosen to examine the acute effects of the ACE inhibitors captopril and enalaprilat, the nonpeptide AII receptor antagonist losartan and AII itself on microvascular diameter.

Male SHR were implanted with a DMC and catheters as described in section 2.2, and used for intravital microscopy as described in section 2.3.

Captopril $(3,10,30 \mathrm{mg} / \mathrm{kg})$ and enalaprilat $(30,100,300 \mu \mathrm{g} / \mathrm{g})$ were given as $0.1 \mathrm{ml}$ slow i.v. bolus injections. Each dose and drug were given in random order on different days. Saline, the solvent, was used for control experiments. Video recordings were made before injection and at 30,60, and $90 \mathrm{~min}$ afterwards for the highest two drug doses. For saline and the lowest drug doses, additional recordings were made at $15 \mathrm{~min}$. After analysis of the videotapes, maximal deviations from pre-injection values were taken as the drug effects.

\subsubsection{Exogenous AII and losartan}

Cumulative doses of 1,3 and $10 \mathrm{ng} / \mathrm{kg} / \mathrm{min}$ AlI $(10 \mu \mathrm{l} / \mathrm{min})$ were infused i.v. before and starting $10 \mathrm{~min}$ after injection of $3 \mathrm{mg} / \mathrm{kg}$ losartan. Each All dose was infused for $10 \mathrm{~min}$, while at the end of each such a period video recordings were made. Infusion was stopped and MAP allowed to return to baseline values. Subsequently, the protocol was repeated with $10 \mathrm{mg} / \mathrm{kg}$ losartan.

\section{2 .3}

Endogenous All and losartan

The effects of 3 and $10 \mathrm{mg} / \mathrm{kg}$ losartan were examined in one group of SHR under both normal and renin-activated conditions. The doses were injected with a 15 min time interval inbetween. Video recordings were made 10-15 min after each dose. Activation of the RAS was induced at least one day after losartan had been tested in normal SHR. Then, $8 \mathrm{mg} / \mathrm{kg}$ of the diuretic furosemide was 
Table 7.1 Arteriolar pre-injection diameters (O, $\mu \mathrm{m})$

Vessel type

a1 $\quad$ O

I. ACE-inhibitors

Saline $(0.1 \mathrm{ml})$

Captopril (mg/kg)

3
10
30

30

Enalaprilate $(\mu \mathrm{g} / \mathrm{kg})$

$\begin{array}{ccccccc}30 & 10 & 96 \pm 7 & 16 & 57 \pm 4 & 12 & 30 \pm 2 \\ 100 & 13 & 97 \pm 7 & 17 & 52 \pm 2 & 9 & 33 \pm 2 \\ 300 & 13 & 94 \pm 6 & 16 & 53 \pm 3 & 9 & 29 \pm 1\end{array}$

II. Exogenows $\mathrm{AII}$ and losartan $(\mathrm{mg} / \mathrm{kg})$

$\begin{array}{ccc}0 & 10 & 97 \pm 7 \\ 3 & 10 & 103 \pm 8 \\ 10 & 10 & 101 \pm 8\end{array}$

III. Endogenous AII and losartan

Normal SHR

Renin-acitvated SHR $\quad 9 \quad 86 \pm 4$
A2

1 0

$8 \quad 47 \pm 4$

$12 \quad 52 \pm 2$

$1250 \pm 3$

11. $47 \pm 3$

$31 \pm 4$

$12 \quad 30 \pm 2$

12 $31 \pm 2$

$81 \pm 6$

$1+8$

$17 \quad 26 \pm 2$

$17 \quad 28 \pm 2$

$17 \quad 31 \pm 3$
$14 \quad 46 \pm 3$

$16 \quad 45 \pm 3$

$\begin{array}{llll}14 & 46 \pm 3 & 17 & 26 \pm 2 \\ 14 & 50 \pm 5 & 17 & 28 \pm 2 \\ 14 & 46 \pm 5 & 17 & 31 \pm 3\end{array}$

injected s.c. and rats were deprived of drinking water. This procedure is reported to elevate plasma renin activity about 2.5 times (Wong et al, $1990 \mathrm{a}$ ). On the next. day, losartan was tested as described above.

\subsubsection{Statistics}

Effects are calculated as percentual differences from pre-injection values and expressed as means \pm S.E.M. Data were analysed with an analysis of variance (ANOVA) for multiple group comparisons (see section 2.4). Statistical significance was accepted if $\mathrm{p}<0.05$.

\section{3}

\section{Results}

Baseline MAP ranged from $161 \pm 4$ to $191 \pm 5 \mathrm{mmHg} \quad(\mathrm{n}=5-9)$ in individual experimental groups and can be read from figs. 7.1, 7.4, and 7.6. Tables 7.1 and 7.2 give arteriolar and venular baseline diameters, respectively. There were no statistical differences in baseline values between the individual groups of either group of experiments. 
Tabel 72 Venular pre-injection diameters $\left(0_{0} \mu \mathrm{m}\right)$

Vessel type

\begin{tabular}{|c|c|c|c|}
\hline V3.V4 & & $\mathrm{V} 2$ & \\
\hline $\mathscr{\varnothing}$ & $\mathbf{n}$ & $\varnothing$ & n \\
\hline
\end{tabular}

1. ACE-Inhibitors

Salitie $(0.1 \mathrm{ml})$

Captopril (mg/kg)

3

10

30

$2031 \pm 2$

$1378 \pm 5$

$9 \quad 167 \pm 20$

$12 \quad 63 \pm 4$

13 $\quad 137 \pm 9$

$17 \quad 69 \pm 4$

$14 \quad 175 \pm 14$

$1666 \pm 3$

$9 \quad 148 \pm 16$

Enalaprilate $(\mu \mathrm{g} / \mathrm{kg})$

30

100

11. $39 \pm 2$

$10 \quad 38 \pm 3$

$16-66 \pm$

$10 \quad 39 \pm 3$

$16 \quad 65 \pm 3$

$1477 \pm 5$

$1562 \pm 3$

$12 \quad 145 \pm 15$

$8 \quad 146 \pm 8$

$16 \quad 160 \pm 13$

II. Exogenows $A M$ and Losartan $(\mathrm{mg} / \mathrm{kg})$

$\begin{array}{rrr}0 & 16 & 34 \pm 2 \\ 3 & 22 & 31 \pm 2 \\ 10 & 22 & 29 \pm 2\end{array}$

III. Endogenous AII and losartan

Normal SHR $\quad 16 \quad 34 \pm 2$

Renin-activated SHR $\quad 16 \quad 30 \pm 2$

$20 \quad 60 \pm 3$

$24 \quad 59 \pm 3$

$2456 \pm 3$

$6 \quad 140 \pm 9$

$6 \quad 151 \pm 9$

$6130 \pm 9$

16 $30 \pm 2$

$20 \quad 60 \pm 3$

$6 \quad 140 \pm 10$

$6 \quad 136 \pm 13$

\section{3 .1}

$A C E$-inhibitors

The effects of the ACE-inhibitors captopril and enalaprilat on MAP are shown in fig. 7.1. About 10-15 min after injection, both drugs caused a decrease in MAP of about $10 \%$. The magnitude of the decrease was not clearly dose-dependent but the duration increased significantly with higher drug doses. After $30 \mathrm{~min}$, the effect of the lowest doses began to wane, and was abolished approximately one hour after injection. The highest doses caused a decrease in MAP that was stable throughout the entire duration of the experiment of at least 2 hours. Saline injections had no effect on MAP.

Microvascular effects of the tested ACE-inhibitors are shown in figs. 7.2 and 7.3. These figures indicate the maximal effects observed during the $90 \mathrm{~min}$ postinjection observation time. Basically, there were no significant reactions at any arteriolar level (fig. 7.2), though a slight tendency towards A3.A4 arteriolar dilatation could be noticed for the medium dose of captopril. This dilatation, however, was not observed for the highest dose of captopril. On the venular side (fig. 7.3) there were no effects on V1 venules, while V3.V4 and V2 venules showed a tendency to constrict. This tendency reached significance only for high enalaprilat doses. 
MAP before $\square$ and after injection
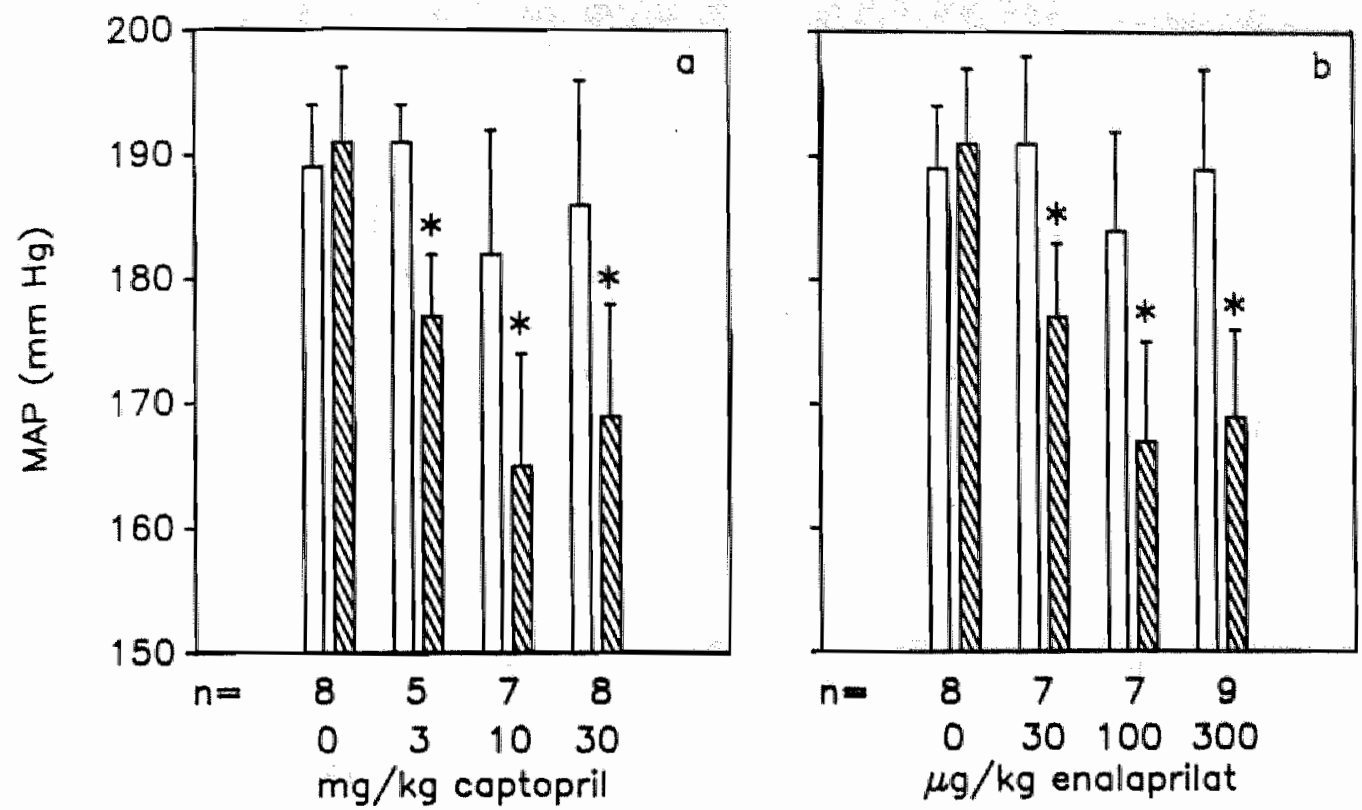

Figure 7.1 Effects of captopril and enalaprilate on MAP.

\subsection{2}

\section{Exogenous All and losartan}

Losartan had a dose-dependent antagonistic effect on AlI-induced pressor responses (fig. 7.4). Infusions of All quickly induced a stable increase in MAP of about $10 \%$ which itself was not dose-dependent. Pilot studies showed no pressor effect of infusions of lower doses of AII. When the different doses of AII were infused $10 \mathrm{~min}$ after injection of $3 \mathrm{mg} / \mathrm{kg}$ losartan, the pressor response was reduced by more than half, while after $10 \mathrm{mg} / \mathrm{kg}$ losartan, no significant pressor response could be observed anymore.

As shown in fig. 7.5, All did not cause constriction at any arteriolar level. Similarly, there were no effects at any venular level. The same was observed when AII was infused after injection of losartan; in neither of these cases any effect at any microvascular level could be detected.

\subsubsection{Endogenous $A$ II and losartan}

In fig. 7.6, the blood pressure lowering effects of losartan in normal and in renin-activated SHR are shown. Baseline MAP in both groups was not significantly different. The RAS activation procedure significantly lowered body weight $(233 \pm 3$ vs. $205 \pm 2 \mathrm{~g}$ ). In normal SHR, both doses of losartan caused a significant but small decrease in MAP of about $3 \%$. In renin-activated SHR, however, losartan caused a much larger decrease in MAP of about $10 \%$, the 


\section{captopril}

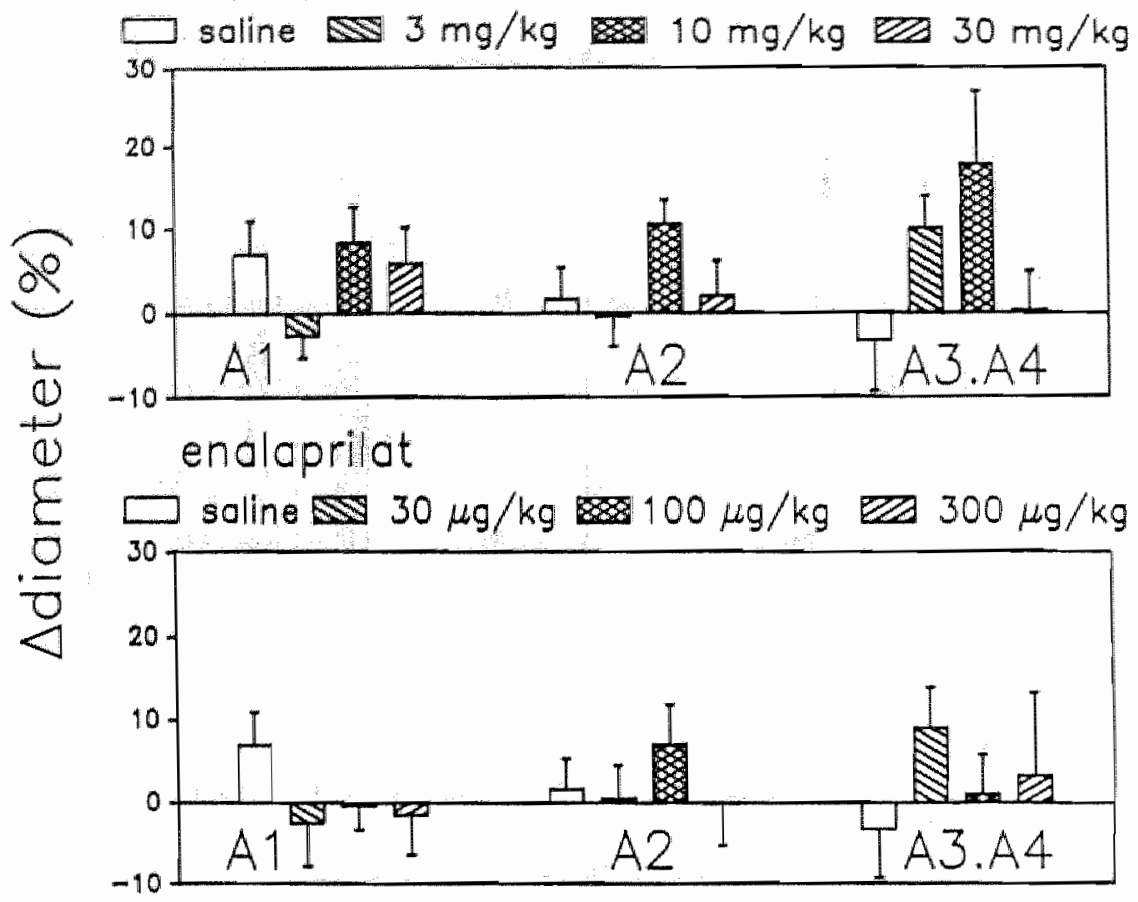

Figure 7.2 Effects of captopril and enalaprilate on arteriolar diameters.

highest dose enhancing the effect of the smallest one slightly, but not significantly. After the highest dose, MAP remained lowered for at least one hour.

Microvascular diameters in renin-activated rats did not differ from those in normal rats (tables 7.2 and 7.3 ), although $A 1$ arterioles tended to be slightly constricted. The different doses of losartan did not have any effect on venular diameters of rats in both states. On the arteriolar side (fig. 7.7), there were also no effects on A1 and A2 arterioles, while A3.A4 arterioles tended to dilate in normal SHR, which they did significantly in renin-activated SHR. In this case a dilatation of $22 \%$ was reached after $10 \mathrm{mg} / \mathrm{kg}$ losartan. 
captopril

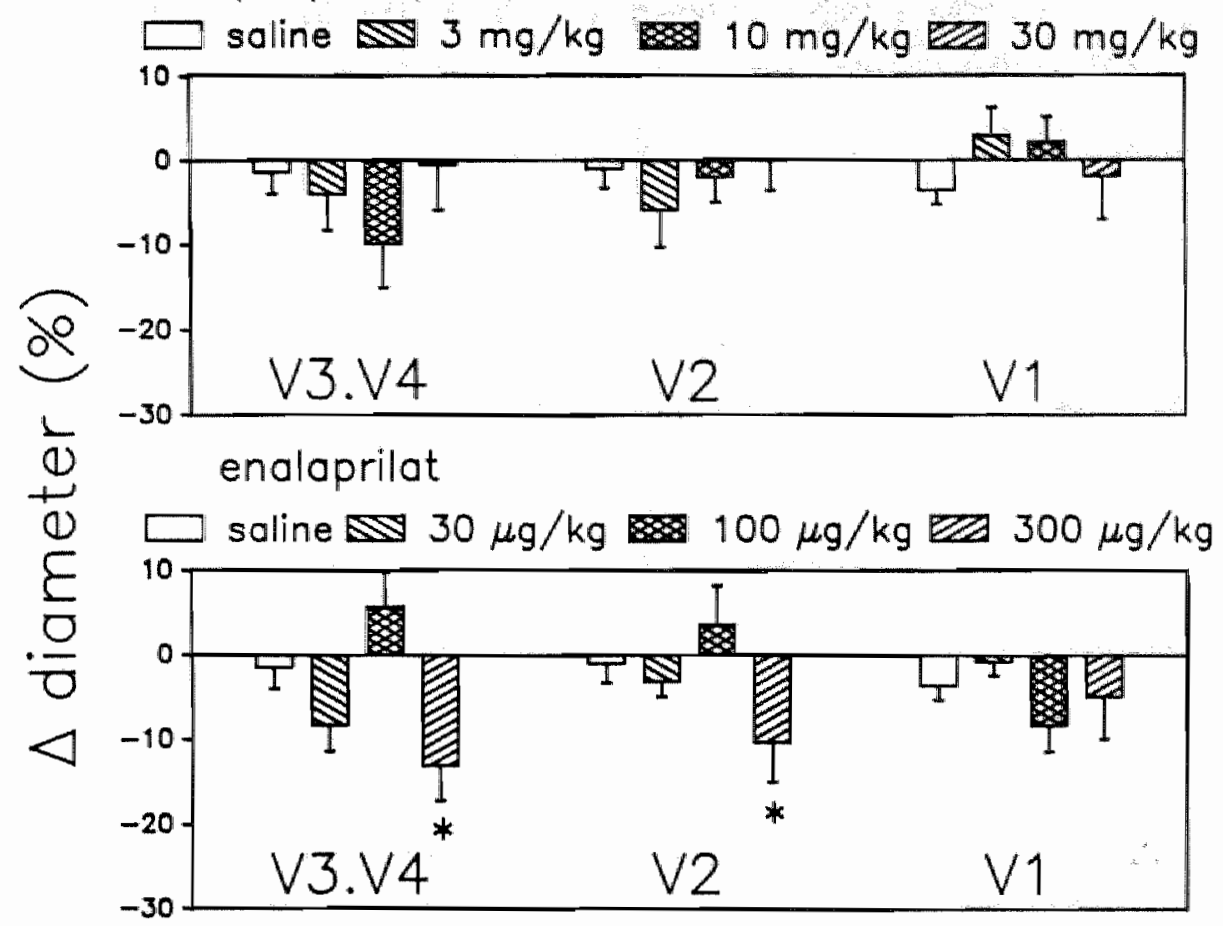

Figure 7.3 Effects of captopril and enalaprilate on venular diameters.

In this study it is shown for the first time in conscious SHR that neither inhibition nor activation of the renin-angiotensin system (RAS), nor exogenous angiotensin II (AII) induce a major effect on intact striated muscle microvascular diameter. In rats with a normally functioning RAS (normal SHR), the ACE-inhibitors captopril and enalaprilat, and the nonpeptide AII receptor antagonist losartan, significantly lowered MAP. Losartan antagonised the AIIinduced pressor response. Activation of the RAS by dehydration (renin-activated SHR) caused a significantly larger depressor effect following losartan. Microvascular effects, however, were limited. Enalaprilat in normal SHR doseindependently constricted V2 and V3.V4 venules by 10-15\%. Losartan in reninactivated SHR dilated A3.A4 arterioles by $22 \%$. All did not have any effect at all on microvascular diameter.

We found that inhibition of ACE by captopril or enalaprilat to a blood pressure 


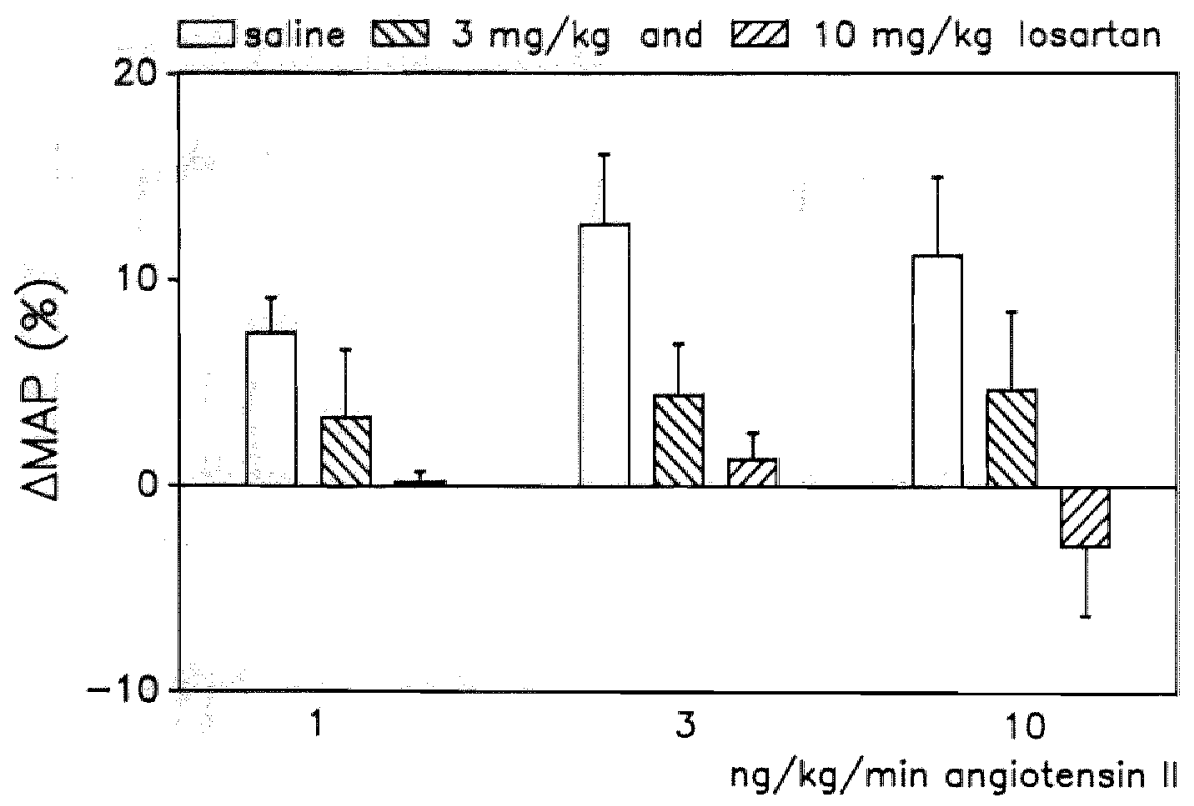

Figure 7.4 Antagonistic effect of losartan on a pressor response induced by angiotensin $I$.

lowering degree is not accompanied by arteriolar dilatation in striated muscle of conscious intact SHR. Studies on microvascular effects of ACE-inhibitors have not been performed before, but results from other investigations are compatible with our data. Smits and Struyker Boudier (1984) followed the same protocol in SHR to study systemic and regional haemodynamic effects of captopril. They found no effect on hindquarter flow but a strong increase in renal flow. In general, the effects of ACE-inhibitors have been shown to be tissue-specific (Richer et al., 1987; Cushman et al., 1989), the strongest effect being exerted on the renal vascular bed and only a minor effect on striated muscle haemodynamics. Also in other types of rats, e.g. renovascular hypertensive (Teranishi et al., 1988), normotensive (Drexler et al., 1987; Muller et al., 1990; Nelissen-Vrancken et al., 1992), or rats with heart failure (Drexler et al., 1987; Nelissen-Vrancken et al., 1992), similar acute tissue-specific effects were found. Thus, a decrease in striated muscle resistance does not seem to contribute to the blood pressure lowering effect of ACE-inhibitors. However, the RAS may still contribute to microvascular tone in striated muscle microvessels. Inhibition of ACE does not exclude the formation of AII since this vasoactive peptide can also be formed via ACE-independent pathways (Dzau, 1990). Thus, the conversion of AI into AII may be catalysed by other enzymes than ACE or AII may be formed directly from angiotensinogen. However, it is not known whether or when these pathways are active in SHR striated muscle. 


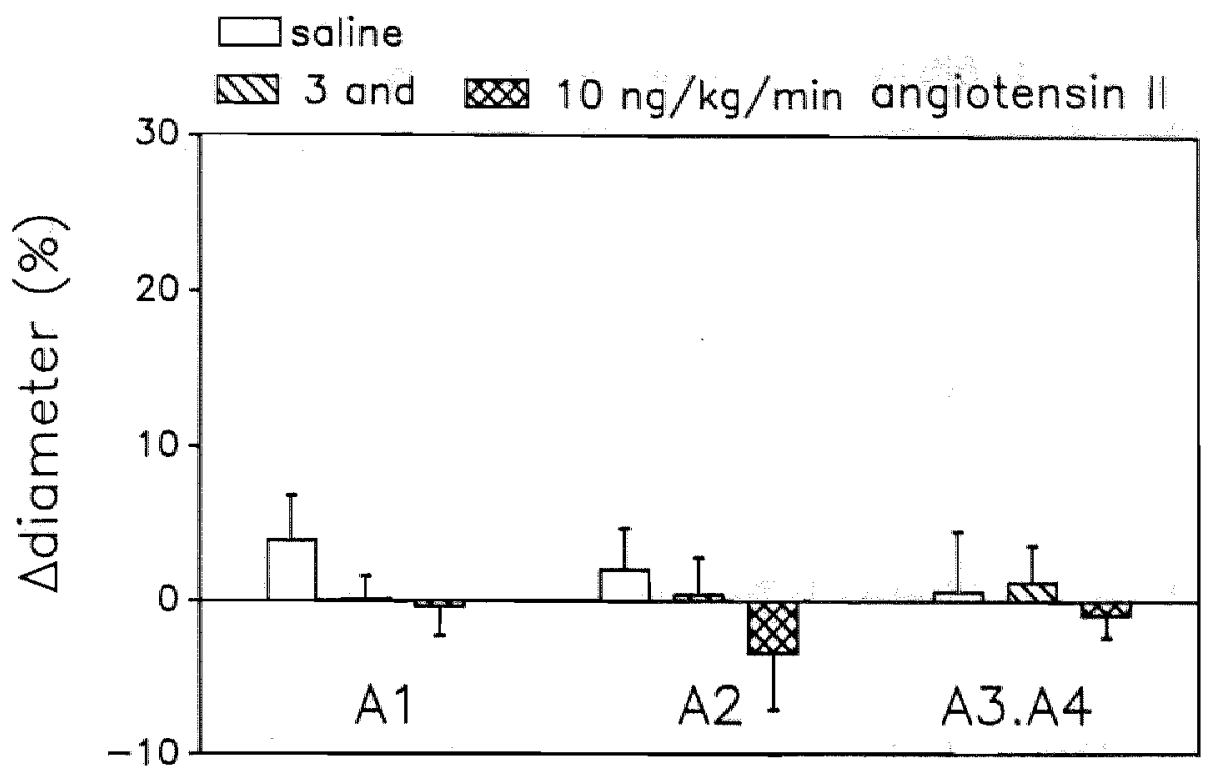

Figure 7.5 Effects of angiotensin II on arteriolar diameters.

The contribution of AlI to microvascular tone may also vary, depending on the degree of activity of the RAS. After activation of the RAS, Muller and co-workers (1990) found a dose-independent increase in hindlimb flow after intravenous administration of different ACE-inhibitors to water-depleted Brattleboro rats.

To further investigate the role of the RAS in the regulation of striated muscle microvascular tone in SHR, we used AII and the nonpeptide AII receptor antagonist losartan. We observed a strong, dose-dependent antagonistic effect of losartan on the pressor response induced by exogenous AII. Similar findings have been reported before in SHR (Wong et al., 1990a) and have also been observed in normotensive (Wong et al., 1990c) and renovascular hypertensive rats (Wong et al., 1990b). Losartan also antagonised endogenous AII as evidenced by the acute decrease in MAP in both normal and renin-activated SHR. Activation of the RAS greatly augmented the blood pressure lowering effect, reaching a degree of MAP decrease similar to that induced in normal SHR by ACE-inhibitors. An acute antihypertensive effect of losartan has been reported not only in SHR (this study, Wong et al., 1990a; Chung and Schips, 1991) but also in renovascular hypertensive rats (Wong et al., 1990b). Sustained antihypertensive effects for up to 7 days have been reported in SHR (Bunkenburg et al., 1991). These observations indicate that the antihypertensive potency of losartan strongly depends on the activity of the RAS even to a more pronounced extent than ACE-inhibitors. Captopril and enalaprilat induced a depressor effect in normal SHR similar to the effect of losartan in renin- 


\section{$\square$ baseline MAP}

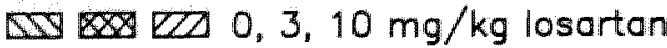

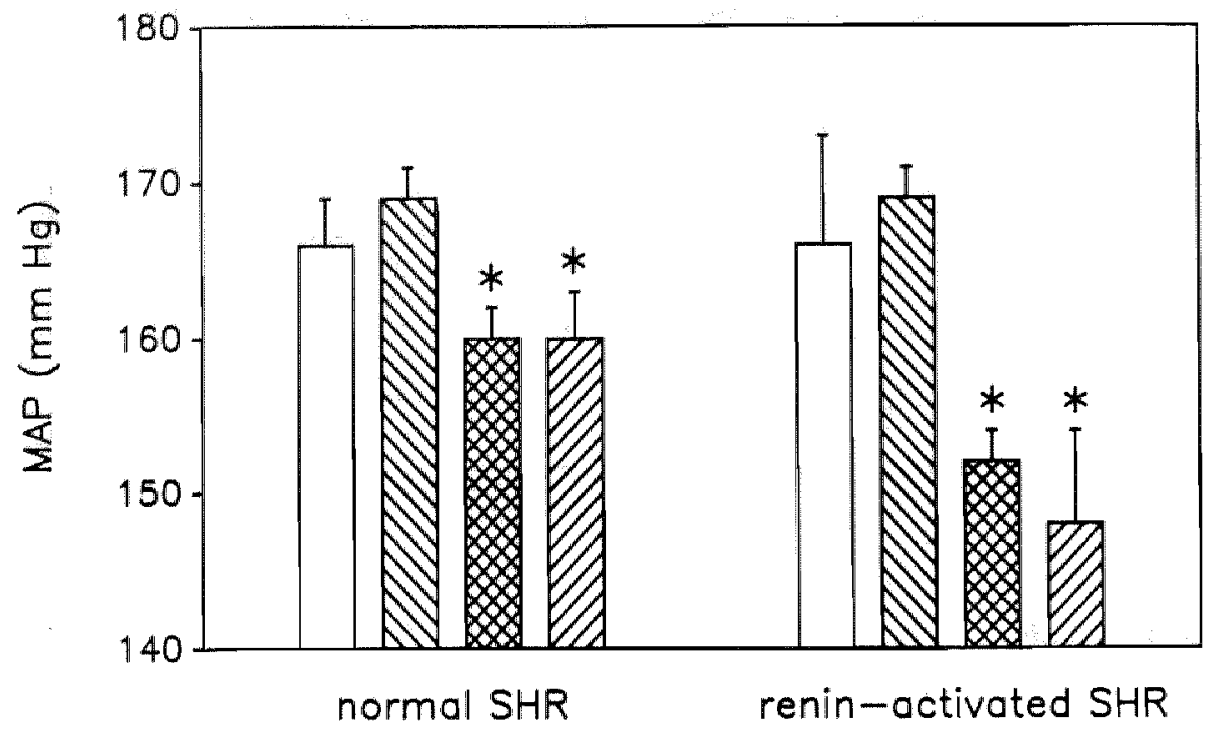

Figure 7.6 Effects of losartan on mean arterial pressure (MAP) in normal $(n=7)$ and reninactivated SHR $(n=7)$. * $p<0.05$ vs. baseline MAP.

activated SHR. Furthermore, as cited above, losartan antagonised an AII-induced pressor effect independent of the model used, but caused an acute reduction of blood pressure only in renin-dependent hypertensive models. In renin-independent hypertensive models such as the DOCA-hypertensive rat (Wong et al., 1990b) or in various normotensive rats (Wong et al., 1990a,c; Batin et al., 1991), losartan did not lower MAP.

We did not observe an effect of losartan on microwascular diameter, except for a dilatation of distal A3.A4 arterioles in renin-activated SHR. This indicates a lack of an effect of this drug on striated muscle vasculature in normal SHR. This is in accordance with an absence of an effect on hindlimb flow but with an increase in renal flow in Brattleboro rats (Batin et al., 1991) and resembles the effects of ACEinhibition.

Moreover, levels of AII increased by infusion or by activation of the RAS did not cause striated muscle microvascular constriction. In the in situ cremaster muscle preparation of normotensive Sprague-Dawley rats, Vicaut and co-workers (1989) were able to evoke a constriction by intra-arterial injection of AII in A3 to A5 arterioles $(<30 \mu \mathrm{m})$ but not in A2 arterioles (approximately $55 \mu \mathrm{m}$ ). This 


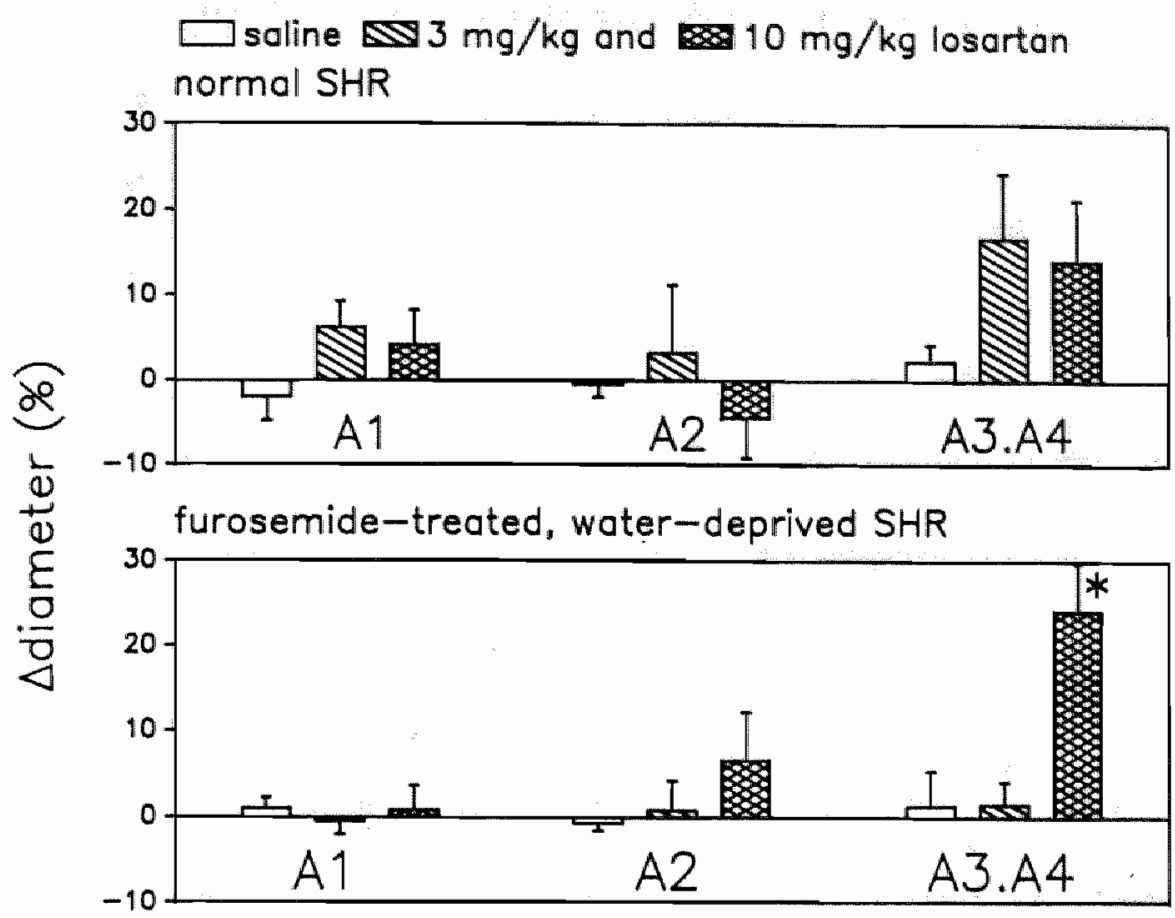

Figure 7.7 Effects of losartan on arteriolar diameters in normal and renin-activated SHR.

discrepancy may be caused by the relatively high dosages of AII used in the latter study. We chose doses that increased blood pressure, but were still within a physiological range. However, together with our results, these observations indicate that in rats the RAS does not play a role in striated muscle microvascular tone regulation of larger arterioles and that the sensitivity of smaller arterioles may depend on various factors such as strain, tissue or experimental conditions.

Taken together, the acute effects of captopril, enalaprilat and losartan on cutaneous maximus muscle microvascular diameter in conscious SHR are small in comparison to those of other drugs in similar blood pressure decreasing ranges. Dihydropyridine calcium antagonists (Messing et al., 1991, chapter 4) caused significant dilatations of $\mathrm{A} 2$ and A3.A4 arterioles, while larger arterioles dilated after a higher degree of blood pressure decrease. The potassium channel opener lemakalim (chapter 5) induced similar effects. Studies with selective $\alpha$-adrenoceptor antagonists (Messing et al., 1990, chapter 6) revealed that in this model $\alpha_{-1}$ adrenoceptors are likelly to be restricted to larger arterioles and venules and that $\alpha_{-2}$ adrenoceptors are present throughout the arteriolar, but not the venullar microvessels. These results indicate that mechanisms that are involved in microvascular tone regulation contribute to a different extent at individual microvascular levels. Thus, 
at the level of the simallest arterioles calcium and potassium and $\alpha$-adrenergic mechanisms are important whereas All is not.

As for the acute antihypertensive action of ACE-inhibitors and losartan, this study showed that the depressor effect is not exerted through an effect on striated muscle microvascular diameter. Renal effects most likely play an important role in this regard. In the long run, striated muscle may be important for the antihypertensive effect of these drugs because of the structural regression of vascular hypertrophy they can induce. This has been shown for captopril in the cremaster muscle of normotensive and renovascular hypertensive Wistar rats (Wang and Prewitt, 1990) and for losartan in SHR hindlimb vasculature (Friberg et al., 1991).

In conclusion, the ACE-inhibitors captopril and enalaprilat and the nonpeptide All receptor antagonist losartan in blood pressure lowering doses do not exert an acute effect on cutaneous maximus muscle microvascular diameter of conscious SHR except for a dilatation of small A3.A4 arterioles in renin-activated SHR. AII did not induce a change in microvascular diameter in this preparation. These results indicate that AII does not contribute to microvascular tone in striated muscle of conscious SHR under normal conditions, while in the renin-activated state the contribution of All is restricted to the smallest arterioles. 


\section{CHAPTER 8}

\section{General discussion}

In this thesis, pharmacological studies on mechanisms that contribute to microvascular resistance in experimental, genetic hypertension are described. The experiments were performed on the microvasculature of the cutaneous maximus muscle of the spontaneously hypertensive rat (SHR). Regulation of microvascular resistance results from a complex, integrated interplay of a diversity of factors (Bohr and Webb, 1986; Folkow, 1991). Perturbations of microvascular resistance control play an important role in the pathogenesis and maintenance of hypertension (Schmid-Schönbein and Chien, 1986). Microvascular resistance depends on structural and functional factors. Structural factors are the anatomy of the microvascular network and the structure of the microvascular wall. Functionally vascular smooth muscle cell activity determines vascular resistance. These factors have been evaluated using vasoactive compounds that were in general antihypertensive drugs, belonging to different drug classes. Each of these substances interferes with a specific mechanism involved in microvascular resistance control.

In hypertension, alterations in functional as well as structural properties of the microcirculation have been observed. These alterations comprised a decreased diameter of large arterioles (Harper and Bohlen, 1984; Engelson et al., 1986; Meininger et al., 1986) and rarefaction of small arterioles (Hutchins and Darnell, 1974; Henrich et al., 1978; Prewitt et al., 1982). The morphometric comparison of the SHR cutaneous maximus muscle microvasculature with that of its normotensive counterpart, the Wistar Kyoto rat (WKY) revealed that the main alteration was a major decrease in diameter of large (A1 and A2) arterioles (chapter 3). Furthermore, as shown by infusion of the calcium antagonist felodipine, the dilating capacity of the largest (A1) arterioles was significantly elevated. However, after dilatation the diameters of the large arterioles in SHR were still smaller than those in WKY. This suggests a structural component in the decreased arteriolar diameter size in combination with an increased tone. Dilatation also revealed an increasing degree of tone going from large to small arterioles, both in WKY and SHR. This is in agreement with an increasing myogenic activity towards the smallest arterioles (Johnson, 1991). Reactivity and diameter size of small (A3.A4) arterioles were unchanged. However, the number of small arterioles had increased, possibly in an attempt to compensate for the increased resistance in the large arterioles. In addition to the increase in number, functional rarefaction of small arterioles was found, i.e. part of the small arterioles is completely constricted in the control 
situation. This suggests that the augmented vasoconstrictor activity of large arterioles is somehow carried on to a part of the small arterioles, causing rarefaction. The largest impact on resistance in the cutaneous maximus muscle, however, is exerted by the decreased diameters of the large arterioles. Thus, it is suggested that in this muscle the microwascular alterations that occur in hypertension are primarily located in the flow distributing $\mathrm{A} 1$ and $\mathrm{A} 2$ arterioles and not in the flow regulating A3.A4 arterioles. Based on these findings, large arterioles should therefore be a primary target for antihypertensive therapy. Reactivity of the affected vessels can thereby be normalised on a short term basis. During chronic therapy, structural changes, which we did not specifically investigate, should normalise as well..

Vascular smooth muscle cell activity is the functional factor that determines vascular resistance. This activity is regulated by several control mechanisms as discussed in section 1.1.4. They all increase the sarcoplasmic free calcium ion concentration. Free calcium plays a key role in vascular smooth muscle cell activity (see section 1.2.1). An elevated calcium concentration leads to contraction, a reduced concentration leads to dilatation. Calcium can be released from the sarcoplasmic reticulum, or it can flow into the sarcoplasm from the extracellular space through specific calcium channels. Calcium antagonists block the influx of extracellular calcium and thus in a direct way induce a decrease in sarcoplasmic calcium concentration. The vasodilatations elicited in this way (chapter 4) were restricted to the arteriolar vasculature and were strongest in small arterioles. Furthermore, vasomotion, a myogenic phenomenon exhibited in this preparation by small but not by large arterioles was extinguished by calcium antagonists.

Similar data were obtained with the potassium channel opener lemakalim. This drug has a direct effect on membrane potential, and through this on calcium channels. In the resting vascular smooth muscle cell, the membrane potential is between $-50 \mathrm{mV}$ and $-60 \mathrm{mV}$. Depolarisation increases the influx of extracellular calcium, which leads to contraction. Hyperpolarisation decreases calcium influx and leads to relaxation. Potassium channel openers, such as Jemakalim, enhance efflux of potassium ions. Thus, the sarcoplasm looses positive charge, leading to a hyperpolarisation of the sarcolemma. This inhibits calcium ion influx and thereby causes vasodilatation. Administration of lemakalim resulted in arteriolar dilatation which was strongest in the small arterioles (chapter 5). No effects on diameter were seen on the venular side of the microvasculature.

These data show that calcium antagonists as well as lemakalim exert their strongest effect on those microvessels that possess the highest degree of tone. In essence, basal tone in these vessels results from myogenic activity (Folkow, 1991). Vasomotion, exhibited by the small arterioles, is also a myogenic phenomenon. These observations indicate that myogenic activity is dependent on influx of extracellular calcium. Thus, myogenic mechanisms are important in the vascular mode of action of calcium antagonists and lemakalim.

The other drugs investigated for this thesis influence the intracellular free calcium concentration by interfering with second messenger systems. Compounds 
Sensitivity to:

calcium antagonists

lemakalim

$\alpha_{1}$-adrenergic drugs

$\alpha_{2}$ adrenergic drugs

angiotensin II inhibition
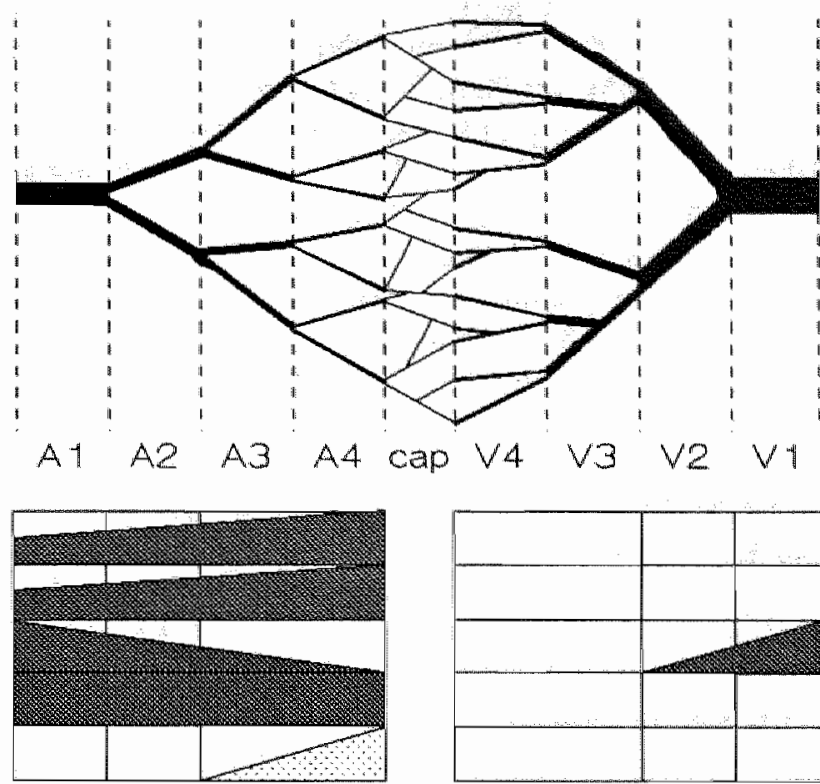

Fig 8.1 Schematic representation of the microcirculation. The Al and A2 arterioles are inwolwed in blood flow distribution; the A3 and A4 arterioles regulate local blood flow; the V4 an V3 venules have a draining function and the V2 and VI wenules are blood callecting and capinance vessels. Under basal conditions, most drugs had a differential effect on microwasular diameter, as indicaned by the shaded areas. Inhibition of angiotensin II had no effect; only after activation of the reninangiotensin system the angiotensin II receptor antagomist losartan dilated small arterioles (stippled area).

with a second messenger function are the cyclic nucleotides CAMP and cGMP, and substances that result from hydrolysis of phosphatidyl inositol biphosphate ( $\left.\mathrm{PIP}_{2}\right)$. We did not investigate drugs that affect cGMP levels. Endogenous substances that cause vasodilatation through an increase in cGMP levels are EDRF (Rapoport and Murad, 1983) and ANP (Winquist et al., 1984).

As specified in chapter $6, \alpha$-adrenoceptors exist as an $\alpha_{1^{-}}$and an $\alpha_{2}$-subtype. Each of them is assumed to be coupled to a different second messenger system. Using specific agonists and antagonists, a differential distribution of $\alpha$-adrenergic reactivity was found, namely a predominance of $\alpha_{1}$-adrenergic reactivity on large arterioles and large venules, while $\alpha_{2}$ adrenergic reactivity was observed in the entire arteriolar, but not in the venular microvasculature. It is noteworthy that the results of the antagonists study correspond very well with the agonists study. The $\alpha_{1}$-adrenoceptor is coupled to the second messenger system that leads to the formation of inositol triphosphate, a second messenger that induces the release of calcium from intracellular stores. Thus, $\alpha_{1}$-mediated contraction is not, or at least not solely, dependent on influx of extracellular calcium. Alpha ${ }_{2}$-mediated contrac- 
tion, on the other hand, relies to a higher degree on influx of extracellular calcium. Thus, $\alpha$-adrenergic mechanisms in small arterioles are more dependent on calcium influx than those in large arterioles. Furthermore, $\alpha_{2}$-adrenoceptors are more sensitive to a variety of lacal metabolic and physical factors than $\alpha_{1}$-adrenoceptors (Faber and McGillivray, 1988; Faber and Meininger, 1990; McGilliwray-Anderson and Faber, 1991). In mixed populations of $\alpha_{1}$-and $\alpha_{2}$ adrenoceptors in arterioles, neural regulation is preferentially mediated through the $\alpha_{1}$-adrenoceptor (Ohyanagi et al., 1991). This indicates that $\alpha_{2}$-adrenoceptors are more involved in local blood flow regulation than $\alpha_{1}$-adrenoceptors.

Finally, using various ways of antagonising angiotensin II, no significant contribution of this hormone to microvascular tone was found under basal conditions (chapter 7). This lack of effect of angiotensin II antagonism was found despite a significant blood pressure lowering effect of both the ACE-inhibitors as well as losartan. Only after activation of the renin-angiotensin system, a contribution of angiotensin II to small arteriolar tone was found. In the haemorrhage experiment described in chapter 6 , it was found that blood pressure lowering as such does not induce microvascular diameter changes in the depressor range comparable to most of the drug induced blood pressure decreases. Therefore, it can be concluded that the microvascular drug effects observed were all drug-specific, not influenced significantly by the blood pressure decrease as such.

The results of our experiments are summarised in fig. 8.1, the completed version of the open scheme presented in section 1.4. In the cutaneous maximus muscle microvasculature of SHR the A1 and A2 arterioles form an arcading meshwork and are involved in blood distribution within the muscle as a whole. Therefore, they have to be sensitive not only to local stimuli, but to remote control as well. Their sensitivity to local stimuli is shown by the vasodilating action of drugs that interfere with transmembrane ion transport, such as calcium antagonists and lemakalim. Remote control of A1 and A2 arterioles is mediated through $\alpha_{1}$-adrenergic mechanisms. Although these vessels also showed $\alpha_{2}$-adrenergic reactivity, it has been reported that neural regulation of large arterioles is preferentially mediated through $\alpha_{1}$-adrenoceptors (Ohyanagi et al., 1991). Alpha ${ }_{1}$-adrenoceptors are also abundant on arteries (Langer and Hicks, 1984). Thus, the $\alpha_{1}$-adrenergic reactivity of large arterioles indicates that they are still part of the systemic blood distributing vasculature.

The A3 and A4 arterioles regulate blood flow at a local level. They are relatively insensitive to remote control, but are sensitive to local stimuli. Thus, while flow through the organ as a whole may remain constant, local flow may fluctuate. In one part of the tissue, A3.A4 arterioles may dilate, while simultaneously they may constrict in an adjacent region. Vasomotion, i.e. rhythmic diameter variations, was exhibited by these small arterioles, and is a myogenic mechanism through which flow regulation is mediated. The sensitivity of A3.A4 arterioles to local stimuli is shown by their strong sensitivity to calcium antagonists and lemakalim, and the low $\alpha_{1}$-adrenergic reactivity. Alpha ${ }_{2}$-adrenergic reactivity, on the other hand, is large. The $\alpha_{2}$-adrenoceptor has been shown to be especially sensitive to a large variety of 
metabolic and physical factors (Faber and McGillivray, 1988; Faber and Meininger, 1990; McGillivray-Anderson and Faber, 1991). The contribution of angiotensin II to A3.A4 arteriolar tone regulation was only significant after activation of the reninangiotensin system. Thus, under these conditions, local flow may be minimised in order to maintain systemic blood pressure.

At the venular side, the scheme is rather empty. This is not surprising because of the absence of a significant degree of vascular tone. The function of the V3.V4 venules is draining of blood from the capillary bed. In addition, an exchange function may be assumed. V2 and V1 venules collect the blood from the muscle tissue and conduct it to the veins. They also have a capacitance function, which means that blood can be recruited from these vessels by nervous reflex mechanisms. The $\alpha_{1}$-adrenergic reactivity of the $\mathrm{V} 2$ and $\mathrm{V} 1$ venules probably underlies this property. In hypertension, capillary pressure is usually normal. This means that the microvascular alterations at the arteriolar side of the microcirculation have protected the capillary bed providing normal metabolic exchange.

As has been proposed above, antihypertensive therapy should be aimed at the large arterioles. Drugs that interfere with local mechanisms are specific candidates for such therapy. The $\alpha_{1}$-adrenoceptor antagonists not only dilate large arterioles, but also arteries, and are therefore not suitable. Calcium antagonists, potassium channel openers and $\alpha_{2}$-adrenoceptor antagonists answer the requirement. These drugs dilate large arterioles, and also dilate small arterioles, which is as such not required but may nevertheless be inevitable. In this sense, dihydropyridine calcium antagonists seem more effective than verapamil. They do not only have a more specific effect on the vasculature in striated muscle, but also seem more effective in dilating large arterioles than verapamil. Alpha 2 -adrenoceptor antagonists with a specific effect on postsynaptic receptors are likely to be more effective than the present ones that also exert presynaptic and/or central actions.

Future research on the present model should also include the investigation of chronic effects of antihypertensive treatment. Also, a more detailed analysis of the structural features of the microvascular network should be made, in SHR as well as in WKY rats. Such an analysis should include histological studies of the microvasculature in order to obtain data on wall structure. Valuable information could be obtained from studies on rats with other forms of experimental hypertension. Furthermore, this model allows prolonged in vivo studies of arterioles. This could provide a helpful reference frame for in vitro studies on the same kind of vessels.

The model provides an intact striated muscle microvascular bed in conscious rats that is continuously available for intravital microscopic observations. The most exciting future application of our model is therefore the investigation of long term microcirculatory effects of antihypertensive treatment. 


\section{CHAPTER 9}

\section{References}

Abdel-Latif AA, 1989: Calcium-mobilizing receptors, polyphosphoinositides, generation of second messengers and contraction in the mammalian iris smooth musle: historical perspectives and current status. Life Sci: 45: 757-786

Alilguist RP, 1948: A study on adrenotropic receptors. Am J Physiol; 153: 586-600

Algire 6, 1943: An adaptation of the transparent chamber technique to the mouse. J Natl Cancer Inst; 4: $1-11$

Angersbach $\mathrm{D}$, Nicholson $\mathrm{CD}, 1988$ : Enhancement of muscle blood cell flux and $\mathrm{pO}_{2}$ by cromakalim (BRL 34915) and other compounds enhancing membrane $\mathrm{K}^{+}$conductance, but not by $\mathrm{Ca}^{2+}$ antagonists or hydralazine, in an animal model of occlusive arterial disease. Naunyn Schmiedeberg's Arch Pharmacol; 337: 341 -346

Arfors KE, Jonsson JA, McKenzie FN, 1970: A titanium rabbit ear chamber: Assembly, insertion and results. Microvase Res; 2: $\$ 16-519$

Baez is, 1973: An open cremaster muscle preparation for study of blood vessels by in vivo microscopy. Microvase Res; 5: 384-394

Baker CH, Nastuk WL, 1986: Microcirculatory technology. Academic Press, Inc.; Orlando, FL, USA

Batin P, Gardiner SM, Compton AM, Bennett T, 1991: Differential regional haemodynamic effects of the non-peptide angiotensin II antagonist, DuP 753, in water-replete and water-deprived Battleboro rats. Life Sci; 48: 733-739

Benjamin N, Vallance P, 1991 : Local control of human peripheral vascular tone: implications for drug therapy. Clin Sci; 80: 183-190

Berridge MJ, Galione A, 1988: Cytosolic calcium oscillators. Faseb J; 2: 3074-3082

Birnbaumer $L, 1990$ : G Proteins in signal transduction. Annu Rev Pharmacol Toxicol; 30: 675-705

Blaustein MP, Hamlyn JM, 1991: Pathogenesis of essential hypertension. A link between dietary salt and high blood pressure. Hypertension; 18: III184-II1195

Boegehold MA, Kotchen TA, 1990a: Arteriolar network morphology in gracilis muscle of rats with salt-induced hypertension. Microvasc Res; 40:169-178

Boegehold MA, Kotchen TA, 1990b: Effect of dietary salt on the skeletal muscle microvasculature in Dahl rats. Hypertension; 15:420-426

Boegehold MA, Huffman LJ, Hedge GA, 1991a: Peripheral vascular resistance and regional blood flows in hypertensive Dahl rats. An J Physiol; 261: R934-R938

Boegehold MA, Johnson MD, Overbeck HW, 1991b: Pressure-independent arteriolar rarefaction in hypertension. Am J Physiol; 261: H83-H87

Boger J, 1987: Clinical goal in sight for small mollecule renin inhibitors. TiPS; $8: 370-372$

Bohlen $\mathrm{HG}_{3}, 1983$ : Intestinal microvascular adlaptation during maturation of spontaneously hypertensive rats. Hypertension; 5: 739-745

Botilen $\mathrm{HG}$, 1989: The microcirculation in hypertension. J Hypertension; 7: S117-S124

Bohlen HG, Gore RW, 1976: Preparation of rat intestinal muscle and mucosa for quantitative microcirculatory studies. Microvase Res; 11: 103-110

Bohr DF, Webb RC, 1986: Physiological mechanisms regulating peripheral vascular resistance. in: Handbook of hypertension, vol 7, Zanchetti A, Tarazi RC, eds. Elsevier, Amsterdam, the Netherlands. pp 311-337

Bollinger A, Fagrell B, 1990: Clinical capillaroscopy. Hogrefe \& Huber Publishers, Toronto, Canada 
Boonen HCM, De Mey JGR, 1990: Increased calcium sensitivity in isolated resistance arteried from spontaneously hypertensive rats: effects of dihydropyridines. Eur I Pharmacol; $179: 403-412$

Bränemark PI, 1971: Intravasular anatomy of blood cells in man. Karger; Basel, Switzerland

Bramemark PI, Eriksson $E_{3}$ 1972: Method for studying qualitative and quantitative changes of blood flow in skeletal muscle. Acta Physiol Scand; 84: 284-288

Brảnemark PI, Lindstrõm J, 1963: A modified rabbit"s ear chamber. High-power high-resolution studies in regenerated and preformed tissues. Anat Rec; $145: 533-540$

Brown MJ, 1988: Sites of action of alpha agonists and antagonists. Am J Cardiol; 61: 18D-21D

Bumpus FM, Catt KJ, Chiu AT, DeGasparo M, Goodfriend Th Husain A, Peach MJ, Taylor DG, Timmermans PBMWM, 1991: Nomenclature for angiotensin receptors. Hypertension; 17: 720 -721.

Bunkenburg B, Schnell C, Baum H-P, Cumin F, Wood JM, 1991: Prolonged angiotensin II antagonism in spontaneously hypertensive rats. Hypertension; 18: 278-288

Cauvin $C$, Loutzenhitzer $R$, wan Breemen $C_{s}$ 1983: Mechanisms of calcium channel antagonist induced vasodilatation. Annu Rev Pharmacol Toxicol; 23: 373-396

Chambers R, Zweifach BW, 1944: Topography and function of the mesenteric capillary circulation. Am J Anat; 75: 173-205

Chen II, Prewitt RL, Dowell $\mathrm{RF}_{*}$ 1981: Microvascular rarefaction in spontaneously hypertensive rat cremaster muscle. Ann J Physiol; 241: H306-H310

Chen LQ, Shepherd AP, 1991: Role of $\mathrm{H}^{+}$and alpha ${ }_{2}$-receptors in escape from sympathetic vasoconstriction. Am J Physiol; 261: H868-H873

Chilian WM, 1991: Functional distribution of alpha $1^{-}$and alpha $a_{2}$-adrenergic receptors in the coronary microcirculation. Circ Res; 84: 2108-2122

Chiu AT, Herblin WF, McCall DE, Ardecky RJ, Carini DJ, Pease LJ, Wong PC, Wexler RR, Johnson AL, Timmermans PBMWM, 1989: Identification of angiotensin II receptor subtypes. Biochem Biophys Res Com; 165: 196-203

Chung $O$, Schips $T, 1991$ : The transgenic mRen2 rat: cardiovascular characterization. Naunyn Schmiedeberg's Arch Pharmacol; 343: R73

Clapham JC, Buckingham RE, 1988: The hemodynamic profile of cromakalim in the cat. J Cardiovasc Pharmacol; 8: 798

Coffman JD, 1991: Raynaud's Phenomenon. An Update. Hypertension; 17: 593-602

Colantuoni A, Bertuglia S, Intaglietta M, 1984: The effects of alpha- or beta-adrenergic receptor agonists and antagonists and calcium entry blockers on the spontaneous vasomotion. Microvasc Res; 28: $143-158$

Cook NS, 1990: Potassium channels. Structure, classification, function and therapeutic potential. Ellis Horwood Limited, Chichester, West Sussex, England

Cushman DW, Wang FL, Fung WC, Harvey CM, DeForrest JM, 1989: Differentiation of angiotensin-converting enzyme (ACE) inhibitors by their selective inhibition of ACE in physiologically important target organs. Am J Hypertension; 2: 294-306

Daniel EE, Shi AG, Wang, ZL, Guan YY, Hoo K, Cargoe EJ, Kwan CY, 1991: Alpha-adrenoceptors in vascular smooth muscle: all is not well. Blood Vessells; $28: 104-114$

DeClerck F, Loots W, Voeten J, Janssen PAJ, 1989: Differential effects of verapamil and flunarazine on epinephrine-induced vasoconistriction and on spontaneous vasomotion of arterioles in skeletal muscle in the rat in vivo. J Cardiowasc Pharmacol; 13:76-83

DeFouw DO, Rizzo VJ, Steinfeld R, Feinberg RN, 1989: Mapping of the microcirculation on the chick chorioallantoic membrane during normal angiogenesis. Microvasc Res; 38: 136-147

DeLano FA, Schmid-Schönbein. GW, Skalak TC, Zweifach BW, 1991 : Penetration of systemic blood pressure into the microvasculature of rat skeletal muscle. Microvasc. Res; $41: 92-110$

De Mey J, Vanhoutte PM, 1981: Uneven distribution of postjunctional alpha $1^{-}$and alpha $2^{-1 \text { like }}$ adrenoceptors in canine arterial and wenous smooth muscle. Circ Res; 48: 875-884

D'Oyley HM, Pang CCY, 1990: Effects of alpha $\mathrm{i}^{-}$and alphat ${ }_{2}$-adrenoceptor antagonists on venous tone in conscious rats. Eur J Pharmacol; 182: 283-290 


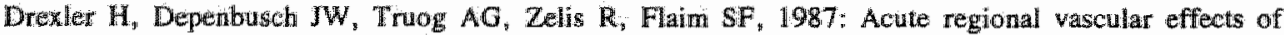
intravemous captopril in a rat model of myocardial infarction and failure. J Pharmacol Exp Ther; 241 : $13-19$

Duling $\mathbb{B R}_{3}$ 1973: The preparation and use of the hamster cheek pouch for studies of the microcirculation. Microvase Res; $5: 423-429$

Dusseau IW, Hutchins PM, 1989: Microvascular response to chronic hypoxia by the chick chorioallantoic membrane. A morphometric analysis. Microvase Res; $37 ; 138-147$

Dusseau $\mathrm{JW}$, Hutchins PM, Malbasa DS, 1986: Stimulation of angiogenesis by adenosine on the chick chorioallantoic membrane. Circ Res; 59: 163-170

Duty $\$$, Weston A, 1990: Potassium channel openers. Pharmacological effects and future uses. Drugs; 40: 785.791

Dzau WJ, 1990: Multiple pathways of angiotensin production in the blood vessel wall: evidence, possibilities and hypothesis. I Hypertension; 7: 933-936

Edwards G, Weston AH, 1990: Structure-activity relationships of $\mathrm{K}^{*}$ channel openers. TiPS; 11: $417-422$

Egleme C, Cressier F, Wood JM, 1990: Local formation of angiotensin II in the rat aorta: effect of endothelium. Br J Pharmacol; 100: 237-240

Endrich B, Asaishi $K$, Gotz A, Messmer K, 1980: Technical report. A new chamber technique for microvascular studies in unanesthetized hamsters. Res Exp Med (Berl); 177: 125-134

Engelson ET, Schmid-Schönbein GW, Zweifach BW, 1985a: The microvasculature in skeletal muscle. III. Venous network anatonomy in normotensive and spontaneously hypertensive rats. Int J Microcirc Clin Exp; 4: 229-248

Engelson ET, Skalak TC, Schmid-Schönbein GW, 1985b: The microcirculation in skeletal muscle. $Y_{\text {. }}$ Arteriolar network in rat spimotrapezius nausle. Microvasc Res; $30: 29-44$

Engelson ET, Schmid-Schönbein GW, Zweifach BW, 1986: The microvasculature in skeletal muscle II. Arteriolar network amatomy in normotensive and spontaneously hypertensive rats. Microvase Res ${ }^{*} 31$ : 356-374

Evenwel RT, Kasbergen CM, Struyker Boudier HAJ, 1983: Central and regional hemodynamics and plasma volume distribution during the developement of spontaneous hypertension in rats. Clin Exp Hypertension; A5: 1511-1536

Faber JE, 1988a: Effect of local tissue cooling on microvascular smooth muscle and postjunctional

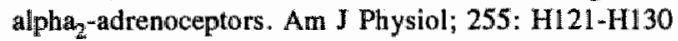

Faber JE, 1988b: In situ analysis of alpha-adrenoceptors on arteriolar and venular smooth muscle in rat skeletal muscle microcirculation. Circ Res; $62: 37-50$

Faber JE, McGillivray KM, 1988: Distribution and control of alpha-adrenoceptor function in the microcirculation: effect of temperature, $\mathrm{pH}$, and atrial natriuretic factor. in: Resistance Arteries, Halpern W, Pegram BL, Brayden JE, Mackey K, Mclaughlin MK, Osol $G$, eds. Perinatology Press; Ithaca, NY, USA. pp 119-128

Faber JE, Meininger GA, 1990: Selective interaction of alpha-adrenoceptors with myogenic regulation of microvascular smooth muscle. An J Physiol; 259: Hill 26-H1133

Folkow B, 1982: Physiological aspects of primary hypertension. Physiol Rev; 62: 347-504

Folkow B, 1991: The resistance vasculature. in: The resistance vasculature, Bevan JA, Halpern W, Mulvany MJ, edss. Humana Press; Totowa, NJ, USA. pp 23-43

Folkow B, Hansson L, Johansson B, 1989: Myogenic mechanisms in the control of systemie resistance. J Hypertension; 7: $\$ 1$

Forbes HS, 1928: The cerebral circulation I. Observation and measurement of pial vessels. Arch Neurol Psychiatry; 19: 751-761

Friberg P, Wahlander H, Adams MA, Sohtell M, 1991: Influence of chronic angiotensin II-receptor antagonism on blood pressure and cardiovascular structure in SHR. Proceedings of the VII International Symposium on SHR and related studies; Lyon, France. P59 (abstract)

Fulton GP, Jackson RG, Lutz BR, 1946: Cinephotomicroscopy of normal blood circulation in the cheek pouch of the hamster, Cricetus auratus. Anat Rec; $96: 537$ 
Ganten D, Takahashi ST, Lindpaintmer K, Mullins $J$, 1991: Genetic basis of bypertension. The renin-amgiotensin paradigm. Hypertension; 18: IM109-1II114

Gray SD, 1973: Rat spinotrapezius muscle preparation for microseopic observation of the teminal viascular bed. Mierovase Res; 5: $395-400$

Greene AS, Tonellato PJ, Lui J, Lombard JH, Cowley AW, 1989: Microvascular rarefaction and tissue vascular resistance in bypertension. Am J Physiol; 256: H126-H131

Grega GJ, Adamski SW, 1987: Patterns of constriction produced by vasoactive agents. Fed Proo; 46: $270-275$

Gustafsson D, 1987: Microvascular mechanisms involved in calcium channel antagonist edema formation. J Cardiovase Pharmacol; 10: S121-S131

Gustafsson D, Grănde P-O, Borgström $\mathbb{P}$, Lindberg $L$, 1988: Effects of calciun channel antagonists on myogenic and neurogenic control of resistance and capitance vessels in cat skeletal muscle. I Cardiovase Pharmacol; 12: 413-422

Gustafsson D, Länne T, Bjerkholl P, Johansson P, Lundvall J, 1989: Microvascular effects and oedema formation of felodipine in man. J Hypertension; 7: S161-S167

Haack DW, Schaffer JJ, Simpson JG, 1980: Comparisons of eutaneous microvessels from spontaneously hypertensive, normotensive Wistar-Kyoto, and normal Wistar rats. Proe Soc Exp Biol Med; 164: $453-458$

Haberl RL, Decker PJ, Einhaeupl KM, 1991 : Angiotensin degradation products mediate endothelium-dependent dilatation of rabbit brain arterioles. Circ Res; 68: 1621-1627

Hansen-Smith F, Greene AS, Cowley AW, Lombard JH, 1990: Structural changes during microvascular rarefaction in chronic hypertension. Hypertension; 15: $922-928$

Harper RN, Moore MA, Marr MC "Watts LE, Hutchins PM, 1978: Arteriolar rarefaction in the conjuctiva of human essential hypertensiwes. Microvase Res; 16: 369-372

Harper SL, Bohlen HG, 1984: Microvascular adaptation in the cerebral cortex of adult spontaneously hypertensive rats. Hypertension; 6: 408-419

Hashimoto H, Prewitt RL, Efaw CW, 1987: Alterations in the microvasculature of one-kidney, one-clip hypertensive rats. Am J Physiol; 253: H933-H940

Henrich $H$, Hecke A, 1978: A gracilis muscle preparation for quantitative microcirculatory studies in the rat. Microvase Res; 15:349-356

Henrich H, Hertel $R$, Assmann R, 1978: Structural Differences in the mesentery microcirculation between normotensive and spontaneously hypertensive rats. Pflügers Arch; 375: 153-159

Henrich HA, Romen W, Heimgärtner K, Hartung E, Bäumer F, 1988: Capillary rarefaction characteristic of the skeletal muscle of hypertensive patients. Klin Wschr; 66: 54-60

Heusch G, Deussen A, Schipke J, Thaemer V, 1984: Alpha - and alpha - -adrenoceptor-mediated vasoconstriction of large and small canine arteries in vivo. J Cardiovasc Pharmacol; 6: 961-968

Higashimori $K$, Gante J, Holzemann G, Inagami T, 1991: Significance of vascular renin for local generation of angiotensins. Hypertemsion; 17: 270-277

Hilbert P, Lindpainter K, Beckmann JS, Serikawa T, Soubrier F, Dubay C, Cartwright P, De Gouyon $B$, Julier C, Takahasi $S$, Vincent $M$, Ganten D, Georges $M$, Lathrop $G_{n}$ 1991: Chromosomal mapping of two genetic loci associated with blood-pressure regulation in hereditary hypertensive rats. Nature; 353: $5211-529$

Hutchins $\mathrm{PM}_{\text {, Darmell }} \mathrm{AE}$, 1974: Observations of a decreased number of small arterioles in

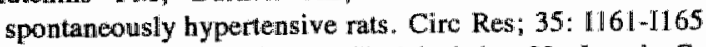

Hutchins PM, Marshburn TH, Maultsby SJ, Lynch C, Smith TL, Dusseau JW, 1988: Long-term microvascular response to hydralazine in spontaneously hypertensive rats. Hypertension; 12: 74-79

Hutehins PM, Lynch CD, Maultsby SJ, 1991: Chronic microvascular preparations for local application. of pharmacological agents. Blood Vessels; $28: 297$

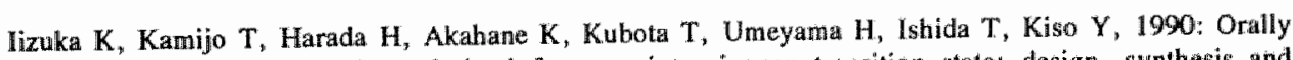
potent human renin inhibitors derived from angiotensinogen transition state: design, synthesis and mode of interaction. J Med Chem; 33: 2707-2714 
Intaglietta $M$, Tompkins WR, 1973: Microvascular measurements by vidleo image shearing and splitting. Microvase Res; $5: 309-312$

Irwin JW, MacDonald J, 1953: Microscopic observations of the intrahepatic circulation of living guinea pirgs. Anat Rec; 117: 1-15

Jackson T, 1991: Structure and function of $G$ protein coupled receptors. Pharmac Ther; 50: $425-442$

Jacob HI, Lindpainter K, Lincoln SE, Kusumi K, Bunker RK, Mao Y-P, Ganten D, Dzau VJ, Lander ES, 1991: Genetic mapping of a gene causing hypertension in the stroke-prone spontaneously hypertengive rat. Cell; $67: 213-224$

Jaiswal N, Tallant EA, Diz Dr, Khosla MC, Ferrario CM, 1991: Subtype 2 angiotensin receptors: mediate prostaglandin synthesis in human astrocytes. Hypertension; 17: 1115-1120

Johnson PC, 1991: "The myogenic response. in: The resistance vasculature, Bevan JA, Halpern W, Mulvany MJ, eds. Humana Press; Totowa, NJ, USA. pp 159-168

Johansson B, 1989: Myogenic tone and reactivity: definitions based on muscle physiology. J Hypertension; 7: $55-\$ 8$

Jones Tw, 1852: Discovery that the weins of the bat"s wing are endowed with rythmical contractility" and that onward flow of blood is accelerated by each contraction. Trans $\mathbb{R}$ Soc; 142: 131-136

Julou $\mathrm{G}$, Fresion JL, 1986: Effects of calcium chanmel entry blockers on $\mathrm{Ca}^{2+}$ induced contraction of depolarized and moradrenaline exposed rat resistance vessels. Eur J Pharmacol; 129: 261-270

Juul B, Aalkjer C. Mulvany MJ, 1987: Responses of femoral resistance vessels to angiotensin in vitro. Eur J Pharmacol; 135: 61-68

Kajioka S, Nakashima M, Kitamura K, Kuriyama H, 1991: Mechanisms of vasodilatation induced by potassium-channel activators. Clin Sci; 81: 129-139

Knisely MH, 1936: Spleen studies. I. Microscopic observations of the circulatory system of liwing unstimulated mammalian spleens. Anat Rec; 65: 23-50

Kvist S, Mulvany MJ, Aalkjar C, 1991: Studies of the renin-angiotensin system in the wall of rat femoral resistance vessels. Eur J Pharmacol; 198: 77-83

Laher I, Bevan JA, 1989: Stretch of vascular smooth muscle activates tone and ${ }^{45} \mathrm{Ca}^{2+}$ influx. J Hypertension; 7: S17-S20

Lamb FS, Nyers JH, Hamlin MN, Webb RC, 1985: Oscillatory contractions in tail arteries from genetically hypertensive rats. Hypertension; 7: $125-130$

Langer SZ, Hicks PE, 1984: Alpha-adrenoceptor subtypes in blood vessels: physiology and pharmacology. I Cardiovasc Res; 6 S547-S558

Lee RE, Holze EA, 1950: The peripherall vascular system in the bulbar conjunctiva of young normotensive adults at rest. J Clin Invest; $29: 146-150$

Levasseur JE, Wel EP, Raper AJ, Kontos HA, Patterson JL, 1975: Detail description of a cranial window techaique for acute and chromic experiments. Stroke; $6: 308-317$

Lombard JH, Roman RJ, 1990: Assessment of muscle blood flow by laser-Doppler flowmetry during henorrhage in SHR. Am J Pliysiol; 259: H860-H865

Lombard JH, Hinojosa-Laborde C, Cowley AW, 1989: Hemodynamics and microcirculatory alterations in reduced renal mass hypertension. Hypertension; 13: 128-138

Majno G, Gilmore $V$, Leventhal $M, 1967$ : A technique for the microscopic study of blood wessels in living striated muscle (cremaster). Circ Res; $21: 823-832$

Marshall JM, 1982: The influence of the sympathetic nervous system on individual vessels of the microcirculation of skeletal muscle of the rat. J Physiol; 332: 169-186

Marshall JM, 1991: The venous vessels within skeletal muscle. NiPS; 6: 11-15

Martini J, Honig CR, 1969: Direct measurement of intercapillary distance in beating rat heart in situ under various conditions of $\mathrm{O}_{2}$ supply. Microvasc Res; 1 : 315-323

MeGilliwray-Anderson KM, Faber JE, 1990: Effects of acidosis on contraction of microvascular smooth muscle by alpha - and alpha $_{2}$-adrenoceptors. Circ Res; 66: 1643-1657 
MicGillivray-Anderson KM, Faber IE, 1991: Effect of reduced blood flow on alphi ${ }^{-}$and

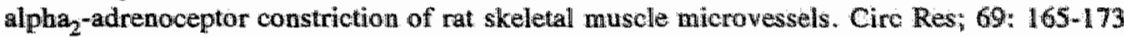

Meininger GA, Harris PD, Joshua 1G, 1984: Distributions of microvascular pressure in skeletal musole of one-kidney, one clip, two-kidney, one clip, and deoxycorticosterone-stalt hypertensive rats. Hypertension; 6: 27-34

Meininger GA, Fehr $\mathbb{K L}_{\text {, Y }}$ Yates MB, Borders JL, Granger $\mathrm{HJ}$, 1986: Hemodynamic characteristics of the intestinal microcirculation in renal hypertension. Hypertension; 8: 66-75

Messing MWJ, van Essen H, Struyker Boudier HAJ, 1991: Microvaseular actions of antihypertensive drugs. in: Resistance arteries. Structure and function, Mulvany MJ, Aalkjer C, Heagerty AM, Nyborg NCB, Strandgaard S, eds. Elsevier Science Publishers BV; Ansterdam, the Netherlands. pp 270-274

Messing MWJ, van Essen H, Struyker Boudier HAJ, 1990: Effects of alpha-adrenoceptor antagonists on striated muscle microcirculation of conscious rats. Drugs: 40 (suppl 4): $31-33$

Messing MWJ, van Essen H, Smith TL, Smits JFM, Struyker Boudier HAJ, 1991: Microvasular actions of calcium channel antagonists. Eur I Pharmacol; 198: 189-195

Minneman KP, 1988: Alpha,-adrenergic receptor subtypes, inositol phosphates, and sources of cell $\mathrm{Ca}^{2+}$. Pharmacol Rev; 40: 87-119

Mizuno K, Nakamura M, Higashimori K, Inagami $T$, 1988: Local generation and release of angiotensin II in peripheral vascular tissue. Hypertension; 11: 223-229

Muller AF, Gardiner SM, Compton AM, Bennett $T$, 1990: Regional haemodynamic effects of captprill, enalaprilat and lisinopril in conscious water-replete and water-deprived Battleboro rats. Clin Sci; 79 : 393-401

Mulvany $\mathbf{M J}, 1990$ : Structure and function of small arteries in hypertension. J Hypertension; 8: $\$ 225-\$ 232$

Mulvany MJ, 1991a: Are vascular abnormalities a primary cause or secondary consequence of hypertension. Hypertension; 18: 152-157

Mulvany MJ, 1991b: Direct actions of angiotensin II on vascular tone: a brief review. in: Current advances in ACE inhibition 2, 1 st ed, MacGregor GA, Sever PS, eds. Churchill Livingstone, Edinburgh London Melbourne New York and Tokyo. pp 15-19

Mulvany $\mathrm{MJ}$, Nyborg $\mathrm{N}, 1980$ : An increased calcium sensitivity of mesenteric resistance vessels in young and adult spontaneously hypertensive rats. Br J Pharmacol; 71: 585-596

Murray KJ, 1990: Cyclic AMP and mechamisms of vasodilation. Pharmac Ther; 47: 329-345

Myers TO, Joyner WL, Gilmore JP, 1988: Angiotensin reactivity in the cheek pouch of renovascular hypertensive hamster. Hypertension; 12: 373-379

Nelissen-Vrancken HJMG, Struyker Boudier HAJ, Smits JFM, 1992: Renal hemodynamic effects of non-hypotensive doses of angiotensin-converting enzyme inhibitors in hypertension and heart failure rats. J Cardiowasc Pharmacol; 19: 163-168

Nelson MT, Patlak JB, Worley JF, Standen NB, 1990: Caicium channels, potassium channels, and voltage dependence of arterial smooth muscle tone. Am J Physiol; 259: C3-C18

Nichols AJ, Motley ED, Ruffolo RR, 1989: Effect of pertussis toxin treatment on postjunctional alphatand alpha ${ }_{2}$ adrenoceptor function in the cardiovascular system of the pithed rat. $J$ Pharmacol Exp Ther; 249: 203-209

Nielsen $H_{*}$ Thom SMcG, Hughes AD, Martin GN, Mulvany MJ, Sever PS, 1989: Postjunctional alpha $\mathrm{a}_{2}$-adrenoceptors mediate vasoconstriction in human subcutaneous resistance vessels. Br J Pharmacol; 97: 829-834

Nielsen H, Mortensen FV, Mulvany MJ, 1990a: Differential distribution of postjunctional alpha 2 adrenoceptors in human omental small arteries. J Cardiovase Pharmacol; 16: 34-40

Nielsen $\mathbf{H}_{4}$ Mortensen FV, Mulvany MJ, 1990b: Responses to noradrenaline in buman subcutaneous resistance arteries are mediated by both alpha, ${ }^{-}$and alpha ${ }_{2}$-adrenoceptors. Br I Pharmacol; 99: $31-34$

Nielsen H, Hasenkam JM, Pilegaard HK, Mortensen FV, Mulvany MJ, 1991: Alpha-adrenoceptors in human resistance arteries from colon, pericardial fat, and skeletal muscle. Am J Physiol; 261: H762-H767 
Nievelstein HMNW; wan Essen H, Tyssen CM, Smits JFM, Struyker Boudier, 1985: Systenic and regional hemodynamic actions of calcium entry blockers in conscious sponianeously hypertensive rats. Eur I Pharmacol; il $13: 187-198$

Nishigaki K, Faber JE, Ohyamagi $M, 1991$ : Occlusion of cremaster collateral circulation alters microwascular reactivity. Microwase Res; $41: 173-183$

le Noble FAC, Hekking JWM, van Straaten HWM, Slaaf DW, Struyker Boudier HAJ, 1991: Angiotensin II gtimulates angiogenesis in the chorio-allantoic membrane of the chick embryo. Eur J Pharmacot, 195; $305-306$

le Noble FAC, Schreurs N, van Straten HWM, Slaaf DW, Smits JFM, Struyker Boudier HAJ, 1992: Angiotensin II induced angiogenesis is not mediated through the $A T_{1}$ receptor. Faseb $\mathrm{J}_{\text {; }}$ in press

le Noble JLML, Smith TL, Hutchins PM, Struyker Boudier HAJ, 1990a: Microvascular alterations in adult conscious apontaneously hypertensive rats. Hypertension; 15: 415419

le Noble JLML, Tangelder GJ, Slaaf DW, van Essen H, Reneman RS, Struyker Boudier HAJ, 1990b: A functional morphometric study of the cremaster muscle micracirculation in young spontaneously hypertensive rats. J Hypertension; 8: $741-748$

Nordlander MIL, 1989: Inilibition of vascular myogenic tone and reactivity by calcium antagonists. $J$ Hypertension; 7: \$1141-\$145

Nyborg NCB, Mulvany MJ, 1984: Effect of felodipine, a new dihydropyridine vasodilator, on contractile responses to potassium, noradrenaline and calcium in mesenteric resistance vessels of the trat. I Cardiovase Pharmacol; 6: 499-505

Nyborg NCB, Nielsen PJ, Prieto D, Benedito S, 1990: Angiotensin II does not contract bovine retinal resistance arteries in vitro. Exp Eye Res; 50: 469-474

Ohyanagi M, Faber JE, Nishigaki $\mathbb{K}, 1991$ : Differential activation of alpha - and alpha $_{2}$-adrenoceptors on microvascular smooth musele during sympathetic nerwe stimulation. Circ Res; $68: 232-244$

Okamota K, Aoki K, 1963: Developement of a strain of spontameously hypertensive rats. Jpn Circ J; 27: 282.293

Ondetti MA, 1991: Angiotensin converting enzyme inhibitors. An overview. Hypertension; 18: III134-IIII 35

Ono $Z_{n}$ Prewitt RL, Stacey DL, 1989: Arteriolar changes in developing and chronic stages of two-kidney, one clip hypertension. Hypertension; 14: 36-43

O'Rourke M, 1990: Arterial stiffness, systolic blood pressure, and logical treatment of arterial hpertension. Hypertension; 15: 339-347

Osol G, 1991: Myogenic properties of blaod vessels in vitro. in: The resistance vasculature, Bevan JA, Halpern W, Mulvany MJ, eds. Humana Press; Totowa, NJ, USA. pp $143-157$

Oude Vrielink HHE, 1988: Vasomotion and skeletal perfusion. PhD thesis, University of Limburg, Maastricht, the Netherlands

Paoleti R, Vanhoutte PM, 1987: International symposium on calcium antagonists. Pharmacology and clinical research, New York City 1987

Papenfuss HD, Gross JF, Intaglietta M, Treese FA, 1979: A transparent access chamber for the rat dorsal skin fold. Microwasc Res; $18: 311-318$

Pickering TO, 1990: Does psychological stress contribute to the developement of hypertension and coronary heart disease? Eur J Clin Pharmacol; 39: S1-\$7

Prewitt RL, Chen IIH, Dowell R, 1982: Development of microvascular rarefaction in the spontaneously hypertensive rat. Am J Physiol; 251: H243-H251

Prewitt $\mathrm{RL}$, Chen IIIN, Dowell $\mathrm{RF}_{\text {, }}$ 1984: Microvascular alterations in the one-kidney, one-clip renal hypertensive rat. Am J Physiol; 246: H728-H732

Rapoport RM, Murad F, 1983: Agonist-induced endothelium-dependent relaxation in the rat thoracic aorta may be mediated through cGMP. Cire Res; $52: 352-357$

Raymond JR, Hnatowich M, Lefkowitz RJ, Caron MG, 1990: Adrenergic receptors models for regulation of signal transduction processes. Hypertension; 15: 119-131 
Reilly TM, Wong PC, Price WA, Timmermans PBMWM, 1988: Characterization of the functional antagonism and antihypertensive activity displayed by a monoclonal antibody to angiotensin $\mathrm{I}$. I Pharmacol Exp Ther; 244: 160-165

Reneman RS, Slaaf DW, Lindbom L, Tangelder G, Arfors K-E, 1980: Muscle blood flow disturbances produced by simultaneously elevated venous and total muscle tissue preissure. Microwaso Res; 20: 307-318

Rhodin JAG, 1980: Architecture of the vessel wall. in: Handbook of Physiolgy wol II $_{\text {, Bohr DF, }}$ Somlyo AP, Sparks HV J $r_{7}$ eds. American Physiological Society, Bethesda, MD, USA. pp 1-30

Richer C, Pratz J, Mulder $P$, Mondot S, Giudicelli JF, Cavero I, 1990: Cardiovascular and biological effects of $\mathrm{K}^{+}$channel openers, a class of drugs with vasorelaxant and cardioprotective properties. Life Sci; 47: 1693-1705

Richer $C_{p}$ Doussau M-P, Giudicelli J-F, 1987: Systemic and regional hemodyramic profile of five angiotensin I converting enzyme inhibitors in the spontaneously hypertensive rat. Am I Cardiol; 59: 12D-17D

Rosenberg A, Guth PH, 1970: A method for the in vivo study of the gastric microcirculation. Microvase Res; 2: 111-112

Safar ME, London GM, Asmar RG, Hugues CJ, Laurent SA, 1986: An indireet approach for the study of the elastic modulus of the brachial artery in patients with essential hypertension. Cardiovase Res; 20: 563-567

Sanders $\mathrm{AG}_{3}$ 1963: Microcirculation in grafts of normal and malignant tissue. J Anat; 97 : 631-632

Sanders $A G$, Shubik $P$, 1964: A transparent window for use in the Syrian bamster. Isr J Exp Med: 11: 118

Sandison JC, 1924: A new method for the microscopic study of living growing tissues by the introduction of a transparent chamber in the rabbit's ear. Anat Rec; $28: 281-287$

Sandison JC, 1928: The transparent chamber of the rabbit's ear, giving a complete description of improved technique of construction and introduction, and general account of growth and behavior of living cells and tissues as seen with the microscope. Am J Anat; $41: 447-473$

Schmid-Schönbein GW, Chien $S, 1986$ : The microcirculation in hypertension. in: Handbook of Hypertension, vol 7: Pathophysiology of Hypertension - Cardiovascular Aspects, Zanchetti A, Tarazi $\mathrm{RC}_{\text {, }}$ eds. Elsevier Science Publishers BV; Amsterdam, the Netherlans. pp $465-489$

Schmid-Schönbein GW, Zweifach BW, 1991: Biophysical framework of the microcirculation as an organized functional unit in skeletal muscle: Topology, pressure, tone, resistancce. in": Resistance arteries, structure and function, Mulvany MJ, Aalkjer C, Haegerty AM, Nyborg NCB, Strandgaard S, eds. Elsevier Science Publishers BV; Amsterdam, the Netherlands. pp 65-68

Schmid-Schönbein GW, Seiffge D, DeLano FA, Shen K, Zweifach BW, 1991: Leukocyte counts and activation in spontaneously hypertensive and normotensive rats. Hypentension; $17: 323-330$

Seidelin PH, Collier JG, Struthers AD, Webb DJ, 1991: Angiotensin 11 augments sympathetically mediated arteriolar constriction in man. Clin Sci; $81: 261-266$

Sewell 1,1966 : Studies of the microcirculation using transparent tissue observation chambers inserted in the hamster cheek pouch. I Anat; 100: 839-856

Shi A-G, Ahmad S, Kwan Y, Daniel EE, 1990. Alphawadrenoceptors in dog mesenteric vessels -subcellular distribution and number of $\left[^{3} \mathrm{H}\right.$ prazosin and $\left[{ }^{3} \mathrm{H}\right]$ rauwolscine binding sites. I Cardiovasc Pharmacol; 15: 515-526

Smith TL, Osborne SW, Hutchins PM, 1985: Long-term micro- and macrocirculatory measurements in conscious rats. Microvasc Res; 29: 360-370

Smits JFM, Struyker Boudier HAJ, 1984: Systemic and regional hemodynamics following acute inhibition of angiotensin I-converting enzyme in the conscious spontaneously hypertensive rat. Prog Pharmacol; 5: 39-49

Sokolova IA, Manukhina EB, Blinkov SM, Koshelev VB, Pinelis VG, Rodionov IM, 1985: Rarefaction of the arterioles and capillary network in the brain of rats with different forms of hypertension. Microvasc Res; 30: 1-9

Stacey DL, Prewitt RL, 1989: Attenuated microvascular alterations in coarctation hypertension. Am J Physiol; 256: H213-H221 
Steinhausen $M$, Snoei $H$, Parekh $N$, Baker $R$, Johnson PC, 1983: Hydronephrosis: A new method to visualize vas afferens, efferens, and glomerular network. Kidney Int; 23: 794-806

Streetem DHP, Anderson GH $I_{r}$, 1984: Angiotensin-receptor blocking drugs, in: Handbook of hypertension, woll 5, Clinical phartnacology of anthypertensive drugs, Doyle AE, ed. Elsevier Science Publishers BV; Amsterdam, the Netherlands. pp 246-271

Struyker Boudier HAJ, De Mey JGR, Smits JFM, Nievelstein HMNW, 1989: Hemodynamic actions of calcium entry blockers. Prog Basic Clin Pharmacol, 2: 21-66

Struyker Boudier HAJ, van Bortel LMAB, De Mey JGR, 1990a: Remodeling of the vascular tree in hypertension: drug effects. TiPS; 11: 240-245

Struyker Boudier HAJ, Messing MWJ, wan Essen H, 1990b: Potassium channel activation and small arteriolar dilatation in conscious spontaneously hypertensive rats. Int J Microcirc Clin Exp: 9: 176

Struyker Boudier HAJ, Smits JPM, De Mey JGR, 1990e: The pharmacology of calcium antagonists: a review. $J$ Cardiovasc Pharmacol; $15:$ S1-S10

Sullivan JM, Prewitt RL, Josephs JA, 1983: Attenuation of the microcirculation in young patients with high output borderline hypertension. Hypertension; 5: 844-851

Suttoin DW, Schmid-Schönbein GW, 1990" In skeletal muscle microcirculation the additional pressure drop per granulocyte is about 1000 times that of an erythrocyte (abstract). Faseb J; 4: A287

Teranishi $\Psi$, Shimamoto $\mathrm{H}$, Iriuchijima $J, 1988$ : Acute effects of captoril on blood pressure and regional blood flows in two types of renowascular hypertensive rats in conscious state. Jap J Physiol; 38: $777-785$

Timmermans PBMWM, Carini DJ, Chiu AT, Duncia JV, Price WA, Wells GJ, Wong PC, Wexler RR, Johnson $A L$, 1991: Angiotensin II receptor antagonists. From drug discovery to antihypertensive drugs. Hypertension; 18: 111136-1II 42

Torres Filho IP, Boegehold MA, Bouskela E, House SD, Johnson PC, 1989 : Microcirculatory responses in cat sartorius muscle to hemorrhagic hypotension. Am J Physiol; 257: H1647-H1655

Tsien RW, Ellinor PT, Horne WA, 1991: Mollecular diversity of woltage-dependent $\mathrm{Ca}^{2+}$ channels. TiPS; 12: 349-354

Vicaut E, Stucker O, 1990: An intact cremaster muscle preparation for studying the microcirculation by in viwo microscopy. Microvasc Res; 39: 120-122

Vicaut E, Montalescot G, Hou X, Stucker O, Teisseire B, 1989: Arteriolar vasoconstriction and tachyphilaxis with intraarterial angiotensin II. Microvase Res; 37: 28-41

Wallenstein S, Zucker $\mathrm{CI}_{p}$ Fleiss JL, 1980: Some statistical methods useful in circulation research. Circ Res; 47: 1-9

Wang D H, Prewitt RL, 1990: Captoprill reduces aortic and microvascular growth in hypertensive and normotensive rats. Hypertension; 15: 68-77

Watson S, Abbott A, 1992: TiPS Receptor Nomenclature Supplement, January 1992

Wearn JT, Ernstene AC, Bromer AW, Barr JS, German WJ, Zschiesche LJ, 1934: The normal behawior of the pulmonary blood vessels with observations on the intermittence of the blood flow in the arterioles and capillaries. Am J Physiol; 109: 226-256

Webb DJ, Benjamin N, Vallanee P, 1989: The potassium channel opening drug cromakalim produces arterioselective vasodilation in the upper limbs of healthy volunteers. $\mathrm{Br} J$ Clin Pharmacol; 27: $757-761$

Weber AH, Fitch-Burke MC, Harriugton DG, Shah $J, 1990$ : No rarefaction of cerebral arterioles in hypertensive rats. Can J Physiol Pharmacol; 68: 476-479

Whitebread S, Mele M, Kamber B, de Gasparo M, 1989: Preliminary biochemical characterization of two angiotensin II receptor subtypes. Biochem Biophys Res Com; 163: 284-291

Wiedeman MP, Tuma RF, Mayrovitz HN, 1981: An introduction to microcirculation, vol 2. Biophysics and bioengeneering series, Noordergraaf A, ed. Academic press, inc.; New York, NY, USA

Wiederhielm CA, Slaaf DW, 1987: A new skeletal muscle preparation for the study of microwascular function in intact unanesthetized animals. Microvase Res; 33: 413-416

Willette RN, Hieble JP, Sauermelch CF, 1991: The role of alpha adrenoceptor subtypes in sympathetic 
control of the acral-cutaneous microcirculation. I Pharmacol Exp Ther 256: 599 605

Williams RG, 1934: An adaptation of the transparent chamber to the skin of the body. Anat Ree: 60 : 493-499

Winquist RJ, Faison EP, Waldman SA, Schwartz K, Murad F, Rapoport RM, 1984: Atrial natriuretic factor elicits an endothelium-independent relaxation and activates particulate guarylate oyclase in vascular smooth muscle. Proc Natl Acad Sci; 81: 7661-7664

Wong PC, Price WA, Chiu AT, Duncia JV, Carini DJ, Wexler RR, Johnson AL, Timmermans PBMWM, 1989: Nonpeptide angiotensin II receptor antagonists. VIII. Characterization of functional antagonism displayed by DuP 753, an orally active antihypertensive agent. J Pharmacol Exp Ther; 252: 719-725

Wong PC, Price WA, Chiu AT, Duncia IV, Carini DJ, Wexler RR, Johnson AL, Timmermans PBMWM, 1990a: Hypotensive action of DuP 753, an angiotensin II antagonist, in spontaneously hypertensive rats. Hypertension; 15: 459-468

Wong PC, Price WA, Chiu AT, Duncia JV, Carini DJ, Wexler RR, Johnson AL, Timmermans PBMWM, 1990b; Nonpeptide angiotensin II receptor antagonists. IX. Antilypertensiwe activity in rats of DuP 753, an orally active antihypertensive agent. J Pharmacol Exp Ther; 252: 726-732

Wong PC, Price WA, Chiu AT, Duncia JV, Carini DJ, Wexler RR, Johnson AL, Timmermans PBMWM, 1990c: Nonpeptide angiotensin II receptor antagonists. VIII. Claaracterization of functional antagonism displayed by DuP 753 , an orally active antihypertensive agent. I Pharmacol Exp Ther; 252: 719-725

Wong PC, Reilly TM, Timmermans PBMWM, 1990d: Angiotensin II monodlonal antibody: blood pressure effects in normotensive and spontaneously hypertensive rats. Eur J Pharmacol; 186: 353-356

Wood AJJ, 1989: Calcium antagonists Pharmacological differences and similarities. Circulation; 80: IV184-IV188

Xiu R-J, Jun C, Berglund O, 1991: Microcirculatory disturbances in AlDS patients - A firșt report. Microvase Res; 42: 151-159

Yamaura H, Suzuki $M$, Sato $H$, 1971: Transparent chamber in the rat skin for studies on microcirculation in cancer tissues. Gann; 62: 177-185

Yuan X-Q, Smith TL, Prough DS, DeWitt DS, Dusseau JW, Lynch CD, Fulton JM, Hutchins PM, 1990: Long-term effects of nimodipine on pial microvasculature and systemic circulation in conscious rats. Am J Physiol; 258: H1395-H1401

Zelis $\mathbb{R}_{\text {, Moore }} \mathbf{R}, 1989$ : Recent insights into calcium channels. Circulation; 80: IV14-IV16

Zweifach BW, 1983: The microcirculation in experimental hypertension. Hypertension; 5: 110-116

Zweifach BW, 1991: Vascular resistance. in: The resistance vasculature, Bevan JA, Halpern W" Mulvany MS, eds. Humana Press; Totowa, MU, USA. pp 1.22

Zweifach BW, Lipowsky HH, 1977: Quantitative studies of tnicrocirculatory structure and function. III.

Microvascular hemodynamics of cat mesentery and rabbit omentum. Cire Res; $41: 380-390$

van Zwieten PA, 1988: Pharmacology of the alpha $2_{2}$ adrenoceptor agonist rilmenidine. Am $\mathrm{f}$ Cardiol; 61: 6D-14D

van Zwieten PA, 1989a: Drugs interacting with aspha adrenoceptors. Cardiovase Drugs Ther; 3: $121-133$

wan Zwieten PA, 1989b: Pharmacological background of the therapeutic activities and side effects of calcium antagonists. in: Clinical aspects of calcium entry blockers, vol 2, van Zwieten PA, ed. Karger, Basel, Switzerland. pp 1-20 


\section{Chapter 10}

\section{Summary}

The microcirculation plays an important role in the pathogenesis and maintenance of hypertension. A variety of remote and local control systems is involved in vascular tone regulation in arterioles, the main site of resistance in the vascular system. Disturbances in these control systems lead to the elevated resistance present during hypertension. These disturbances can have a structural or a functional basis. A variety of antihypertensive drugs is used for treatment of hypertension. Little is known about the actions these drugs exert on the microcirculation, the affected part of the vasculature. In this thesis, the results are presented on experiments carried out to investigate what microvascular alterations are associated with hypertension and how several antihypertensive drugs act on the altered microvasculature. The microvascular preparation used was the intact cutaneous maximum muscle of conscious spontaneously hypertensive rats (SHR). To expose this muscle for intravital microscopic observations, a dorsal microcirculatory chamber was implanted on the dorsal skinfold of the rats. This methodology is described in detail in chapter 2.

The results of a morphological comparison of the cutaneous maximus muscle microvasculature in SHR and their normotensive counterpart, the Wistar Kyoto rat (WKY) are described in chapter 3. Differences in network anatomy have been shown to be minor. However, diameters of large arterioles were about $30 \%$ narrower in SHR, which is most likely the main cause of resistance increase in this tissue. These vessels are assumed to be mainly involved in blood flow distribution. Furthermore, vascular tone in large arterioles of SHR was elevated. Interestingly, there was no difference in reactivity or diameter size of small arterioles. However, the number of small arterioles was higher in SHR, while simultaneously functional rarefaction was present in SHR, but not in WKY. The main function of small arterioles is most likely regulation of blood flow at a local level. There were also no significant differences at the venular side of the microcirculation, except for an increase in number of small venules.

The remaining experimental chapters all report on the acute effects of systemic intravenous administration of antihypertensive drugs on microvascular diameter. Drugs that influence transmembrane ion transport, i.e. calcium antagonists (verapamil, nifedipine, and felodipine) and potassium channel openers (lemakalim), induced strong arteriolar dilatation with the strongest effect on small arterioles, while there was no effect on venular diameter (chapters 4 and 5). This indicates that vessels with a high degree of myogenic tone are most sensitive to disturbances in local mechanisms of vascular tone regulation. 
In chapter 6 , an analysis of $\alpha$-adrenergic reactivity of the microvasculature is given. This was done by measuring microvascular diameter changes induced by the specific $\alpha$-adrenergic agonists phenylephrine $\left(\alpha_{1}\right)$ and azepexolle $\left(\alpha_{2}\right)$, and antagonists prazosin $\left(\alpha_{1}\right)$ and yohimbine $\left(\alpha_{2}\right)$. Alpha ${ }_{1}$-adrenergic reactivity, which is preferentially under neural control, was present in large arterioles and large venules, but not in smaller vessels. Alpha ${ }_{2}$-adrenergic reactivity, which is very sensitive to changes in local environment, was found on the entire arteriolar, but not the venular side of the microvasculature. These differences in distribution of $\alpha_{1^{-}}$ and $\alpha_{2}$-adrenergic reactivity could be involved in differential tone regulation at different levels of the microvascular tree. Whole organ flow is partly under remote, neural regulation, while local flow is only sensitive to locall mechanisms.

Also in chapter 6, the microvascular effects of graded haemorrhage are presented. This non-pharmacological way of blood pressure reduction had no acute effects on microvascular diameters. Therefore, it can be concluded that the microvascular effects observed after drug administration were drug-specific and were not influenced by the depressor response as such.

Chapter 7 presents the results of experiments in which angiotensin II was antagonised in different ways. First, angiotensin II formation was inhibited using the angiotensin-converting enzyme (ACE) inhibitors captopril and enalaprilat. Secondly, the action of angiotensin II was antagonised with the non-peptide angiotensin II receptor antagonist losartan (until recently referred to as DuP 753). Furthermore, the acute effects of angiotensin II infusion were investigated. Although significant changes in blood pressure were observed, no significant changes in diameter of any type of microvessel was observed. Only in SHR with an activated renin-angiotensin system, a losartan-induced dilatation of small arterioles was seen. From these data, it is concluded that in normal SHR, angiotensin II does not contribute to microvascular tone of striated muscle microvessels.

It is concluded that in SHR striated muscle the main microvascular alterations are located at the level of the large arterioles. These vessels are mainly involved in blood flow distribution. The small arterioles, part of which are functionally rarefied, do not contribute to resistance increase. Pharmacological interventions as described here, generally affected the arteriolar, but not the venular microvasculature. Especially calcium antagonists, potassium channel openers, and $\alpha_{2}$-adrenoceptor antagonists are effective in dilating these arterioles. Although they do not specifically exert their action on the most affected arterioles, the large blood distributing ones, but also on smailer ones, these drugs seem the most rational ones for antihypertensive therapy. On an acute basis, they may normalise large arteriolar reactivity. After chronic therapy they should normalise, or at least increase large arteriolar baseline diameters.

More work is needed to further elucidate microvascular functional and structural changes that occur in the present model. The work should also be extended to other models of experimental hypertension. Prolonged in vivo observations of arterioles could also provide a helpful reference frame for in vitro studies of the same vessels. 
An intact striated muscle preparation in conscious rats is continuously available for intravital microscopic observations during a period of several weeks to months. Therefore, a most exciting future application that our model offers is to study long term microcirculatory effects of antihypertensive treatment. 


\section{HOOFDSTUK 11}

\section{Samenvatting}

\subsection{Antihypertensiva en de microcirculatie}

\subsubsection{Inleiding}

Hoge bloeddruk of hypertensie is een afwijking waaraan zo'n 15 tot $20 \%$ van de volwassen bevolking lijdt. De ernst van de afwijking is niet altijd zodanig dat behandeling met een geneesmiddel nodig is. Aanpassing van leef- en eetgewoonten kan al helpen. Voor gevallen waarin behandeling wel nodig is, zijn verschillende geneesmiddelen beschikbaar, die bekend staan onder de verzamelnaam antihypertensiva: geneesmiddelen tegen hoge bloeddruk.

Voordat antihypertensiva mogen worden voorgeschreven door de arts, worden ze uitgebreid onderzocht op hun werkzaamheid en eventuele schadelijke bijwerkingen. Dit gebeurt overigens met alle geneesmiddelen. Pas als een medicijn voldoende veilig is bevonden, mag het worden voorgeschreven. Dit betekent echter niet dat dan ook alle effecten van dat medicijn precies bekend zijn. Daarom blijft onderzoek van geneesmiddelen doorgaan, ook nadat ze al mogen worden voorgeschreven. Aan de hand van de resultaten kunnen geneesmiddelen verder verbeterd worden.

In dit proefschrift staan de resultaten beschreven van eem onderzoek naar de effecten van antihypertensiva op de microcirculatie. In het onderstaande zal eerst uitgelegd worden wat de microcirculatie precies is en wat het belang van de microcirculatie is bij bloeddrukregulatie. Vervolgens zal uitgelegd worden hoe de experimenten zijn uitgevoerd. Daarna volgt een korte beschrijving van de onderzochte antihypertensiva. In het laatste deel van deze samenvalting zullen de belangrijkste onderzoeksresultaten en de conclusies daaruit besproken worden.

\subsubsection{De microcirculatie: een deel van het bloedvatenstelsel}

Mensen en dieren beschikken over een bloedvatenstelsel (fig 11.1). Hierin stroomt het bloed rond met als doel weefsels en organen van voedingsstoffen te voorzien en afvalstoffen af te voeren. De bloedstroom wordt in stand gehouden door het hart. Het hart pompt het bloed in grote, stevige vaten, de slagaders of arteriën. Naar de weefsels en organen toe vertakken de arteriën zich in steeds kleinere vaten, de arteriolen. In de allerkleinste bloedvaten, de haarvaten of capillairen vindt de uitwisseling van voedings- en afvalstoffen plaats. Daarna 
stroomt het bloed terug naar het hart. Eerst door de kleine aders, de venulen, en geleidelijk aan door grote aders, de venen. In de longen wordt het bloed van zuurstof voorzien, waarna het weer het lichaam wordt ingepompt. De grote bloedvaten, dus de arteriën en venen, worden samen met het hart aangeduid als de macrocirculatie. Hierdoor vindt het transport van het bloed naar en van de organen en weefsels plaats.

De rest van het bloedvatenstelsel wordt aangeduid als de microcirculatie. De microcirculatie bestaat dus uit arteriolen, capillairen en venulen en ligt geheel binnenin de organen en weefsels (zie fig 11.1). Elke soort vat heeft een eigen functie. De arteriolen reguleren de doorbloeding van een orgaan, in de capillairen vindt de uitwisseling van voedings- en afvalstoffen plaats, en de venulen verzamelen het bloed dat het orgaan weer verlaat. De arteriolen reguleren de doorbloeding van een orgaan door hun diameter te variëren. Dit kunnen zij doen door de spierlaag in hun wand meer of minder samen te trekken. Arteriolen worden wijder als een orgaan actief is. Hierdoor wordt de bloedstroom vergroot, waardoor in de verhoogde behoefte aan zuurstof en voedingsstoffen kan worden voorzien. Komt het orgaan tot rust, dan vernauwen de arteriolen, waardoor de bloedstroom door dat orgaan weer afneemt.

\subsubsection{De bloeddruk}

Het hart pompt het bloed rond door het bloedvatenstelsel. Doordat dit stelsel een gesloten systeem is, ontstaat er door het pompen van het hart een druk, de bloeddruk. Deze druk is nodig om het bloed vanaf het hart naar de organen en weefsels te stuwen. Op zijn weg ondervindt het bloed weerstand, doordat het langs de vaatwanden wrijft. Hierdoor wordt het bloed afgeremd en hoe verder het bloed van het hart afkomt, des te lager de druk wordt. In de capillairen aangekomen is nog maar zo'n $10 \%$ van de begindruk over. Deze lage druk voorkomt dat de dunne wand van de capillairen beschadigd wordt, waardoor de uitwisseling van voedingsen afvalstoffen verstoord zou raken. De resterende druk is echter nog wel voldoende om het bloed terug te voeren naar het hart.

De hoogte van de bloeddruk wordt bepaald door twee factoren. Ten eerste is dit de hoeveelheid bloed die per minut uit het hart stroomt, het zogenaamde hartminuutvolume. Ten tweede is dit de weerstand die het bloed op zijn weg door het vaatstelsel ondervindt door het wrijven langs de vaatwanden. De weerstand die het vaatstelsel in zijn geheel veroorzaakt, wordt totale perifere weerstand genoemd. Hartminuutvolume en totale perifere weerstand bepalen dus de bloeddruk. Stijgt een van beide dan wordt de bloeddruk hoger. Onderzoek heeft aangetoond dat bij mensen met hypertensie meestal niet het hartminuutvolume, maar vooral de totale perifere weerstand is toegenomen. Dit betekent dat een goede regulatie van de totale perifere weerstand belangrijk is voor de handhaving van een normale bloeddruk. Hierbij speelt de microcirculatie een belangrijke rol, zoals in de volgende paragraaf zal worden uitgelegd. 


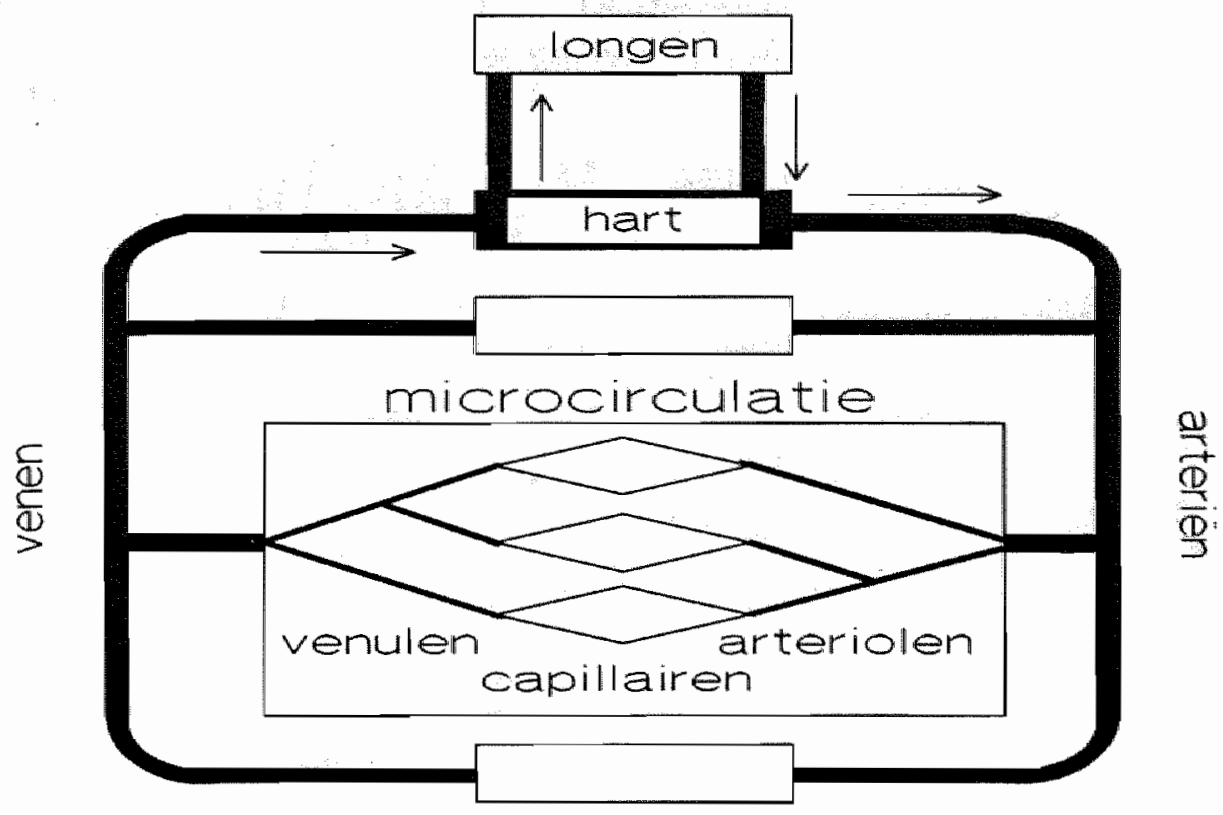

Figuur 11.I Een schematische weergave van het bloedvatenstelsel met daarin een aantal organen. In éen orgaan is de microcirculatie aangegeven.

\subsubsection{De microcirculatie en bloeddrukregulatie}

De totale perifere weerstand wordt bepaald door de weerstanden van de afzonderlijke bloedvaten en de manier waarop de bloedvaten in het bloedvatenstelsel zijn gerangschikt.

De weerstand van een bloedvat wordt voornamelijk bepaald door zijn diameter. Hoe groter de diameter, des te gemakkelijker het bloed door het vat kan stromen, dus hoe lager de weerstand. De weerstand zal in de grootste arterie, de aorta, dus laag zijn, en in de arteriolen hoog. De weerstand in het bloedvatenstelsel neemt echter in de richting van de arteriolen niet gelijkmatig toe. Dit komt doordat de aorta zich splitst in meerdere takken, die zich op hun beurt ook weer vertakken. Hierdoor neemt de diameter van de vaten wel steeds meer af, maar hun aantal neemt toe. Het bloed krijgt op deze manier steeds meer wegen ter beschikking om doorheen te stromen. Dit doet de weerstandstoename door de diameterafname deels weer teniet. De weerstandstoename wordt dus bepaald door het samenspel van diameterafname en toename van het aantal vaten. Onderzoek heeft aangetoond dat door dit samenspel de weerstand over de arteriën relatief klein is. Daardoor is er over de arteriën weinig drukverval. De weerstand over de arteriolen is echter groot, zodat er over deze vaten een groot drukverval plaatsvindt. De weerstand over de rest van het vaatstelsel is weer laag.

Het belangrijkste deel van de totale perifere weerstand ligt dus in de arteriolen van de microcirculatie. Bij hypertensie is de totale perifere weerstand verhoogd, 
wat voor een belangrijk deel veroorzaakt zal zijn door veranderingen in de arteriolen. Het kan zijn dat hun diameter is afgenomen of dat hun aantal kleiner is geworden. De experimenten die in dit proefschrift beschreven staan, zijn uitgevoerd op een spier van ratten met hypertensie. De hypertensie bij deze ratten ontstaat spontaan door een erfelijke afwijking, die door inteelt is ontstaan. Daarom worden ratten van deze stam aangeduid als spontaan hypertensieve ratten, afgekort SHR. Aangezien spieren in mens en dier de meest voorkomende weefselsoort zijn, zullen veranderingen in dit weefsel belangrijk kunnen bijdragen aan een verhoogde bloeddruk. Daarom is er in dit onderzoek voor gekozen de microcirculatie van een spier te bestuderen. Eerst is onderzocht, waarom de weerstand in deze spier is verhoogd en vervolgens wat de effecten van verschillende antihypertensiva op de microcirculatie van deze spier zijn. Daarbij is gekeken, of het bloeddrukverlagende effect van deze geneesmiddelen te verklaren is, doordat zij de weerstand in de microcirculatie verlagen.

\section{2}

\section{De uitvoering van de experimenten}

Bij onderzoek van de microcirculatie wordt gebruik gemaakt van een microscoop. Het zal echter duidelijk zijn dat kleine bloedvaatjes niet zomaar zichtbaar worden als een proefdier, meestal een rat of een ander knaagdier, onder de microscoop wordt gelegd. Door middel van een chirurgische ingreep moet een geschikt stukje weefsel vrijgeprepareerd worden. Om een dergelijke operatie mogelijk te maken moet het proefdier verdoofd worden. Meestal vindt aansluitend aan de operatie het experiment plaats. Deze procedure heeft als nadeel dat de toestand waarin de microcirculatie bestudeerd wordt, beïnvloed is door het verdovingsmiddel en door de chirurgische handelingen. Om dit probleem op te lossen is gebruik gemaakt van ratten met een huidkamer, zoals te zien is op de foto (fig 11.2). In de huidkamer is de microcirculatie van een huidspierlaag zichtbaar, die bestudeerd kan worden in wakkere ratten die hersteld zijn van de operatie. In hoofdstuk 2 staat beschreven, hoe de huidkamer geïmplanteerd wordt.

Tijdens de experimenten zitten de ratten in een speciale houder die in de microscoop wordt gezet. De houder is nodig om de ratten stil te laten zitten, zodat de huidkamer goed voor de lens van de microscoop blijft. De ratten zijn er op getraind in de houder te zitten en kunnen dat zonder problemen een aantal uren volhouden. Door de microscoop zijn de arteriolen en venulen zichtbaar. Capillairen zijn met de gebruikte apparatuur niet te zien. Aan de microscoop zijn een videocamera en een videorecorder gekoppeld. Voordat de rat een antihypertensivum krijgt toegediend, worden video-opnamen gemaakt van een aantal arteriolen en venulen. Na de toediening worden van dezelfde arteriolen en venulen weer opnamen gemaakt. $\mathrm{Na}$ het experiment worden de videobanden met een speciaal apparaat geanalyseerd. Hiermee kunnen de diameters van de vaatjes gemeten worden. Door nu van elk vat de diameter voor toediening te vergelijken met die na toediening is na te gaan of vaatverwijding in de huidspier een rol speelt bij het bloeddrukverla- 


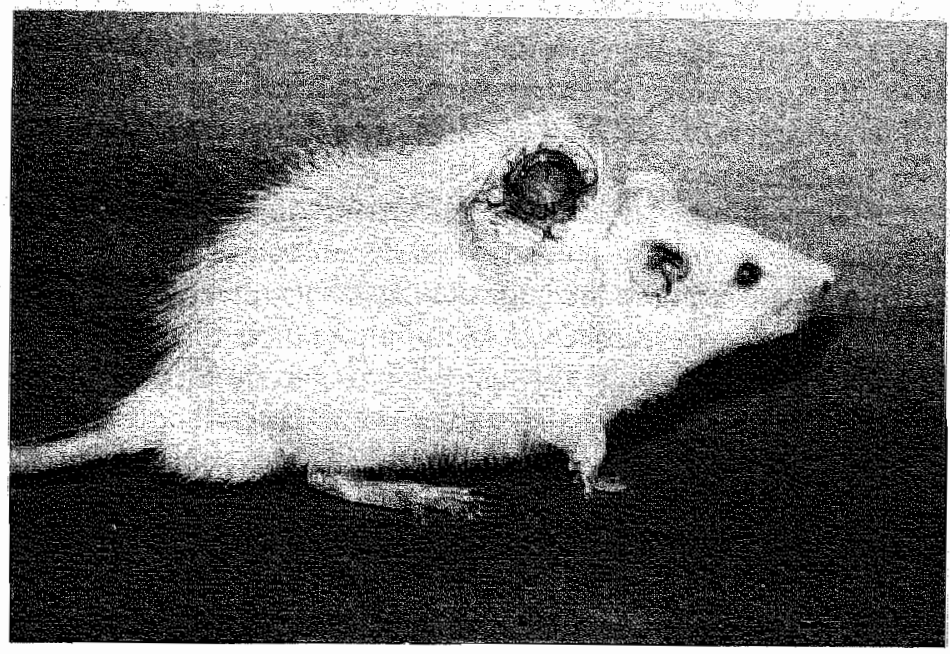

Figuur 11.2 Een rat met een huidkamer. In de huidkamer is de microcircuiarie van de huidspier zichtbaar.

gend effect van het onderzochte antihypertensivum. Om na te gaan of arteriolen en venulen van verschillende grootte even sterk reageren op het antihypertensivum worden ze ingedeeld naar grootte en vertakkingsgraad, zoals is aangegeven op de voorkant van dit proefschrift. De grootste arteriolen die de huidkamer binnen komen, worden A1 genoemd, hun zijtakken A2 en zo verder naar A3 en A4. Met de venulen wordt hetzelfde gedaan. De grootste zijn V1 en hun vertakkingen V2 en zo verder naar V3 en V4. Zo is dus voor elke klasse van vaatjes hun reactie op een antihypertensivum bepaald.

\subsection{De onderzochte antihypertensiva}

Antihypertensiva kunnen de kracht verminderen waarmee spiercellen in de vaatwand zich samentrekken. Daardoor worden de bloedvaten wijder en wordt de totale perifere weerstand lager, zodat de bloeddruk daalt. De mate waarin de vaatwand zich samentrekt, hangt af van een complex samenspel van diverse regelmechanismen. Dit betreft onder andere zenuwactiviteit en de concentratie in het bloed van hormonen en stofwisselingsproducten. Elk van deze mechanismen kan door een antihypertensivum beïnvloed worden. Dat betekent dat er veel verschillende manieren zijn waarop een bloeddrukdaling opgewekt kan worden.

Om te beginnen, is voor de samentrekking van een spiercel is calcium nodig. Vanuit de omgeving stroomt calcium door speciale kanalen de spiercel in. Er zijn antihypertensiva die deze kanalen direct of indirect blokkeren, zodat de spiercel niet meer kan samentrekken door gebrek aan calcium. Zulke antihypertensiva zijn bij de 
experimenten van de hoofdstukken 4 en 5 gebruikt.

Verder zijn er zijn in het lichaam verschillende hormonen die de vaatwand kunnen laten samentrekken. Hiertoe binden zij aan speciale structuren aan de buitenkant van de spiercel, de zogenaamde receptoren. Door deze binding worden de processen geactiveerd die de cel doen samentrekken. Een voorbeeld van zulke hormonen zijn adrenaline, dat vit de bijnieren afkomstig is, en noradrenaline, dat door zenuwuiteinden wordt vrijgezet. Van de receptor waar deze hormonen aan binden, de zogenaamde adrenoceptoren, bestaan verschillende subtypen. Deze subtypen verschillen in chemische structuur en hebben daardoor een verschillende gevoeligheid voor hun hormoon. Bij de regulatie van de bloedvatdiameter zijn twee subtypen van belang, de zogenaamde alf $a_{1}$ - en alfa $a_{2}$-adrenoceptor. Doordat beide subtypen niet overal in het bloedvatenstelsel evenveel voorkomen, is het mogelijk de diameter van bijvoorbeeld kleine arteriolen anders te reguleren dan die van grote arteriolen. In hoofdstuk 6 staan experimenten beschreven waarin de verdeling van alfa $_{1}{ }^{-}$en alfa $a_{2}$-adrenoceptoren in de microcirculatie van de huidspier van de SHR is onderzocht. Dit is gedaan met stoffen die qua structuur precies op het alfa $_{1}$ - of het alfa $_{2}$-subtype passen. Voor elk receptorsubtype betrof dit een antihypertensivum, dat dus vaatverwijding veroorzaakte, en een stof die de vaatwand kon doen samentrekken. Door nu na te gaan welke stof waar in de vaatboom een vaat verwijding of -vernauwing veroorzaakte, kon een uitspraak worden gedaan over de verdeling van beide receptorsubtypes.

Een ander hormoon dat betrokken is bij de bloeddrukregulatie, is angiotensine II. Het zorgt ervoor dat de bloeddruk op peil blijft als het te ver dreigt te gaan dalen. Angiotensine II wordt in een aantal stappen in de bloedbaan en in vele organen, gevormd. Er is een grote groep antihypertensiva die de bloeddruk kunnen verlagen door de vorming van angiotensine II te remmen. Daarnaast is er vrij onlangs een antihypertensivum ontwikkeld dat de werking van angiotensine II verhindert door de receptor voor dit hormoon te blokkeren. Beide soorten antihypertensiva zijn gebruikt om te onderzoeken wat de rol van angiotensine II is bij de weerstandsregulatie in de huidspier van de SHR. De resultaten van dit onderzoek staan beschreven in hoofdstuk 7.

\section{4}

\section{Resultaten en conclusies}

De ratten die gebruikt zijn krijgen door een erfelijke afwijking hypertensie. Dit gaat gepaard met een verhoging van de totale perifere weerstand. Om te beginnen is onderzocht waarom de weerstand in de huidspier, die in dit onderzoek bestudeerd is, verhoogd is. Dit is gedaan door het vaatpatroon van de huidspier van de hypertensieve ratten te vergelijken met dat van ratten van een verwante stam die geen hypertensie hebben, de zogenaamde Wistar-Kyoto rat, afgekort WKY. De resultaten van dit onderzoek staan beschreven in hoofdstuk 3 . De belangrijkste bevinding was dat de diameter van de grote arteriolen (A1 en A2) van de SHR zo"n $30 \%$ kleiner was, dan die van de WKY. Deze diameterafname is 
hoogst waarschijnlijk de belangrijkste oorzaak van een toegenomen weerstand in de huidspier van de SHR.

In de hoofdstukken 4 tot en met 7 staan de experimenten met antihypertensiva beschreven. Voor deze experimenten zijn alleen SHR gebruikt. Alle antihypertensiva zijn onderzocht in doseringen die de bloeddruk van de ratten verlaagden. Dit had bijna nooit invloed op de venulen, wat verklaard kan worden door het feit dat venulen geen rol spelen bij de weerstandsregulatie. Op de arteriolen hadden de antihypertensiva zeer uiteenlopende effecten. Meestal veroorzaakten zij een sterke vaatverwijding. Directe of indirecte blokkade van calcium-kanalen verwijdde de keinste arteriolen het sterkst, maar ook op de grote arteriolen waren er duidelijk meetbare effecten. De alfa 1 -adrenoceptor komt volgens de resultaten in zowel de grote arteriolen als de grote venulen voor, terwijl de alfa $\mathrm{a}_{2}$-adrenoceptor op de grote èn de kleine arteriolen, maar niet op de venulen voorkomt. Remming van de vorming van angiotensine II, en ook blokkade van zijn receptor had geen vaatverwijding tot gevolg. Dit duidt erop dat angiotensine II geen belangrijke rol speelt bij de weerstandsregulatie in de huidspier van de SHR

Uit deze resultaten kan geconcludeerd worden dat de mechanismen die betrokken zijn bij de bloeddrukregulatie, niet allemaal even sterk op de microcirculatie werken en dat er wat dit betreft zelfs binnen de microcirculatie verschillen bestaan. Bij hypertensie is het belangrijkste deel van de verhoging van de totale perifere weerstand in de microcirculatie gelegen. De totale perifere weerstand kan weer verlaagd worden door met een antihypertensivum die mechanismen van bloeddrukregulatie te remmen die hun sterkste invloed in de microcirculatie hebben. Daarom komen voor behandeling van hypertensie met name die antihypertensiva in aanmerking, die in de microcirculatie een sterke vaatverwijding veroorzaken. 


\section{Curriculum vitae}

12 augustus 1958

1970-1975

$1975-1978$

$1978-1979$

1980-1981

1981-1987

1988-1992

\author{
M.W.J. Messing
}

Geboren te Steenderen

HAVO aan het Baudartiuscollege te Zutphen

Opleiding medisch analist $\mathrm{HBO}-\mathrm{A}$ te Deventer

Dienstplichtig onderofficier

Microbiologisch analist in het Antonius Ziekenhuis te Utrecht (thans te Nieuwegein)

Student Biologie aan de Rijksuniversiteit Utrecht. Hoofdvak: Scheikundige Dierfysiologie

Nevenrichting: Veterinaire Pathologie

Bijvak: Russische Taal

AIO bij de vakgroep Farmacologie, Cardiovascular Research Institute Maastricht, Faculteit der Geneeskunde, Rijksuniversiteit Limburg 


\section{List of pubications}

\section{Full papers}

Messing MWJ, van Essen H, Struyker Boudier HAJ, 1990: Effects of alpha-adrenoceptor antagonists on striated muscle microcirculation of conscious rats. Drugs; 40 (suppl 4): $31-33$

Messing MWJ, van Essen H, Smith TL, Smits JFM, Struyker Boudier HAJ, 1991: Microvascular actions of calcium channel antagonists. Eur J Pharmacol; 198: 189-195

Messing M, van Essen H, Struyker Boudier HAJ, 1991 : Microvascular actions of antihypertensive drugs. in: Resistance arteries. Structure and function, Mulvany MJ, Aalljjer C, Heagerty AM, Nyborg NCB, Strandgaard S, eds. Elsevier Science Publishers BV; Amsterdam, the Netherlands. pp 270-274

Messing MWJ, van Essen H, Slaaf DW, Struyker Boudier HAJ, 1992: Alpha-adrenergic reactivity of striated muscle microvessels in conscious spontaneously hypertensive rats. submitted

Messing MWJ, vam Essen H, Smits JFM, Struyker Boudier HAJ, 1992: On the role of angiotensin II in striated muscle microvascular tone in conscious hypertensive rats. submitted

Struyker Boudier HAJ, Messing MWJ, 1989: Vascular actions of calcium antagonists, in: The use of isradipine and other calcium antagonists in cardiovascular diseases, van Zwieten PA, ed. Royad Society of Medicine Services, London, New York. pp 17-21

Struyker Boudier HAJ, Messing MWJ, Nelissen HJMG, Huijberts MSP, Le Noble FAC, Smits JFM, 199l: Vascular actions of ACE inhibitors in hypertension: structural and functional consequences. in: Current adwances in ACE inhibition 2, Ist ed, MacGregor GA, Sever PS, eds. Churchill Livingstone, Edinburgh London Melbourne New York and Tokyo. pp 26-29

Struyker Boudier HAJ, Le Noble JLML, Le Noble FAC, Messing MWJ, van Essen H, 1991: Hypertension, the microcirculation and serotonin. Clin Physiol Biochem; 8: 28-39

Struyker Boudier HAJ, Messing MWJ, van Essen H, 1992: Preferential small arteriolar vasodilatation by the potassium channel opener lemakalim in conscious spontaneously hypertensive rats. submitted Voogt PA, den Besten PJ, Kusters GCM, Messing MWJ, 1987: Effects of cadmium and zinc on steroid metabolism and steroid level in the sea star Asterias rubens L. Comp Biochem Physiol; 86C: 83-89

\section{Abstracts}

Messing MWJ, van Essen H, Smits JFM, Smith TL, Struyker Boudier HAJ, 1989:Microvascular actions of calcium antagonists in the rat. Fund Clin Pharmacol; 3: 436

Messing MWJ, wan Essen H, Struyker Boudier HAJ, 1989: Analysis of alpha-adrenoceptors in blood vessels of striated muscle of the spontaneously hypertensive rat. Pharm Wkbl So Ed; 11: J8

Messing MWJ, van Essen H, Smits JFM, Smith TL, Struyker Boudier HAJ, 1990: Microcirculatory effects of dihydropyridine calcium antagonists in the spontaneously hypertensive rat. I Hypertension; 7: $\$ 384$

Messing MWJ, van Essen H, Struyker Boudier HAJ, 1990: Alphi-adrenergic reactiviy of rat striated muscle microvessels. Int J Microcirc Clin Exp; $9: 322$

Messing MWJ, wan Essen H, Struyker Boudier HAJ, 1990: Analysis of alpha-adrenoceptors in microvessels of striated muscle of the spontaneously hypertensive rat. Naunyn Schmiedeberg "s Arch Pharmacol; $341: 226$

Messing MWJ, van Essen H, Struyker Boudier HAJ, 1990: in wivo effects of angiotensin-converting enzyme inhibitors on striated muscle microvessels of conscious spontaneously hypertensive rats. Pharm Wrkbl Sc Ed; $12: \mathrm{H} 8$

Messing MWJ, vam Essen H, Struyker Boudier HAJ, 1990: In vivo effects of calcium antagonists on rat striated muscle arterioles in relation to the alpha-adrenoceptor distribution. Eur J Pharmacol; 183: 814 
Messing MWJ, wan Essen H, Struyker Boudier H.AJ, 1990: Pharmacological analysis of alpha-adremergic reactivity in striated nuscle microvessels of the conscious spontaneously hypertensive rat. Int J Mierocirc Clin Exp:9: 25

Messing MWJ, wan Essen H, Smits JFM, stnuyker Boudier HAJ, 1991: Effects of the nonpeptide angiotensin II (AII) antagonist DuP 753 on striated muscle microcirculation of conscious spontaneously hyperteniwe rats. Proceedings of the Fifth World Congress for Microcirculation. Louisville, Kentucky, USA. August 31- September 5, 1991; 447

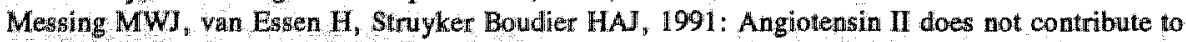
striated muscle arteriolar tone in conscious spontaneously hypertensive rats. Naunyn Schmiedeberg's Arch Pharmacol, $343, \mathrm{R72}$

Messing MWJ, van Essen H, Struyker Boudier HAJ, 1991: Angiotensin II (Ang II) does not contribute to the in vivo tone of striated muscle arterioles in conscious spontaneously hypertensive rats. Blood Vessels; 28,317

Messing MWJ, van Essen $\mathrm{H}_{\text {, }}$ struyker Boudier HAI, 1991 : Inhibition of angiotensin converting enzyme does not influence arteriolar tone in striated muscle of conscious spontaneously hypertensive rats. Acta Clin Belg; 46: 252-253

Struyker Boudier HAJ, Messing MWJ, van Essen H, 1990: Potassium channel activation and small arteriolar dilatation in conscious spontaneously hypertensive tats. Int J Microcirc Clin Exp; 9: 176 